\title{
1 Lipid accumulation promotes scission of caveolae
}

2 Madlen Hubert ${ }^{1}$, Elin Larsson ${ }^{1}$, Naga Venkata Gayathri Vegesna ${ }^{1}$, Maria Ahnlund ${ }^{2}$, Annika

3 I. Johansson ${ }^{3}$,Lindon W. K. Moodie ${ }^{4, \#}$ and Richard Lundmark ${ }^{1, *}$

$4 \quad{ }^{1}$ Department of Integrative Medical Biology, Umeå University, SE-901 87 Umeå, Sweden

$5 \quad{ }^{2}$ Swedish Metabolomics Centre, Department of Forest Genetics and Plant Physiology,

6 Swedish University of Agricultural Sciences, SE-901 83 Umeå, Sweden

$7 \quad{ }^{3}$ Swedish Metabolomics Centre, Department of Molecular Biology, Umeå University, SE-

890183 Umeå, Sweden

9 는 Department of Chemistry, Umeå University, SE-901 87 Umeå, Sweden

10 "Present address: Department of Medicinal Chemistry, Uppsala University, Box 574, SE-751

1123 Uppsala, Sweden

$12{ }^{*}$ Corresponding Author:

13 Richard Lundmark, Department of Integrative Medical Biology, Umeå University, 90187

14 Umeå, Sweden, phone: +46 706202464, email: richard.lundmark@umu.se

15 Running title: Lipid induced caveolae scission 
bioRxiv preprint doi: https://doi.org/10.1101/2020.01.22.915173; this version posted January 22, 2020. The copyright holder for this preprint (which was not certified by peer review) is the author/funder, who has granted bioRxiv a license to display the preprint in perpetuity. It is made available under aCC-BY 4.0 International license.

16 Keywords: caveolae, EHD2, cell surface stability, scission, fusogenic liposomes,

17 glycosphingolipids, cholesterol, membrane lipid composition, single particle tracking,

18 correlative light electron microscopy. 
20 Caveolae, bulb-shaped invaginations of the plasma membrane (PM), show distinct behaviors of scission and fusion at the cell surface. Although it is known that caveolae are enriched in cholesterol and sphingolipids, exactly how lipid composition influences caveolae surface stability has not yet been elucidated. Accordingly, we inserted specific lipids into the PM of cells via membrane fusion and studied acute effects on caveolae dynamics. We demonstrate that cholesterol and glycosphingolipids specifically accumulate in caveolae, which decreases their neck diameter and drives their scission from the cell surface. The lipid-induced scission was counteracted by the ATPase EHD2. We propose that lipid accumulation in caveolae generates an intrinsically unstable domain prone to scission if not balanced by the restraining force of EHD2 at the neck. Our work advances the understanding of how lipids contribute to caveolae dynamics, providing a mechanistic link between caveolae and their ability to sense the PM lipid composition.

\section{SUMMARY}

Caveolae serve as mechanoprotectors and membrane buffers but their specific role in sensing plasma membrane lipid composition remains unclear. Hubert et al. show that cholesterol and glycosphingolipids accumulate in caveolae and drive subsequent scission from the cell surface. These results provide new insight into how lipids contribute to budding and scission of membrane domains in cells. 


\section{INTRODUCTION}

39 Caveolae are bulb-shaped invaginations of the plasma membrane (PM), enriched in cholesterol (Chol), sphingolipids and the integral membrane protein caveolin1 (Cav1) (Parton $\&$ del Pozo, 2013). Caveolae are present in most cell types, with a particularly high density in endothelial cells, adipocytes and smooth muscle cells. Absence or malfunction of caveolae is associated with a number of conditions such as lipodystrophy, muscular dystrophy and cardiovascular diseases (Cohen et al., 2004; Pilch \& Liu, 2011). Whilst the mechanism of how caveolae dysregulation drives the phenotype of disease is not well understood, they have been proposed to serve as signaling platforms, endocytic carriers, and PM reservoirs involved in mechanoprotective processes or lipid buffering (Parton \& del Pozo, 2013; Sinha et al., 2011). In adipocytes, which are key lipid homeostasis regulators, caveolae are estimated to account for more than $50 \%$ of the surface area (Thorn et al., 2003). The clinical manifestation of caveolae loss in both patients (Cao et al., 2008; Hayashi et al., 2009; Kim et al., 2008) and mouse models (Liu et al., 2008; Razani et al., 2002) reveals severe malfunction of adipocytes, in addition to other cell types involved in lipid turnover and storage.

Biogenesis of caveolae is tightly coupled to the PM lipid composition and is thought to be driven by Chol-sensitive oligomerization of Cav1 and subsequent association with the cavin coat proteins (Fig. S1A) (Parton \& del Pozo, 2013). Cav1 is embedded into the lipid bilayer via its intramembrane and scaffolding domains, which interact with Chol (Parton \& del Pozo, 2013). Chol depletion from the PM causes caveolae disassembly, leading to the disassociation of cavins from Cav1, which then disseminates throughout the PM (Morén et al., 2012; Rothberg et al., 1992). Relative to the bulk PM, phosphatidylserine, glycosphingolipid (GSL) and sphingomyelin (SM) has also been proposed to be enriched in caveolae (Hirama et al., 2017; Örtegren et al., 2004; Singh et al., 2010). However, it has not been determined whether specific lipids are enriched in caveolae in living cells and, 
furthermore, how exactly they influence biogenesis, i.e., through a general physical effect on the membrane bilayer or via direct interactions with the caveolae coat proteins. Additionally, it is not known whether these lipids can diffuse freely in and out of the caveolae bulb or if they are sequestered by interactions with the caveolae coat and membrane curvature restraints.

Whilst caveolae are typically associated with the PM as bulb-shaped invaginations, they also exhibit dynamic behaviour including flattening (Nassoy \& Lamaze, 2012), short-range cycles of fission and fusion with the PM, and endocytosis (Boucrot et al., 2011; Morén et al., 2012; homology domain-containing protein 2 (EHD2), which oligomerizes around the neck of caveolae, restraining their scission (Fig. S1A) (Morén et al., 2012; Stoeber et al., 2012). EHD2 extensively colocalizes with Cav1 and most of the membrane-associated EHD2 is found in caveolae (Morén et al., 2012). Although not considered part of the caveolae coat, EHD2 appears to be a critical component for maintaining caveolae integrity in terms of surface attachment. Despite that all the above-mentioned proposed functions of caveolae would heavily depend on whether they are surface associated or released, it is not clear how the balance between these states is controlled physiologically. Furthermore, the biological function of their atypical dynamics remains elusive.

Lipids are also thought to influence caveolae dynamics, e.g., addition of bovine serum albumin-complexed lactosyl ceramide (LacCer) and elevated levels of Chol have been proposed to reduce the number of surface-connected caveolae and increase their mobility (Le Lay et al., 2006; Sharma et al., 2004). However, despite their essential structural role in caveolae, little is known about how they influence caveolae biogenesis and dynamics. This knowledge gap can be partly attributed to limitations associated with the current methods 
employed to study such phenomena. Drugs such as statins, that inhibit Chol synthesis, require multi-day treatments, and, in addition to altering transcriptional regulation, may also elicit major secondary effects (Crescencio et al., 2009). This results in downregulated expression of Cav1, making it difficult to decipher between the effects of Chol levels on caveolae biogenesis and caveolae dynamics. In addition, drugs such as myriocin, which inhibit sphingosine synthesis, will also affect the levels of all sphingolipid species, thus hampering direct conclusions. BSA-coupled Bodipy-LacCer has been used as a fluorescent marker of endocytosis (Puri et al., 2001; Sharma et al., 2004; Singh et al., 2006; Singh et al., 2003), but this procedure involved $\mathrm{PM}$ loading at $4{ }^{\circ} \mathrm{C}$ followed by a temperature shift to $37^{\circ} \mathrm{C}$, known to heavily influence membrane fluidity and exacerbate endocytosis (Kleusch et al., 2012). While previous work indicates that lipids might influence both caveolae numbers and their dynamics, they have been unable to address whether caveolae dynamics respond directly to alterations in PM lipid composition and if proposed effects are dependent on concentration or species of different lipids present. In general, our understanding of the levels of quantitative changes in PM lipid composition that can be sensed and controlled is relatively sparse, not to mention the alteration in lipid composition required to influence caveolae. It is also not known if lipids could affect caveolae dynamics by changing the composition of the caveolae bulb or the surrounding membrane and whether the proposed effects on caveolae mobility is caused by direct effects on caveolae scission from the cell surface.

To address this, we aimed to rapidly and selectively manipulate cellular membrane lipid composition in a system where both the lipids and caveolae could be tracked. Here, we have applied fusogenic liposomes that allowed us to directly insert specific unlabeled or fluorescently-labeled lipids into the PM of living cells and study their effect on caveolae dynamics. Our data shows that a relatively small increase in glycosphingolipids and Chol results in their accumulation in caveolae, reducing the caveolae neck diameter, and driving 
caveolae scission from the PM. EHD2 was identified to counterbalance the stability of caveolae in response to lipid composition and in accordance with a recent study (Matthäus et al., 2019; Morén et al., 2019), we describe a key regulatory role of EHD2 in lipid homeostasis.

\section{RESULTS}

\section{Lipids rapidly insert into the PM of living cells via liposome-mediated membrane fusion}

As a tool to study the effects of an altered lipid composition on caveolae dynamics, we employed fusogenic liposomes. This enabled us to rapidly insert lipids into the PM of HeLa cells via membrane fusion (Fig. 1A). To assess the effect of lipids known to be enriched in caveolae, different Bodipy-labeled analogues of sphingolipids (Cer, SM $\mathrm{C}_{5}$ and $\mathrm{SM} \mathrm{C}_{12}$ ), GSLs [ganglioside GM1 and lactosyl ceramide (LacCer)], Chol and phosphatidyl ethanolamine (PE) (Fig. S1B) were incorporated into liposomes [DOPE/Dotap/Bodipytagged lipid (47.5/47.5/5)] (Csiszar et al., 2010). Liposomes had diameters between 160-300 nm (Fig. S1C) and an average fluorescence per liposome of 600 a.u (Fig. S1D). The Bodipy fluorophore allowed us to track and quantify the lipid incorporation in the PM and study colocalization with caveolae components. To ensure the observed effects are not significantly influenced by the fluorophore motif, the results were verified with unlabeled lipids. Fusion of the liposomes with the PM of HeLa cells occurred immediately upon contact and the lipids were rapidly distributed throughout the basal membrane, as observed using live-cell TIRF microscopy (Figs. 1B and S1E, exemplified by LacCer). The total fluorescence attributed to the Bodipy motif increased uniformly in various regions of interest (ROIs) (Fig. 1B, bar plot).

To determine the amounts of lipids that were incorporated in the membrane through liposome fusion, we used quantitative mass spectrometry on whole cells as $90 \%$ of these lipids are located in the PM (Lorizate et al., 2013). The method was verified by altering the lipid 
composition using myriocin ( $24 \mathrm{~h}$ treatment) or sphingomyelinase (SMase, $2 \mathrm{~h}$ treatment),

which are known to lower the levels of sphingomyelin (Gulshan et al., 2013). Analysis showed that these treatments drastically decreased $\operatorname{SM}(\mathrm{d} 18: 1 / 16: 0)$ levels, the major endogenous species of SM (Fig. 1C). Next, we incubated cells with fusogenic liposomes containing Bodipy-labeled LacCer or $\mathrm{SM} \mathrm{C}_{12}$, and analyzed the lipid composition by LCESI-MS/MS. The detected levels of endogenous LacCer(d18:1/16:0) and SM(d18:1/16:0) in untreated control samples were in agreement with previously reported levels in HeLa cells (Kjellberg et al., 2014). In comparison, in samples treated with fusogenic liposomes, the incorporated Bodipy-lipids could be detected (Figs. S1F-G). The incorporated levels of Bodipy-LacCer and Bodipy-SM C 12 per 400000 cells were measured to be 4.2 pmol and 2.7 pmol, respectively, (i.e., $6.3 \times 10^{6}$ and $4.0 \times 10^{6}$ lipids/cell) (Fig. 1D). To assess the incorporation efficiency of Chol, deuterium labeled Chol, d7-Chol, was included into fusogenic liposomes. GC-MS/MS analysis revealed that d7-Chol was incorporated to similar levels as Bodipy-labeled LacCer and $\mathrm{SM} \mathrm{C}_{12}$. Given that the PM of these HeLa cells harbor around 7 x $10^{9}$ lipids/cell (see Methods section for details), the levels of Bodipy- and d7labeled lipids detected by mass spectrometry led to a $0.02-0.09 \%$ increase in specific labeled lipids and a $0.4-1.6 \%$ of total lipids.

To determine the rate of incorporation of the different Bodipy-labeled lipid species, we used spinning disk microscopy in a central confocal plane of the cell (Fig. 1E). Quantitative analysis of lipid incorporation into the PM over time revealed similar levels for most lipids ranging from 1900 to 4800 arbitrary units at $10 \mathrm{~min}$ (Fig. 1E). The variation in incorporation rates between the different lipids may be due to marginal differences in the fusogenicity of the liposomes or differences in the PM-turnover of each particular lipid. To monitor the lateral diffusion of the Bodipy-lipids within the PM, cells were incubated with fusogenic liposomes for $10 \mathrm{~min}$, and the recovery of Bodipy fluorescence in a defined region of interest 
161 (ROI) after bleaching was monitored. Lateral diffusion within the PM was similar between the different Bodipy-lipids employed (Fig. 1F).

To conclude, the use of fusogenic liposomes enabled rapid incorporation of approximately 4 x $10^{6}$ specific lipids into the PM per living cell over 10 minutes. Based on our tracking data, we estimated that each cell contains around 300 caveolae, comprising around $0.1 \%$ of the surface area. Caveolae are approximately $60 \mathrm{~nm}$ in diameter, and each lipid occupies $0.62 \AA$. Therefore $c a .10 \times 10^{6}$ lipids are contained within the caveolae, of which $50 \%$ is Chol. The amount of specific incorporated lipids in our system is therefore about half of the total amount of lipids contained within caveolae. The immediate addition of extra lipids to the PM did not result in a detectable effect on the cell volume (Fig. S1H).

\section{GSLs and Chol decrease the surface stability of caveolae}

We next aimed to elucidate if lipids are involved in controlling the balance between stable and dynamic caveolae at the PM and if effects could be attributed to individual lipid species. To visualize caveolae, we generated a stable mammalian Flp-In T-Rex HeLa cell line expressing Cav1-mCherry, hereafter named Cav1-mCh HeLa cells. Protein expression was induced by doxycycline (Dox) to achieve expression of Cav1-mCherry at similar level as endogenous Cav1 (Fig. S1I). Using TIRF microscopy and single-particle tracking, we determined the time each Cav1-mCh positive punctuate structure spent at the PM (track duration) and the speed of an object (track mean speed) in, or close to, the PM (see Method section for detailed tracking parameters). Given the previously reported surface dynamics of caveolae (Boucrot et al., 2011; Mohan et al., 2015; Pelkmans \& Zerial, 2005), we postulated that stable caveolae will have a long duration and low speed, limited by their lateral diffusion in the PM (Fig. 2A, "Stable"). Caveolae that scission off ("Scissioned intermediate") or re- 
intermediate duration and moderate speed, whereas caveolae that undergo rounds of scission and fusion ("Surface adjacent"), but remain close to the surface will have a high speed and short duration as they are not stably fused with the PM and short duration (Fig. 2A). We did indeed observe a clear correlation between the track duration and track mean speed where, in general, short tracks exhibited higher speeds, whereas long tracks displayed lower speeds (Figs. 2B and S2A). Although the numbers of caveolae in each cell were similar at the beginning and end of the recording, we found that the number of tracks far exceeded the caveolae numbers (Fig. S2C). This was expected as surface adjacent caveolae would give rise to several tracks. However, a drop in the fluorescent signal just below the set threshold value, would also contribute to a divided track resulting in an overestimation of short tracks versus long tracks. Therefore, we did not consider the average durations as absolute, but rather used them to compare between experimental runs with differing conditions. To verify that the tracking was sensitive to differences in caveolae dynamics, we depleted cells of EHD2, which has been shown to stabilize caveolae to the cell surface (Morén et al., 2012; Stoeber et al., 2012). Particle tracking analysis showed that the pool of surface adjacent caveolae increased, while the pool of stable caveolae decreased (Figs. 2B' and S2A'). When the average track duration was considered, this translated into a 0.65 fold change compared to control cells (Fig. 3E), proving that the particle tracking indeed was sensitive enough to register caveolae dynamic changes.

Next, we screened the influence of different lipid species on caveolae mobility at the PM using tracking. To do this, fusogenic liposomes loaded with relevant lipids were added to

206 Cav1-mCh HeLa cells and TIRF movies were recorded immediately (Fig. 2C). PE was used in control liposomes as it is abundant in the PM. Following incorporation of PE, caveolae dynamics remained unchanged, showing that the fusion of liposomes did not obstruct caveolae dynamics (Figs. 2D and S2B). In comparison to controls, Bodipy-labeled GSLs 
210 (GM1 and LacCer) and Chol significantly reduced the lifetime of caveolae at the cell surface

211 as indicated by decreased track duration measurements (Figs. 2C-D and S2B, Video 1-3).

212 Besides enhanced mobility, caveolae also showed an increase in mean speed (Fig. 2E). For

213 example, the treatment with LacCer gave a ratio of surface adjacent caveolae versus stable

214 that was comparable to the EHD2 depletion (Figs. 2B', S2A' and S2F-G). A direct comparison between LacCer and Cer revealed that Cer did not enhance caveolae dynamics in a similar fashion (Figs. 2D and S2B). No difference in the number of caveolae present in the PM was observed before and after the addition of liposomes (Fig. S2D). To verify that the effect was not due to the the Bodipy label, we treated cells with liposomes containing either unlabeled LacCer [(LacCer(d18:1/16:0)] or unlabeled Chol and quantified the track duration. This showed that the unlabeled lipids had the same effect on the track duration as the corresponding Bodipy-labeled analogues (Fig. 2F).

When cells were treated with Bodipy-SM $\mathrm{C}_{12}$, most of the caveolae were stable at the PM of the track mean speed (Figs. 2D and 2E). To further investigate the role of SM, we analyzed caveolae duration following SMase treatment, and found that this resulted in a decreased track duration, in agreement with a surface-stabilizing role for this lipid (Fig. 2G).

\section{Chol and GSLs induce surface release of caveolae via an EHD2-dependent mechanism}

EHD2 normally localizes with the majority of surface associated caveolae (Morén et al., 2012). We aimed to address if the increased caveolae dynamics induced by either Chol or

GSLs were due to their PM release, as characterized by loss of the stabilizing protein EHD2.

Therefore, we treated Cav1-mCh HeLa cells with the different fusogenic liposomes and visualized endogenous EHD2 using indirect immunofluorescent labeling (Fig. 3A). These 
significantly lower amount of EHD2 localized to Cav1 (Fig. 3A, scatter plot). This data suggests that the caveolae release induced by increased PM levels of LacCer and Chol is due to a loss of EHD2-mediated stabilization. Conversely, Cer and $\mathrm{SM} \mathrm{C}_{12}$, as well as its short chain analogue $\mathrm{SM} \mathrm{C}_{5}$, did not appear to have any significant effect on the association of EHD2 with Cav1 (Fig. 3A, scatter plot). Further experiments showed that, following lipid treatment, the majority of caveolae remained associated with cavin1, revealing that no disruption of the caveolae coat, and subsequent release of cavin1, occurred (Fig. 3B).

Since increased scission of caveolae from the cell surface results in more mobile intracellular caveolar vesicles (Stoeber et al., 2012), we performed fluorescence recovery after photobleaching (FRAP) experiments to investigate the recovery rate of caveolae. Addition of LacCer resulted in more mobile caveolae inside the cells in comparison with control cells (Figs. 3C-D). The recovery rate after LacCer addition was similar to the rate in EHD2depleted cells (Figs. 3C-D). This further supported the hypothesis that lipid incorporation drives caveolae scission (Figs. 3C-D). When LacCer or Chol was added to EHD2-depleted cells we found that the caveolae track duration was not further reduced in comparison with EHD2-depleted cells (Figs. 3E and S3A-B). These results supported our hypothesis that the lipid-induced effect on caveolae dynamics was due to the loss of surface stability mediated by EHD2, and implied that EHD2 controls the stability of caveolae in response to lipid composition. To test whether increased levels of EHD2 could restore caveolae stability after lipid treatment, we transiently expressed BFP-tagged EHD2 in Cav1-mCh HeLa cells. Analysis of TIRF live cell movies showed that EHD2-BFP positive caveolae were highly stable compared to controls (Fig. 3F). In the presence of EHD2-BFP, the destabilizing effect seen for GM1, LacCer and Chol was abolished, as demonstrated by negligible changes in track duration compared to control conditions (Fig. 3F). This suggested that excess levels of 
caveolae in cells stably expressing Cav1-mCh and EHD2-BFP showed that most of the caveolae were positive for EHD-BFP $(96 \%)$ and that this population was more stable than the population lacking EHD2-BFP (4\%) (Figs. S3C-E). Surprisingly, SM $\mathrm{C}_{12}$ had an additive effect and led to predominantly stable caveolae (Fig. 3F), implying that the increased cell surface stability of caveolae may be due to changes in membrane fluidity rather than EHD2 recruitment.

To test if the suppression of the lipid effect by increased levels of EHD2 relied on multiple rounds of assembly and disassembly of EHD2 at caveolae, we overexpressed a BFP-tagged ATP-cycle mutant, EHD2-I157Q. The increased ATP hydrolysis rate of this mutant leads to stable association of EHD2-I157Q to caveolae and a slower exchange rate (Fig. S3F) (Daumke et al., 2007; Hoernke et al., 2017; Stoeber et al., 2012). We observed that, when coexpressed in Cav1-mCh cells, both EHD2-I157Q and EHD2 stabilized caveolae at the PM to similar extents, independent of treatment with either LacCer or Chol (Fig. S3G). This verified that stable assembly, but not disassembly of EHD2, is necessary to stabilize caveolae. prior to lipid addition, fluorescently labeled, purified EHD2 (EHD2-647) was microinjected into Cav1-mCh HeLa cells (Fig. 3G). Within 20 min, EHD2-647 colocalized with Cav1, confirming that the microinjected protein was indeed recruited to caveolae (Figs. S3H-I).

277 Next, we tested if an acute injection of EHD2-647 could rescue the effect on caveolae dynamics caused by LacCer. Strikingly, we found that exogenously added EHD2 stabilized the caveolae to the same extent as the overexpressed EHD2, demonstrating that increased

280 levels of EHD2 can acutely reverse the increased mobility of caveolae induced by lipids (Fig. $3 \mathrm{H})$. 
As GSLs and Chol increased the surface release of caveolae, we aimed to determine whether there was a differential accumulation of lipids within caveolae at the PM. We treated Cav1mCh HeLa cells with fusogenic liposomes and followed the distribution of Bodipy-labeled LacCer or Chol using live-cell TIRF microscopy. After $15 \mathrm{~min}$, both lipids were found to colocalize with Cav1-mCh positive structures (Figs. 4A and S4A, Video 5-6). Data analysis was hindered by high caveolae mobility following lipid addition, and the extent of colocalization could not be quantified. To circumvent this, we overexpressed EHD2-BFP to stabilize caveolae at the PM. Interestingly, nearly $80 \%$ of caveolae positive for EHD2 were also positive for LacCer or Chol (Figs. 4B-B' and S4B, Video 7-8). In comparison, Cer, which had no effect on caveolae dynamics, did not localize to caveolae, even in the presence of EHD2-BFP (Figs. S4C-D).

To investigate the exchange of lipids between the stable caveolae and the surrounding PM, we performed FRAP experiments. The Bodipy-LacCer signal reappeared rapidly at precisely the bleached spot positive for Cav1-mCh, with a close to quantitative fluorescence recovery (Figs. 4C-D). This indicated that the lipid diffused freely throughout the PM and, following photobleaching, re-accumulated quickly within caveolae. In comparison, Bodipy-Chol recovered much slower with $60 \%$ of the initial signal being restored after 5 min acquisition time (Figs. 4D and S4E). This showed that there is a large immobile pool of Chol in caveolae that is sequestered from the rest of the PM. Our data suggests that both LacCer and Chol are highly enriched in caveolae and, while the lateral diffusion of LacCer in and out of caveolae is high, Chol is restrained to this invagination.

\section{Chol accumulation reduces the caveolae diameter in 3T3-L1 adipocytes}

To elucidate whether lipid accumulation affected the overall morphology of surface connected caveolae in Cav1-mCh HeLa cells, we analyzed their ultrastructure in cells 
overexpressing EHD2. Since the number of caveolae in the PM of these cells is relatively low, we used correlative light electron microscopy (CLEM) to specifically identify images of transmission electron microscopy (TEM). Fluorescence light microscopy images of Cav1-mCh HeLa cells were superimposed with correlative electron micrographs to find the closest match of fluorescence signal to structure using the nuclear stain as a guide (Figs. 5A and S5A). The surface connected caveolae in cells treated with LacCer and Chol, displayed a similar flask-shaped morphology as seen in control cells, verifying that lipid addition did not majorly distort caveolae morphology. To be able to quantitatively assess differences in morphology, we differentiated 3T3-L1 cells to adipocytes, which results in upregulation of Cav1 and EHD2 (Fig. S5B) (Morén et al., 2019), and formation of a large number of caveolae (Thorn et al., 2003) that could be clearly distinguished from clathrin-coated pits (Fig. S5C). These cells also provided a more physiologically relevant system since adipocytes are the main source of cholesterol storage and efflux (Krause \& Hartman, 1984). Quantification of lipid incorporation verified that fusogenic liposomes could be used to insert specific lipids into the PM of these cells (Fig. S5D). Using TEM, we analyzed the dimensions of caveolae before and after Chol addition (Figs. 5B-E). We found that the neck diameter of surface associated caveolae were significantly decreased and more homogeneous following Chol incorporation in comparison to control cells (Fig. 5D). Furthermore, the bulb width was also significantly smaller resulting in more drop-shaped caveolae (Fig. 5D'). Quantitative analysis of the spherical population of caveolae without surface connected necks allowed us to measure the surface area of caveolae. Comparison to control cells showed that area, as well as bulb width, decreased following Chol addition (Figs. 5E-E'). Furthermore, Chol incorporation resulted in a more homogeneous caveolae population in terms of size and 
adipocytes induced alterations in the caveolae coat architecture resulting in reduced neck diameter and a smaller more uniform bulb diameter.

\section{GSLs are internalized to the endosomal system independent of Cav1, while Chol is predominantly trafficked to lipid droplets}

Next, we aimed to address if caveolae scission significantly contributed to internalization and trafficking of lipids in our system as previously proposed (Le Lay et al., 2006; Puri et al., 2001; Shvets et al., 2015). We used fusogenic liposomes to investigate if Bodipy-labeled LacCer or Chol were internalized and trafficked through the endosomal pathway following incorporation into the PM. To mark early endosomes (EE), Rab5-BFP was transiently expressed in Cav1-mCh HeLa cells. Cells were incubated with fusogenic liposomes for either $15 \mathrm{~min}$ or $3 \mathrm{~h}$, followed by fixation and EE localization was quantified. We observed localization of LacCer to the EE but not to the Golgi, contrasting previous studies using BSA-Bodipy-LacCer (Puri et al., 2001). After 15 min, more than half of the EE were positive for LacCer $(55 \%)$ compared to only $6 \%$ for Chol (Figs. 6A-B). After $3 \mathrm{~h}$, the number of LacCer-positive EE remained constant, whereas the EE positive for Chol had increased to $18 \%$ (Fig. 6B). To test if caveolae were involved in lipid trafficking to the EE, the experiments were repeated in cells depleted of Cav1 (Figs. 6C-E). After 15 min incubation time, $55 \%$ and $10 \%$ of EE were positive for LacCer and Chol, respectively (Figs. 6C-D). This suggested that while caveolae did not seem to influence the efficiency of LacCer or Chol trafficking to endosomes, loss of Cav1 resulted in an increased amount of Chol accumulating in this compartment. Our data indicate that caveolae serve as buffers or sensors of GSL and Chol concentrations rather than endocytic vesicles.

During our experiments, we noticed that a large fraction of Chol localized to compartments distinct from the endosomal system. To determine whether Chol localized to lipid droplets (LD) as previously proposed (Le Lay et al., 2006; Shvets et al., 2015), we incubated HeLa 
cells with fusogenic liposomes and visualized LD using LipidTOX-DR. On average, $85 \%$ of LDs were positive for Chol after both $15 \mathrm{~min}$ and $3 \mathrm{~h}$ (Figs. 6F-G), and similar levels of localized to LD, we did not observe LacCer associated with LD (Figs. 6F-G). These data are consistent with the hypothesis that excess Chol in the PM is trafficked directly to LD in a process that does not require caveolae per se, and that the levels of Chol taking an alternative route to EE increases in the absence of caveolae.

\section{DISCUSSION}

While PM turnover is typically regulated in a tightly controlled manner, marginal changes in its composition are associated with severe diseases such as cancer, diabetes, and Alzheimer's disease (Harayama \& Riezman, 2018). It has been proposed that caveolae play a major role in preserving lipid homeostasis via sensing and buffering PM properties (Parton \& del Pozo, 2013; Pilch \& Liu, 2011). However, studies detailing how lipid composition influences cellular phenotypes have been hindered by a lack of methods to selectively manipulate the PM lipid composition; especially with regard to introducing specific lipids. To address this, we applied an approach for studying these systems in living cells that employs DOPE/DOTAP-based liposomes capable of mediating highly effective fusion processes with cell membranes to deliver their lipid cargoes. Such liposomes have previously been used as nanocarriers to deliver intracellular proteins (Kube et al., 2017). Our methodology successfully delivered specific lipids into the PM bilayer of living cells with high efficiency. These rapid fusion events enabled us to study, for the first time, how caveolae respond to an acute change in PM lipid composition and to observe lipid exchange in the caveolae bulb.

379 Furthermore, the use of labelled lipids allowed us to measure the levels of incorporation in 380 relation to endogenous levels. Our results demonstrate the power of this approach for 
studying caveolae dynamics and we foresee that our methodology will also be a useful tool outside of this framework.

Our work shows that the surface association of caveolae is highly sensitive to changes in the

PM lipid composition. An acute increase in the levels of Chol and GSLs, which were found to specifically accumulate in caveolae, dramatically increased caveolae mobility. These caveolae traveled at higher speeds, their PM duration was shorter and they also displayed reduced levels of EHD2, a protein indicative of PM-associated caveolae. Therefore, we conclude that accumulation of Chol and GSLs in caveolae trigger surface release of caveolae. In agreement with this, analysis by EM revealed that the caveolae neck diameter was reduced in cells with elevated Chol levels. Our findings are consistent with previous reports suggesting that BSA-LacCer and Chol decrease the number of caveolae associated to the PM and enhance their mobility (Le Lay et al., 2006; Sharma et al., 2004). Based on the present study, increased caveolae mobility is a direct result of lipid accumulation in these structures. As our methodology allowed us to determine the levels of specifically incorporated lipids, we found that rapid, yet relatively small increases in specific lipids can affect caveolae dynamics. composition.

Previous studies have suggested that a threshold concentration of Chol is required to maintain caveolae integrity and proposes that assembly and disassembly is in a dynamic equilibrium dependent on Chol levels (Hailstones et al., 1998). This is also in line with our experiments showing that excess Chol drives caveolae assembly towards scission and that Chol was indeed found to accumulate in caveolae when these structures were restrained to the surface by EHD2 overexpression. Furthermore, our methodology enabled, for the first time, 
measurement of lipid lateral flow in and out of the caveolae bulb using FRAP. Comparing the

FRAP recovery of Bodipy-LacCer and Bodipy-Chol, which were both enriched in caveolae, diffusion after 2 min, photobleached Bodipy-Chol was only exchanged by $50 \%$. This showed that Chol was sequestered in caveolae, potentially through its interaction to Cav1 (Parton \& del Pozo, 2013). In contrast, Bodipy-Cer, which lacks the disaccharide structural motif of LacCer, did not accumulate in caveolae and had no effect on their dynamics, which is in agreement with earlier reports (Sharma et al., 2004). Precisely how the lactosyl group mediates the caveolae-enrichment of LacCer and how this in turn drives caveolae scission is not clear. Interestingly, we found that Bodipy-SM $\mathrm{C}_{12}$, but not Bodipy-SM $\mathrm{C}_{5}$, dramatically increased caveolae stability, in terms of both speed and duration. The contrasting effects of SM analogues were highly intriguing as both lipids are thought to partition into a liquid disordered phase in artificial giant unilamellar vesicles (Klymchenko \& Kreder, 2014). However, the altered chain length might influence their interactions with Chol. Interestingly, SM has been shown to sequester a pool of Chol in the PM, which, together with an accessible and inaccessible pool, aid in the sensing of the Chol levels in the PM (Das et al., 2014). The elevated levels of $\mathrm{SM} \mathrm{C}_{12}$ may alter the levels of SM-sequestered Chol, thereby affecting caveolae stability. In agreement with this, we found that a dramatic reduction of SM using SMase indeed increased the dynamics of caveolae.

While an area of extensive research, a consensus on the exact mechanism of caveolae scission has not yet been reached. Our observations suggest a model, where the accumulation of lipids in caveolae reduces the neck diameter, leading to scission. We speculate that this could be due to increased access of scission-mediating molecules like dynamin to the neck, or that that these lipids promote assembly of Cav1 and cavins, which drive curvature towards scission. The lipid-driven assembly of Cav1 may be an intrinsically unstable system, 
eventually resulting in scission if no restraining forces are applied. This indicates that scission is tightly coupled to, and a continuum of caveolae biogenesis. In line with this, expression of caveolin in bacterial systems induced the formation of internal caveolae-like vesicles containing caveolin so-called heterologous caveolae (Walser et al., 2012). The scission step could also involve lipid phase separation. A similar mechanism has previously been proposed but not experimentally validated (Lenz et al., 2009), and our new data shows that a locally increased concentration of GSLs and Chol in caveolae may induce phase separation and therefore facilitate budding and scission of caveolae. Consistent with this, model membrane studies have shown that sterol-induced phase separation can promote membrane scission (Bacia et al., 2005; Roux et al., 2005). Of interest, in other systems GSLs and Chol have been suggested to play a crucial role in membrane nanodomain budding to generate intracellular transport carriers (Schuck \& Simons, 2004).

EHD2 has been shown to confine caveolae to the cell surface (Morén et al., 2012; Stoeber et al., 2012). In the current study, we acutely altered the lipid composition in order to induce caveolae scission and analyzed the immediate role of EHD2. We found that removal of EHD2, while at the same time changing the lipid composition, did not have an additive effect on caveolae dynamics. However, excess levels of EHD2 due to overexpression or direct microinjection, could suppress the effect of the altered lipid composition. This suggests that an increased assembly rate of EHD2 at the caveolae neck is necessary and sufficient to drive the equilibrium towards stable surface association of caveolae. We conclude that oligomers of EHD2 might provide a restraining force that prevents reduction of the neck diameter and thereby inhibits phase separation or assembly of scission-mediating proteins. Similarly, EHD2 would prevent flattening of caveolae and thus, act to stabilize the typical bulb-shape of changes in both PM lipid composition and membrane tension. 
455 Caveolae have been proposed to play an integral role in intracellular lipid trafficking (Le Lay

456 et al., 2006; Puri et al., 2001; Shvets et al., 2015). This prompted us to examine the cellular

457 fate of our labelled lipids. We found that while Bodipy-LacCer was internalized via the

458 endosomal system, Chol predominately localized to LD. Importantly, and in contrast to

459 previous data (Shvets et al., 2015), we found that loss of caveolae did not majorly influence

460 the trafficking of these lipids in HeLa cells. Based on this, we propose that caveolae should

461 not be considered as vehicles for internalization of lipids, but rather that lipid composition

462 influences caveolae biogenesis and dynamics. Together with the caveolae coat components, it

463 is feasible that sequestered lipids may control formation and define the size and curvature of

464 these PM invaginations. This, together with our data showing that Chol is enriched and sequestered in caveolae, implies that caveolae could serve as reservoirs of Chol in the PM, thereby buffering the surface levels of this lipid.

467 Together, our findings indicate that the dynamic behavior of caveolae is highly sensitive to changes in PM lipid composition. We demonstrate that, following incorporation into the lipid bilayer, GSLs and Chol accumulate in caveolae, which promotes scission of these membrane 470 invaginations from the cell surface. The current study redefines the fundamental understanding of how caveolae dynamics are governed by biologically relevant lipids and will be of future relevance linking caveolae malfunction with lipid disorders. 
MATERIALS AND METHODS

Reagents. erythro-sphingosine [LacCer(d18:1/16:0)] and Lyso-Lactosylceramide (Lyso-LacCer) were purchased from Avanti Polar Lipids Inc. (Alabaster, AL, US). Bodipy ${ }^{\mathrm{TM}}$ FL C5-ganglioside GM1 (Bodipy-GM1), Bodipy ${ }^{\mathrm{TM}}$ FL C5-ceramide (Bodipy-Cer), Bodipy ${ }^{\mathrm{TM}}$ FL $\mathrm{C}_{12^{-}}$ spinghomyelin (Bodipy-SM C 12 ), Bodipy ${ }^{\mathrm{TM}} \mathrm{FL} \mathrm{C} \mathrm{C}_{5}$-spinghomyelin (Bodipy-SM C5 ) were obtained from Thermo Fisher Scientific (Waltham, MA, US). BODIPY ${ }^{\mathrm{TM}}$ Fl-C5 NHS ester (4,4-Difluoro-5,7-dimethyl-4-bora-3a,4a-diaza-s-indacene-3-pentanoic acid, succinimidyl ester) was purchased from Setareh Biotech, LLC (Eugene, OR, US). Cholesterol (Chol), d7cholesterol, N,N-diisopropylethylamine, sphingomyelinase (SMase) from Bacillus cereus, myriocin from Mycelia sterilia, anhydrous dimethylforamide (DMF), chloroform $\left(\mathrm{CHCl}_{3}\right)$ and methanol $(\mathrm{MeOH})$ were purchased from Sigma-Aldrich (St. Louis, MO, US). LC-MS grade formic acid was purchased from VWR Chemicals (Radnor, PA, US). LC-MS grade 2propanol and acetonitrile from Merck Millipore (Billerica, MA, US). Milli-Q ${ }^{\circledR}$ water (Merck Millipore) was used. All reagents and chemicals were used without further purification.

\section{Bodipy-LacCer synthesis.}

Thin layer chromatography was performed on aluminum backed silica gel plates (median pore size $60 \AA$, fluorescent indicator $254 \mathrm{~nm}$, Fisher Scientific, Hampton, NH, US) and visualized by exposure to UV light $(365 \mathrm{~nm})$ and stained with acidic ethanolic vanillin solution. Flash chromatography was performed using chromatography grade silica gel 
AVANCE $(600 \mathrm{MHz})$ spectrometer. ${ }^{1} \mathrm{H}$ Chemical shifts are reported in $\delta$ values relative to tetramethylsilane and referenced to the residual solvent peak $\left(\mathrm{CD}_{3} \mathrm{OD}: \delta_{\mathrm{H}}=3.31 \mathrm{ppm}, \delta_{\mathrm{C}}=\right.$ $49.00 \mathrm{ppm})$. Coupling constants are reported in $\mathrm{Hz}$.

Lyso-LacCer $(5 \mathrm{mg}, 8 \mu \mathrm{M})$ was dissolved in DMF (200 $\mu \mathrm{l})$ and $N, N$-diisopropylethylamine (2.1 $\mu 1,12 \mu \mathrm{M}, 1.5$ eq.) was added. BODIPY ${ }^{\mathrm{TM}}$ Fl-C5 NHS ester (66 $\mu$ l of a stock solution of $5 \mathrm{mg} / 100 \mu \mathrm{LMF}, 8 \mu \mathrm{M}, 1.0$ eq.) was added and the reaction was shielded from light and stirred for $14 \mathrm{~h}$. The reaction mixture was concentrated and purified by column chromatography $\left(\mathrm{CHCl}_{3}, \mathrm{MeOH}, \mathrm{H}_{2} \mathrm{O}, 70: 15: 2\right.$ - 65:25:2) to afford the product BodipyLacCer (6.5 mg, 88\%, Fig. S1A) as a red film (Gretskaya \& Bezuglov, 2013).

Retention factor: $\mathrm{R}_{\mathrm{f}}=0.46\left(\mathrm{CHCl}_{3}, \mathrm{MeOH}, \mathrm{H}_{2} \mathrm{O}, 65: 25: 2\right)$

NMR data: ${ }^{1} \mathrm{H}-\mathrm{NMR}\left(\mathrm{CD}_{3} \mathrm{OD}, 600 \mathrm{MHz}\right) \delta 7.41(1 \mathrm{H}, \mathrm{s}), 7.03(1 \mathrm{H}, \mathrm{d}, J=4.1 \mathrm{~Hz}), 6.36(1 \mathrm{H}, \mathrm{d}$, $J=4.0 \mathrm{~Hz}), 6.18(1 \mathrm{H}, \mathrm{s}), 5.67(1 \mathrm{H}, \mathrm{dt}, J=15.3,6.8 \mathrm{~Hz}), 5.44(1 \mathrm{H}, \mathrm{dd}, J=15.3,7.7 \mathrm{~Hz}), 4.34$ $(1 \mathrm{H}, \mathrm{d}, J=7.7 \mathrm{~Hz}), 4.29(1 \mathrm{H}, \mathrm{d}, J=7.8 \mathrm{~Hz}), 4.17(1 \mathrm{H}, \mathrm{dd}, J=10.1,4.7 \mathrm{~Hz}), 4.07(1 \mathrm{H}, \mathrm{t}, J=7.9$ Hz), 3.99 (1H, ddd, $J=8.2,4.6,3.3 \mathrm{~Hz}), 3.89(1 \mathrm{H}, \mathrm{dd}, J=12.1,2.6 \mathrm{~Hz}), 3.84(1 \mathrm{H}, \mathrm{dd}, J=12.2$, $4.3 \mathrm{~Hz}), 3.81(1 \mathrm{H}, \mathrm{d}, J=3.1 \mathrm{~Hz}), 3.78(1 \mathrm{H}, \mathrm{dd}, J=11.4,7.5 \mathrm{~Hz}), 3.70(1 \mathrm{H}, \mathrm{dd}, J=11.5,4.6 \mathrm{~Hz})$, $3.61-3.59(1 \mathrm{H}, \mathrm{m}), 3.62-3.51(3 \mathrm{H}, \mathrm{m}), 3.52-3.49(1 \mathrm{H}, \mathrm{m}), 3.47(1 \mathrm{H}, \mathrm{dd}, J=9.7,3.3 \mathrm{~Hz})$ $3.39(1 \mathrm{H}, \mathrm{ddd}, J=9.3,4.0,2.7 \mathrm{~Hz}), 3.28(1 \mathrm{H}, \mathrm{t}, J=8.5 \mathrm{~Hz}), 2.94(2 \mathrm{H}, \mathrm{t}, J=7.3 \mathrm{~Hz}), 2.50(3 \mathrm{H}$, s), $2.28(3 \mathrm{H}, \mathrm{s}), 2.25(2 \mathrm{H}, \mathrm{t}, J=7.0 \mathrm{~Hz}), 2.00-1.93(2 \mathrm{H}, \mathrm{m}), 1.79-1.66(4 \mathrm{H}, \mathrm{m}), 1.37-1.20$ $\left(31 \mathrm{H}, \mathrm{m},\left(11-\mathrm{CH}_{2}\right)\right), 0.89(3 \mathrm{H}, \mathrm{t}, J=7.0 \mathrm{~Hz})$.

${ }^{13} \mathrm{C}-\mathrm{NMR}\left(\mathrm{CD}_{3} \mathrm{OD}, 151 \mathrm{MHz}\right) \delta 175.7,160.9,160.2,145.0,136.1,135.2,134.9,131.2$ $130.0,125.6,120.9,117.9,105.1,104.5,80.6,77.1,76.5,76.3,74.8,74.8,73.0,72.5,70.3$, $69.9,62.5,61.8,54.8,37.1,33.4,33.1,30.8,30.8,30.8,30.8,30.8,30.7,30.5,30.4,30.3$, $29.5,29.4,27.0,23.7,14.9,14.5,11.2$. 
Cell lines and primary cultures.

HeLa cells (ATCC-CRM-CCL-2) were cultured in Dulbecco's Modified Eagle Medium (DMEM, Thermo Fisher Scientific) supplemented with 10\% (v/v) Fetal bovine serum (FBS, Thermo Fisher Scientific) at $37^{\circ} \mathrm{C}, 5 \% \mathrm{CO}$. For generation of HeLa Flp-In T-REx Caveolin1-mCherry cells the pcDNA/FRT/TO/Caveolin1-mCherry construct was generated by exchanging the EGFP-tag in the pcDNA/FRT/TO/Caveolin1-EGFP (Mohan et al., 2015) for a mCherry tag by restriction cloning using enzymes AgeI and NotI (Thermo Fisher Scientific). The HeLa Flp-In T-REx EHD2-BFP-P2A-Caveolin1-mCherry construct was generated by linearizing pcDNA/FRT/TO/Caveolin1-mCh with the restriction enzyme HindIII (Thermo Fisher Scientific). The DNA encoding EHD2-BFP and the P2A peptide was inserted by Gibson assembly using NEBuilder HiFi DNA assembly master mix (New England BioLabs, Ipswich, MA, USA). The Flp-In TRex HeLa cell lines were maintained in DMEM supplemented with 10\% (v/v) FBS, $100 \mu \mathrm{g} / \mathrm{ml}$ hygromycin B (Thermo Fisher Scientific), and $5 \mu \mathrm{g} / \mathrm{ml}$ blasticidin $\mathrm{S} \mathrm{HCl}$ (Thermo Fisher Scientific) for plasmid selection at $37^{\circ} \mathrm{C}, 5 \% \mathrm{CO} 2$. Expression at endogenous levels was induced by incubation with $0.5 \mathrm{ng} / \mathrm{ml}$ (Cav1-mCh) and $1.0 \mathrm{ng} / \mathrm{ml}$ (EHD2-BFP-P2A-Cav1mCh) doxycycline hyclate (Dox, SigmaAldrich) for 16-24 h.

3T3-L1 fibroblasts (ATC-CL-173) were maintained in DMEM supplemented with 10\% (v/v) FBS and penicillin-streptomycin (10000 U/ml, 1:100, Thermo Fisher Scientific) at $37^{\circ} \mathrm{C}, 5 \%$ CO2 and differentiated to adipocytes as previously describe (Zebisch et al., 2012). Briefly, cells were either seeded directly into a 6-well plate or on glass coverslips in a 6-well plate at $6 \times 10^{5}$ cells/well (day -3 of differentiation). The cells reached confluency the following day and the medium was changed (day -2). After $48 \mathrm{~h}$ (day 0) the medium was exchanged for differentiation medium I [supplemented DMEM containing $0.5 \mathrm{mM}$ 3-isobutyl-1- 

day 4 of differentiation.

\section{Fusogenic liposomes.}

Liposomes were prepared from a lipid mixture of DOPE, DOTAP and either Bodipy-tagged lipid or unlabeled lipid at a ratio of 47.5:47.5:5. Lipid blends were in $\mathrm{MeOH}: \mathrm{CHCl}_{3}(1: 3$, $\mathrm{v} / \mathrm{v})$. Following the generation of a thin film using a stream of nitrogen gas, the vesicles were concentration $2.8 \mu \mathrm{mol} / \mathrm{ml}$ ) and incubated for $1.5 \mathrm{~h}$ at room temperature. Glass beads were added to facilitate rehydration. The liposome dispersion was sonicated for $30 \mathrm{~min}$ (Transsonic T 310, Elma, Singen, DE). The hydrodynamic diameters (z-average) of the liposomes were measured using dynamic light scattering with a Malvern Zetasizer Nano-S acquisition and analysis of the data.

Lipid quantification by LC-ESI-MS/MS.

One day prior to experiment, cells were seeded in a 6-well plate. Cells were left untreated or treated with $11.7 \mathrm{nmol} / \mathrm{ml}$ of the different fusogenic liposomes for $10 \mathrm{~min}$ at $37^{\circ} \mathrm{C}, 5 \% \mathrm{CO}_{2}$.

The cells were washed three times with PBS and harvested in $500 \mu \mathrm{MeOH}$ by scraping. 
$567(2.5 \mu \mathrm{M})$ and SMase $(0.01 \mathrm{U})$ treatment, cells were incubated for $24 \mathrm{~h}$ or $2 \mathrm{~h}$, respectively.

568 Extraction was performed using a mixer mill set to a frequency $30 \mathrm{~Hz}$ for $2 \mathrm{~min}$, with 1

569 tungsten carbide bead added to each tube. Thereafter the samples were centrifuged at $4^{\circ} \mathrm{C}$,

$57014000 \mathrm{RPM}$, for $10 \mathrm{~min}$. A volume of $260 \mu \mathrm{l}$ of the supernatant was transferred to micro vials

571 and evaporated under $\mathrm{N}_{2}(\mathrm{~g})$ to dryness. The dried extracts were stored at $-80^{\circ} \mathrm{C}$ until analysis. Calibration curves of Bodipy-labeled standards (Bodipy-SM $\mathrm{C}_{12}$ and BodipyLacCer) as well as standards for endogenous LacCer and SM [LacCer(d18:1/16:0) and $\mathrm{SM}(\mathrm{d} 18: 1 / 16: 0)]$ were prepared prior to analysis. Stock solutions of each compound were prepared at a concentration of $500 \mathrm{ng} / \mu \mathrm{l}$ and stored at $-20^{\circ} \mathrm{C}$. A 5-point calibration curve (0.025-0.4 $\mathrm{ngl} / \mu \mathrm{l})$ was prepared by serial dilutions [Bodipy-SM $\mathrm{C}_{12} \quad \mathrm{R}^{2}=0.9909$; LacCer(d18:1/16:0) $\mathrm{R}^{2}=0.9945 ;$ Bodipy-LacCer $\mathrm{R}^{2}=0.9983 ; \operatorname{LacCer}(\mathrm{d} 18: 1 / 14: 0) \mathrm{R}^{2}=$ $0.8742]$, except for endogenous $\operatorname{SM}(\mathrm{d} 18: 1 / 16: 0)$ where $0.025-10.0 \mathrm{ng} / \mu \mathrm{l}$ was used $\left(\mathrm{R}^{2}=\right.$ 0.9991). Samples and calibration curves were analyzed using a 1290 Infinitely system from Agilent Technologies (Waldbronn, Germany), consisting of a G4220A binary pump, G1316C thermostated column compartment and G4226A autosampler with G1330B autosampler thermostat coupled to an Agilent 6490 triple quadrupole mass spectrometer equipped with a jet stream electrospray ion source operating in positive ion mode. Separation was achieved injecting $2 \mu \mathrm{l}$ of each sample (resuspended in $20 \mu \mathrm{l}$ of $\mathrm{MeOH}$ ) onto a $\mathrm{CSH} \mathrm{C}_{18} 2.1 \times 50 \mathrm{~mm}$, $1.7 \mu \mathrm{m}$ column (Waters, Milford, MA, USA) held at $60^{\circ} \mathrm{C}$ in a column oven. The gradient eluents used were 60:40 acetonitrile: $\mathrm{H}_{2} \mathrm{O}$ (A) and 89:10.5:0.4 isopropanol:acetonitrile:water (B), both with $10 \mathrm{mM}$ ammonium formate and $0.1 \%$ formic acid, with a flow rate of 500 $\mu \mathrm{l} / \mathrm{min}$. The initial conditions consisted of $15 \% \mathrm{~B}$, and the following gradient was used with linear increments: 0-1.2 $\min (15-30 \% \mathrm{~B}), 1.2-1.5(30-55 \% \mathrm{~B}), 1.5-4.0$ (55\% B), 4.0-4.8 (55100\% B), 4.8-6.8 (100\% B), 7.1-8.0 (15\% B). The MS parameters were optimized for each 
compound (Table 1). The fragmentor voltage was set at $380 \mathrm{~V}$, the cell accelerator voltage at with using a retention time delta of 0.8 min and 500 millisec cycle scans. The data was quantified using custom scripts (Swedish Metabolomics Centre, Umeå, Sweden).

Table 1. Retention times (RT), MRM-transition stages monitored (precursor ion and product ions) and collision energies of analyzed compounds.

600

\begin{tabular}{lcccc}
\hline Compounds & \multicolumn{2}{c}{ MRM transition } & RT (min) & Collision Energy (V) \\
\cline { 2 - 3 } & Precursor Ion & Product Ion & & \\
\hline Bodipy-LacCer & 926.5 & 562.4 & 1.48 & 30 \\
\hline LacCer(d18:1/16:0) & 862.6 & 520.5 & 2.84 & 20 \\
\hline LacCer(d18:1/14:0) & 834.6 & 264.3 & 2.8 & 40 \\
\hline SM(d18:1/16:0) & 703.6 & 184.1 & 2.9 & 30 \\
\hline Bodipy-SM C 12 & 865.6 & 184.1 & 2.12 & 30
\end{tabular}

One day prior to experiment cells were seeded in a 6-well plate. Cells were left untreated or treated with $11.7 \mathrm{nmol} / \mathrm{ml}$ fusogenic liposomes for $10 \mathrm{~min}$ at $37^{\circ} \mathrm{C}, 5 \% \mathrm{CO}_{2}$. The cells were washed three times with PBS and harvested in $250 \mu \mathrm{MeOH}$ by scraping and two wells were pooled to generate approximately $8 \times 10^{5}$ cells per $500 \mu \mathrm{l}$ sample into Eppendorf tubes. Extraction was performed using a mixer mill set to a frequency $30 \mathrm{~Hz}$ for 2 min, with 1 tungsten carbide bead added to each tube. Obtained extracts were centrifuged at $4^{\circ} \mathrm{C}, 14000$ 
individual micro vials and the extracts were dried under $\mathrm{N}_{2}(\mathrm{~g})$ to dryness. Separate calibration curves were prepared for endogenous and d7-Chol. A 6-point calibration curve spanning from 0-10 ng/ $\mu \mathrm{l}$ was prepared for $\mathrm{d} 7-\mathrm{Chol}\left(\mathrm{R}^{2}=0.9909\right)$. For endogenous Chol a 6point calibration curve spanning from $0-500 \mathrm{ng} / \mu \mathrm{l}$ was prepared $\left(\mathrm{R}^{2}=0.9969\right)$. Methyl stearate at a final concentration of $5 \mathrm{ng} / \mu \mathrm{l}$ was used as internal standard in both calibration curves. Derivatization was performed according to a previously published method (Gullberg et al., 2004) . In detail, $10 \mu \mathrm{l}$ of methoxyamine (15 $\mu \mathrm{g} / \mu \mathrm{l}$ in pyridine) was added to the dry sample that was shaken vigorously for 10 min before left to react in room temperature. After 16 hours $10 \mu \mathrm{l}$ of MSTFA was added, the sample was shaken and left to react for 1 hour in room temperature. A volume of $10 \mu \mathrm{l}$ of methyl stearate $(15 \mathrm{ng} / \mu \mathrm{l}$ in heptane) was added before analysis. For d7-cholesterol quantification, $1 \mu 1$ of the derivatized sample was injected by an Agilent 7693 autosampler, in splitless mode into an Agilent 7890A gas chromatograph equipped with a multimode inlet (MMI) and $10 \mathrm{~m}$ x $0.18 \mathrm{~mm}$ fused silica capillary column with a chemically bonded $0.18 \mu \mathrm{m}$ DB 5-MS UI stationary phase (J\&W Scientific). The injector temperature was $250^{\circ} \mathrm{C}$. The carrier gas flow rate through the column was $1 \mathrm{ml} \mathrm{min}{ }^{-1}$, the column temperature was held at $60^{\circ} \mathrm{C}$ for $1 \mathrm{~min}$, then increased by $60^{\circ} \mathrm{C}$ min- 1 to $300^{\circ} \mathrm{C}$ and held there for $2 \mathrm{~min}$. The column effluent is introduced into the electron impact (EI) ion source of an Agilent 7000C QQQ mass spectrometer. The thermal AUX 2 (transfer line) and the ion source temperatures were $250^{\circ} \mathrm{C}$ and $230^{\circ} \mathrm{C}$, respectively. Ions were generated by a $70 \mathrm{eV}$ electron beam at an emission current of $35 \mu \mathrm{A}$ and analyzed in dMRM-mode. The solvent delay was set to 3 min. For a list of MRM transitions see Table 2. For endogenous 630 Chol analysis, the samples were reanalyzed in split mode $(10: 1)$ together with the Chol 631 calibration curve. Data were processed using MassHunter Qualitative Analysis (Agilent 632 Technologies, Atlanta, GA, USA) and custom scripts (Swedish Metabolomics Centre, Umeå, 633 Sweden). 
Table 2. MRM transitions for labeled and endogenous Chol.

635

\begin{tabular}{lccccccc} 
Compound & Comment & $\begin{array}{c}\text { Precursor } \\
\text { ion }\end{array}$ & $\begin{array}{c}\text { MS1 } \\
\text { resolution }\end{array}$ & $\begin{array}{c}\text { Product } \\
\text { ion }\end{array}$ & $\begin{array}{c}\text { MS2 } \\
\text { resolution }\end{array}$ & RT & $\begin{array}{c}\text { RT delta Min } \\
\text { (total) }\end{array}$ \\
\hline $\begin{array}{l}\text { Methyl } \\
\text { stearate }\end{array}$ & IS-std & 298 & Unit & 101.1 & Unit & 5.6 & 2 \\
\hline Chol & Quant & 329 & Unit & 95 & Unit & 7.8 & 2 \\
\hline Chol & Qual & 368 & Unit & 213 & Unit & 7.8 & 2 \\
\hline d7-Chol & Quant & 336 & Unit & 95 & Unit & 7.8 & 2 \\
\hline d7- Chol & Qual & 375 & Unit & 213 & Unit & 7.8 & 2 \\
\hline
\end{tabular}

636

637 Calculations of the number of PM lipids.

638 The average PM area of fibroblast is around $3000 \mu \mathrm{m}^{2}$ (Sheetz et al., 2006), of which $23 \%$ is

639 estimated to be occupied by proteins (Dupuy \& Engelman, 2008), which translates into that

640 the average PM of a cell contains approximately $7 \times 10^{9}$ lipids (Alberts et al., 2002). Our data

641 is in agreement with these reported values, whereby our measured values for SM(d18:1/16:0)

642 being $40 \%$ of total SM species (Kjellberg et al., 2014), and $21 \mathrm{~mol} \%$ of PM lipids translating

643 to $9.6 \times 10^{9}$ lipids in the PM.

\section{Assessment of lipid incorporation into the PM with live-cell spinning disk microscopy.}

645 One day prior to the experiment, non-induced Cav1-mCh HeLa cells or 3T3-L1 adipocytes 646 were seeded on glass coverslips (CS-25R17 or CS-25R15, Warner Instruments, Hamden, CT, 647 US) in a 6 -well plate at $3 \times 10^{5}$ cells $/$ well $\left(37^{\circ} \mathrm{C}, 5 \% \mathrm{CO}_{2}\right)$. Live cell experiments were 648 conducted in phenol red-free DMEM (live cell medium, Thermo Fisher Scientific) 649 supplemented with $10 \%$ FBS and $1 \mathrm{mM}$ sodium pyruvate (Thermo Fisher Scientific) at $37^{\circ} \mathrm{C}$ 650 in $5 \% \mathrm{CO}_{2}$. To follow the distribution of Bodipy throughout the PM, a POC mini 2 chamber 651 (PeCon, Erbach, DE) was used that allowed addition of the fusogenic liposomes during data 652 acquisition. Liposomes were added at a concentration of $7 \mathrm{nmol} / \mathrm{ml}$ and movies of confocal 
Disk Confocal controlled by ZEN interface with an Axio Observer.Z1 inverted microscope, equipped with a CSU-X1A 5000 Spinning Disk Unit and an EMCCD camera iXon Ultra from ANDOR. For TIRF movies the same system was used but employing a 100X lens and an Axio Observer.Z1 inverted microscope equipped with an EMCCD camera iXonUltra from ANDOR. The increase in fluorescence intensity (FI) of the Bodipy signal was measured within circular regions of interest, which were either evenly distributed over the PM seen in the confocal section or over the basal PM in the case of TIRF. The total FI was determined by calculating integrated density (area x FI), which was then background corrected. Ten regions of interest (ROIs) per cell were analyzed using Zeiss Zen interface ( $n=3$, two independent experiments). Based on that lipids occupy $65 \AA^{2}$, which translates to $3.1 \times 10^{6}$ lipid molecules $/ \mu \mathrm{m}^{2}$ (Dopico, 2007), and that the mean liposomes diameter was $225 \mathrm{~nm}$, corresponding to an area of $0.19 \mu \mathrm{m}^{2}$, we calculated that each liposome contained $0.6 \times 10^{6}$ lipids, of which 5\% were Bodipy-labeled. To estimate the cell volume, the cell surface was segmented with the surface feature within the Imaris x64 9.1.2 (Bitplane, Zurich, $\mathrm{CH}$ ) using the mCherry fluorescence.

\section{Constructs, transfections and cell treatments.}

670 pTagBFP-C (Evrogen, Moscow, RU) was used to generate the expression constructs of Rab5 and EHD2 wt or I157Q. Cav1-mCh HeLa cells were transfected with Lipofectamine ${ }^{\mathrm{TM}} 2000$ (Thermo Fisher Scientific) using Opti-MEMTM I reduced serum medium (Thermo Fisher Scientific) for transient protein expression. For EHD2 and Cav1 depletion, Cav1-mCh HeLa cells were transfected with either stealth siRNA, specific against human EHD2 or human

675 Cav1, or scrambled control (all from Thermo Fisher Scientific) using Lipofectamine ${ }^{\mathrm{TM}} 2000$ and Opti-MEM according to manufacturer's instructions unless otherwise stated. Cells were 
by SDS-PAGE and immunoblotting using rabbit anti-EHD2 (Morén et al., 2012) and rabbit anti-Cav1 antibodies (Abcam, Cambridge, UK). Mouse anti-clathrin heavy chain (clone 23, BD Transduction Laboratories, San Jose, CA, US) was used as loading control. Cells were treated with $2.5 \mu \mathrm{M}$ myriocin in complete medium $24 \mathrm{~h}$ prior to harvesting. SMase was added to cells to generate a final concentration of 0.01 units in complete medium $2 \mathrm{~h}$ prior to harvesting or live cell imaging.

\section{Analysis of caveolae dynamics.}

To track caveolae dynamics, induced Cav1-mCh HeLa cells were treated with fusogenic liposomes $(7 \mathrm{nmol} / \mathrm{ml})$ and $5 \mathrm{~min}$ TIRF movies were recorded with an acquisition time of $3 \mathrm{~s}$. Imaris software was used for tracking analysis of Cav1-mCh positive structures, which were segmented as spots and structures with a diameter of $0.4 \mu \mathrm{m}$ were selected. The applied algorithm was based on Brownian motion with max distance travelled of $0.8 \mu \mathrm{m}$ and a max gap size of 4. Experiments where EHD2 (wt and mutant) was either transiently expressed or depleted were performed and analyzed the same way. Colocalization of EHD2 (wt and mutant) to Cav1-mCh was quantified with Imaris software. Within a ROI, spots were created in one channel (e.g., red channel) and the second channel (e.g., blue channel) was masked. The masked spots show only colocalized red and blue spots and the percentage was correlated to the original channel. The analysis of the dynamic behavior of caveolae positive for or lacking EHD2-BFP was preformed using double Flp-In EHD2-BFP Cav1-mCh HeLa cells. The tracking was done as described above and the data from the tracks of Cav1-mCh spots lacking EHD2-BFP was collected and removed from the data of Cav1-mCh spots positive for EHD2-BFP. Statistical analysis was performed on track duration (s) and track mean speed $(\mu \mathrm{m} / \mathrm{s})$ data and data is shown as fold change. All micrographs and acquired movies were prepared with Fiji (Schindelin et al., 2012) and Adobe Photoshop CS6. 


\section{Intracellular trafficking of lipids.}

703

704

705

706

707

708

709

710

711

712

Induced Cav1-mCh HeLa cells were seeded on glass coverslips (CS-25R15) in a 6-well plate at $3 \times 10^{5}$ cells/well $\left(37^{\circ} \mathrm{C}, 5 \% \mathrm{CO}_{2}\right)$. On the following day, the cells were incubated with fusogenic liposomes $(7 \mathrm{nmol} / \mathrm{ml}$ ) for $15 \mathrm{~min}$ or $3 \mathrm{~h}$. Rab5-BFP (Francis et al., 2015) was either transiently expressed or. To analyze the localization of lipids to lipid droplets (LDs), induced Cav1-mCh HeLa cells were treated with lipids for $15 \mathrm{~min}$ or $3 \mathrm{~h}$, fixed and stained with HCS LipidTOX ${ }^{\mathrm{TM}}$ Deep Red Neutral Lipid Stain (1:200, Thermo Fisher Scientific). Confocal stacks were acquired on Zeiss Spinning Disk Confocal microscope. The colocalization was analyzed as described above. Micrographs were prepared with Fiji (Schindelin et al., 2012) and Adobe Photoshop CS6.

\section{Immunostaining.}

Induced Cav1-mCh HeLa cells were seeded on precision coverslips (No. 1.5H, Paul Marienfeld $\mathrm{GmbH} \& \mathrm{Co} . \mathrm{KG}$, Lauda-Königshofen, DE) in 24-well plates at $50 \times 10^{3}$ cells/well and incubated overnight $\left(37^{\circ} \mathrm{C}, 5 \% \mathrm{CO}_{2}\right)$. Following incubation with fusogenic liposomes $(7 \mathrm{nmol} / \mathrm{ml})$ for $1 \mathrm{~h}$, the cells were washed thrice with phosphate-buffered saline (PBS, pH 7.4). Cells were fixed with $4 \%$ PFA in PBS (Electron Microscopy Sciences, Hatfield, PA, US) and subsequent permeabilization and blocking was carried out simultaneously using PBS containing 5\% goat serum and $0.05 \%$ saponin. Cells were then immunostained with rabbit anti-EHD2 (Morén et al., 2012) and rabbit anti-PTRF (Abcam) followed by goat anti-rabbit IgG secondary antibody coupled to Alexa Fluor 647 (Thermo Fisher Scientific) as previously described (Lundmark et al., 2008). Confocal images were acquired using the Zeiss Spinning Disk Confocal microscope (63X lens). Pearson colocalization coefficients were obtained using Imaris software applying the Coloc feature with automatic thresholding. All Pearson coefficients were derived from two independent 
experiments for the EHD2 stain. Analysis of the colocalization of cavin 1 and Cav1-mCh was Photoshop CS6.

FRAP experiments.

Induced Cav1-mCh HeLa cells were seeded on glass coverslips (CS-25R15) in a 6-well plate at $3 \times 10^{5}$ cells/well and incubated overnight $\left(37^{\circ} \mathrm{C}, 5 \% \mathrm{CO}_{2}\right)$. Cells were treated with 7 $\mathrm{nmol} / \mathrm{ml}$ of Bodipy-labeled liposomes for $10 \mathrm{~min}$ followed by two washes with live cell media before imaging using TIRF using a Zeiss Axio Observer.Z1 inverted microscope. Three reference images were recorded before a ROI was photobleached for $1000 \mathrm{~ms}$ using maximal laser intensity $(488 \mathrm{~nm}$ or $561 \mathrm{~nm})$. The fluorescent recovery images were taken every $3 \mathrm{~s}$ for $5 \mathrm{~min}$. For the lipid incorporation experiment, a region within the PM with homogeneous fluorescence was chosen. FRAP of the EHD2 mutants was performed the same way. For the LacCer and Chol accumulated in caveolae, FRAP was preformed between 15 to 60 min after lipid addition and regions with structures positive for Cav1-mCh, EHD2-BFP and Bodipy-lipid were selected. For FRAP experiments that quantified the recovery of Cav1mCh, induced Cav1-mCh HeLa cells were either untreated, depleted of EHD2 using siRNA or incubated with Bodipy-LacCer liposomes. FRAP experiments were performed as described above using the Zeiss Spinning Disk Confocal microscope (63X lens). The signal recovery monitored in focal plane close to the basal membrane. The intensities of the bleached regions were corrected for background signal and photobleaching of the cell. Data

747 from at least 10 cells were collected per condition and mean FRAP recovery curves were 748 plotted using Prism 5.0 (GraphPad, San Diego, CA, US). 
Mouse EHD2 cysteine mutant construct (L303C,C96S, C138S, C356S) was expressed as Nterminal His 6 -tag fusion proteins in Escherichia coli Rosetta (DE3) and purified (Daumke et al., 2007). Dithiothreitol was removed from the protein using PD-10 columns and the protein was labelled with Alexa Fluor ${ }^{\mathrm{TM}} 647$ C2 Maleimide (Thermo Fisher Scientific) (Hoernke et al., 2017). The protein was diluted to a concentration of $0.5 \mathrm{mg} / \mathrm{ml}$ in $150 \mathrm{mM} \mathrm{NaCl}, 20 \mathrm{mM}$ HEPES pH 7.5 and $1 \mathrm{mM} \mathrm{MgCl}_{2}$. Cav1-mCh HeLa cells were transfected with siRNA and induced as described above. One day prior to the injection experiment, Cav1-mCh HeLa cells were seeded in MatTek dishes (35 mm dish, high tolerance 1.5, MatTek Corporation, Ashland, MA, US) with a cell density of $3 \times 10^{5}$ cells/dish and induced with Dox. In the case of LacCer addition, the cells were treated with $7 \mathrm{nmol} / \mathrm{ml}$ of Bodipy-LacCer fusogenic liposomes for 10 min followed by two washes with live cell media before microinjection. Microinjection was preformed with Injectman NI2 coupled to the programmable (Eppendorf) and injection was done with an injection pressure of $1.0 \mathrm{hPa}$, compensation pressure of $0.5 \mathrm{hPa}$ and injection time of $0.1 \mathrm{~s}$. Live images were acquired on TIRF every $3 \mathrm{~s}$ for a total of five min using a Nikon Eclipse Ti-E inverted microscope with a 100X lens (Apochromat 1.49 Oil 0.13-0.20 DIC N2, Nikon). Z-stacks of injected cells were captured using a 60X lens (Apochromat 1.40 Oil DIC, Nikon). Tracking of Cav1-mCh and colocalization analysis was done with Imaris as previously described.

\section{Correlative light electron microscopy.}

Cav1-mCh cells transiently expressing EHD2-GFP alone or treated with either BodipyLacCer or Bodipy-Chol liposomes were fixed in 2\% paraformaldehyde (PFA) and $0.2 \%$ of glutaraldehyde (Taab Laboratory Equipment Ltd, Aldermaston, UK) in $0.1 \mathrm{M}$ phosphate buffer ( $\mathrm{pH} 7.4$ ) for $1-2 \mathrm{~h}$ and then stored in $1 \%$ PFA at $4{ }^{\circ} \mathrm{C}$. For the grid preparation, the cells 
were scraped into the fixative solution and washed thrice with PBS (pH 7.4) and once with PBS containing $0.1 \%$ glycine (pH 7.4, Merck Millipore, Burlington, US). The cell pellet was embedded in $12 \%$ gelatin (Dr. Oetker, food grade) in $0.1 \mathrm{M}$ phosphate buffer ( $\mathrm{pH} 7.4$ ). Blocks of around $1 \mathrm{~mm}^{2}$ were cut and cryo-protected by overnight infiltration in $2.3 \mathrm{M}$ sucrose (VWR) in $0.1 \mathrm{M}$ phosphate buffer. Next, the blocks were plunge frozen in liquid nitrogen. The sample block was sectioned at $-120^{\circ} \mathrm{C}$ to obtain $80 \mathrm{~nm}$ sections. These were mounted in a drop of in $0.1 \mathrm{M}$ phosphate buffer containing $1: 1$ of $2 \%$ methyl cellulose (Sigma-Aldrich) and 2.3 M sucrose on TEM grids with a carbon-coated Formvar film (Taab Laboratory Equipment Ltd). The grids were incubated with PBS (pH 7.4) at $37^{\circ} \mathrm{C}$ for 20 min and stained with DAPI (4',6-Diamidino-2-Phenylindole, Dilactate, 1:1000 in PBS, pH 7.4, Thermo Fisher Scientific) before imaging on a Nikon Eclipse Ti-E inverted microscope with a 100X lens (Apochromat 1.49 Oil 0.13-0.20 DIC N2, Nikon). Low magnification images were taken at 20X for orientation on the grid and to aid the overlay of fluorescent microscopy images and with the higher resolution images of TEM. Contrasting for TEM was done by embedding the grids in $1.8 \%$ methyl cellulose and $0.4 \%$ uranyl acetate (Polysciences, Inc., Hirschberg an der Bergstrasse, DE) solution prepared in water $(\mathrm{pH} 4)$ for 10 min in the dark. TEM was performed with a Talos 120C transmission electron microscope (FEI, Eindhoven, NL) operating at $120 \mathrm{kV}$. Micrographs were acquired with a Ceta $16 \mathrm{M} \mathrm{CCD}$ camera (FEI) using Maps 3.3 (FEI, Hillsboro, OR, US). The fluorescent images were overlaid atop TEM images of the same cells collected from the ultrathin section using Adobe Photoshop CS6.

\section{Electron microscopy.}

3T3-L1 cells were seeded on MatTek dishes (35 $\mathrm{mm}$ dish, high tolerance 1.5) and differentiated to adipocytes as described above. 3T3-L1 adipocytes were untreated or incubated with Bodipy-Chol liposomes for 45 min, washed with PBS and fixed as follows. 
798 All chemical fixation steps were performed using a microwave (Biowave, TED PELLA, inc.)

799 unless stated and solutions were prepared and rinses were performed in $0.1 \mathrm{M}$ cacodylate

800 buffer (Sigma-Aldrich) or water. Fixation of the cells was performed in $0.05 \%$ malachite

801 green oxalate (Sigma-Aldrich) and 2.5\% gluteraldehyde (Taab Laboratory Equipment Ltd,

802 Aldermaston, UK) in cacodylate buffer. The samples were rinsed four times with cacodylate buffer and post-fixed with $0.8 \% \mathrm{~K}_{3} \mathrm{Fe}(\mathrm{CN})_{6}$ (Sigma-Aldrich) and $1 \% \mathrm{OsO}_{4}$ (Sigma-Aldrich) in cacodylate buffer and rinsed four times with cacodylate buffer. The samples were then stained with $1 \%$ aqueous tannic acid (Sigma-Aldrich). Following two rinses in cacodylate buffer and water, samples were stained with $1 \%$ aqueous uranyl acetate (Polysciences, Inc., Hirschberg an der Bergstrasse, DE). After four washed with water, samples were dehydrated in gradients of ethanol $(25 \%, 50 \%, 75 \%, 90 \%, 95 \%, 100 \%$ and $100 \%)$ (VWR). The samples were infiltrated with graded series of hard grade spurr resin (Taab Laboratory Equipment Ltd, Aldermaston, UK) in ethanol $(1: 3,1: 1$ and $3: 1)$ and then left in $100 \%$ resin for $1 \mathrm{~h}$ at room temperature. The samples were later polymerized overnight at $60^{\circ}$, sectioned and imaged with a Talos 120C transmission electron microscope (FEI, Eindhoven, NL) operating at $120 \mathrm{kV}$. To obtain quantitative data, segmentation of caveolae for measurement of bulb width and measurement of neck diameter for surface-connected caveolae was performed with "icy" (de Chaumont et al., 2012). In order to extract bulb width and surface area, "active cells" plug-in was used with three points to make an elliptical contour that fitted individual

817 caveolae. The neck diameter was obtained by drawing a ROI across the neck of surfaceconnected caveolae. The analysis was performed blinded and with randomized sections.

\section{Statistical analysis.}


Statistical analysis was carried out by two-tailed unpaired Student $t$-test for comparison with control samples using GraphPad Prism 5.0 software. All experiments were performed at least twice with data representing mean \pm SEM unless otherwise stated.

824 Fig. S1 illustrates dynamic behavior of caveolae at the cell surface and shows 825 characterization of liposomes as well as chromatography data. Fig. S2 shows the correlation between track duration and track mean speed and the effect of GSLs and Chol on lifetime of caveolae. Fig. S3 shows the colocalization of EHD2 to Cav1 in double Flp-In cells, analysis of track duration in presence of EHD2-I157Q-BFP and TIRF images of TIRF images of Cav1-mCh HeLa cells with or without microinjection of EHD2-647. Fig. S4 shows that

830 Bodipy-labeled LacCer and Chol accumulate in caveolae at the PM and demonstrates the recovery of lipids within caveolae after photobleaching. Fig. S5 shows CLEM approach and upregulation of EHD2 and Cav1 in 3T3-L1 adipocytes. Video 1-4 show cell surface dynamics of Cav1-mCh untreated (Video 1) or following addition of Bodipy-LacCer (Video

2), Chol (Video 3) or Bodipy-SM C 12 (Video 4). Video 5-6 show colocalization of BodipyLacCer (Video 5) or Bodipy-Chol (Video 6) with Cav1-mCh positive structures. Video 7-8 show accumulation of Bodipy-LacCer (Video 7) or Chol (Video 8) in Cav1-mCh positive structures in presence of EHD2-BFP.

\section{ACKNOWLEDGMENTS}

839 We acknowledge the Biochemical Imaging Center (BICU) and Umeå Core Facility Electron 840 Microscopy (UCEM) at Umeå University and the National Microscopy Infrastructure, NMI 841 (VR-RFI 2016-00968) for providing assistance. We especially thank Irene Martinez at BICU 842 for assistance and expertise with image analysis and data visualization. We thank Mikkel 
bioRxiv preprint doi: $\mathrm{https}$ ://doi.org/10.1101/2020.01.22.915173; this version posted January 22, 2020. The copyright holder for this preprint (which was not certified by peer review) is the author/funder, who has granted bioRxiv a license to display the preprint in perpetuity. It is made available under aCC-BY 4.0 International license.

843

844

845

846

847

848

849

850

851

852

853

854

855

856

857

858

859

860

861

862

863

864

865

866

867

868

869

870

871

872

873

874

875

Roland Holst for help with establishing the HeLa Flp-In T-REx Caveolin1-mCherry cells.

This work was supported by the Swedish Cancer Society (CAN2014/746, CAN 2017/735,

R.L. and M.H.), The Hagbergs Foundation (R.L. and M.H.), Kempe Foundation (L.W.K.M.)

and the Swedish Research Council (dnr 2017-04028, R.L. and E.L.).

\section{AUTHOR CONTRIBUTIONS}

M.H., E.L. and R.L. designed the research; M.H., E.L., N.G.V.G. and R.L. performed research and analyzed data; L.W.K.M. synthesized lipids, M.A. and A.J. performed mass spectrometry, M.H., E.L., L.W.K.M. and R.L. wrote the paper.

\section{DECLARATION OF INTERESTS}

The authors declare no competing interests.

\section{REFERENCES}

Alberts, B., Johnson, A., Lewis, J., Raff, M., Roberts, K., \& Walter, P. (2002). Molecular Biology of the Cell (4 ed.). New York: Garland Science.

Bacia, K., Schwille, P., \& Kurzchalia, T. (2005). Sterol structure determines the separation of phases and the curvature of the liquid-ordered phase in model membranes. Proc. Natl. Acad. Sci. USA, 102(9), 3272-3277. doi:10.1073/pnas.0408215102

Boucrot, E., Howes, M. T., Kirchhausen, T., \& Parton, R. G. (2011). Redistribution of caveolae during mitosis. J. Cell Biol., 124(12), 1965-1972. doi:10.1242/jcs.076570

Cao, H., Alston, L., Ruschman, J., \& Hegele, R. A. (2008). Heterozygous CAV1 frameshift mutations (MIM 601047) in patients with atypical partial lipodystrophy and hypertriglyceridemia. Lipids Health Dis., 7(1), 3. doi:10.1186/1476-511x-7-3

Cohen, A. W., Hnasko, R., Schubert, W., \& Lisanti, M. P. (2004). Role of Caveolae and Caveolins in Health and Disease. Physiol. Rev., 84(4), 1341-1379. doi:10.1152/physrev.00046.2003

Crescencio, M. E., Rodríguez, E., Páez, A., Masso, F. A., Montaño, L. F., \& López-Marure, R. (2009). Statins inhibit the proliferation and induce cell death of human papilloma virus positive and negative cervical cancer cells. J. Biomed. Sci., 5(4), 411-420.

Csiszar, A., Hersch, N., Dieluweit, S., Biehl, R., Merkel, R., \& Hoffmann, B. (2010). Novel fusogenic liposomes for fluorescent cell labeling and membrane modification. Bioconjug. Chem., 21(3), 537-543. doi:10.1021/bc900470y 
bioRxiv preprint doi: https://doi.org/10.1101/2020.01.22.915173; this version posted January 22, 2020. The copyright holder for this preprint (which was not certified by peer review) is the author/funder, who has granted bioRxiv a license to display the preprint in perpetuity. It is made available under aCC-BY 4.0 International license.

Das, A., Brown, M. S., Anderson, D. D., Goldstein, J. L., \& Radhakrishnan, A. (2014). Three pools of plasma membrane cholesterol and their relation to cholesterol homeostasis. Elife, 3, e02882. doi:10.7554/eLife.02882

Daumke, O., Lundmark, R., Vallis, Y., Martens, S., Butler, P. J. G., \& McMahon, H. T. (2007). Architectural and mechanistic insights into an EHD ATPase involved in membrane remodelling. Nature, 449(7164), 923-927. doi:10.1038/nature06173

de Chaumont, F., Dallongeville, S., Chenouard, N., Hervé, N., Pop, S., Provoost, T., MeasYedid, V., Pankajakshan, P., Lecomte, T., Le Montagner, Y., Lagache, T., Dufour, A., \& Olivo-Marin, J.-C. (2012). Icy: an open bioimage informatics platform for extended reproducible research. Nat. Meth., 9, 690. doi:10.1038/nmeth.2075

Dopico, A. M. (2007). Methods in Membrane Lipids (1 ed.). New York City: Humana Press. Dupuy, A. D., \& Engelman, D. M. (2008). Protein area occupancy at the center of the red blood cell membrane. Proc Natl Acad Sci USA, 105(8), 2848-2852. doi:10.1073/pnas.0712379105

Francis, M. K., Holst, M. R., Vidal-Quadras, M., Henriksson, S., Santarella-Mellwig, R., Sandblad, L., \& Lundmark, R. (2015). Endocytic membrane turnover at the leading edge is driven by a transient interaction between Cdc42 and GRAF1.J Cell Sci, 128(22), 4183-4195. doi:10.1242/jcs.174417

Gretskaya, N. M., \& Bezuglov, V. V. (2013). Synthesis of BODIPY® FL C5-Labeled Derythro- and L-threo-Lactosylceramides. Chem Nat Compd, 49(1), 17-20. doi:10.1007/s10600-013-0494-3

Gullberg, J., Jonsson, P., Nordstrom, A., Sjostrom, M., \& Moritz, T. (2004). Design of experiments: an efficient strategy to identify factors influencing extraction and derivatization of Arabidopsis thaliana samples in metabolomic studies with gas chromatography/mass spectrometry. Anal Biochem, 331(2), 283-295. doi:10.1016/j.ab.2004.04.037

Gulshan, K., Brubaker, G., Wang, S., Hazen, S. L., \& Smith, J. D. (2013). Sphingomyelin Depletion Impairs Anionic Phospholipid Inward Translocation and Induces Cholesterol Efflux. Journal of Biological Chemistry. doi:10.1074/jbc.M113.512244

Hailstones, D., Sleer, L. S., Parton, R. G., \& Stanley, K. K. (1998). Regulation of caveolin and caveolae by cholesterol in MDCK cells. J Lipid Res, 39(2), 369-379.

Harayama, T., \& Riezman, H. (2018). Understanding the diversity of membrane lipid composition. Nat. Rev. Mol. Cell Biol., 19, 281. doi:10.1038/nrm.2017.138

Hayashi, Y. K., Matsuda, C., Ogawa, M., Goto, K., Tominaga, K., Mitsuhashi, S., Park, Y. E., Nonaka, I., Hino-Fukuyo, N., Haginoya, K., Sugano, H., \& Nishino, I. (2009). Human PTRF mutations cause secondary deficiency of caveolins resulting in muscular dystrophy with generalized lipodystrophy. J. Clin. Invest., 119(9), 2623-2633. doi:10.1172/jci38660

Hirama, T., Das, R., Yang, Y., Ferguson, C., Won, A., Yip, C. M., Kay, J. G., Grinstein, S., Parton, R. G., \& Fairn, G. D. (2017). Phosphatidylserine dictates the assembly and dynamics of caveolae in the plasma membrane. J. Biol. Chem., 292(34), 1429214307. doi:10.1074/jbc.M117.791400

Hoernke, M., Mohan, J., Larsson, E., Blomberg, J., Kahra, D., Westenhoff, S., Schwieger, C., \& Lundmark, R. (2017). EHD2 restrains dynamics of caveolae by an ATPdependent, membrane-bound, open conformation. Proc. Natl. Acad. Sci. USA, 114(22), E4360-E4369. doi:10.1073/pnas.1614066114

Kim, C. A., Delepine, M., Boutet, E., El Mourabit, H., Le Lay, S., Meier, M., Nemani, M., Bridel, E., Leite, C. C., Bertola, D. R., Semple, R. K., O'Rahilly, S., Dugail, I., Capeau, J., Lathrop, M., \& Magre, J. (2008). Association of a homozygous nonsense caveolin- 
1 mutation with Berardinelli-Seip congenital lipodystrophy. J. Clin. Endocrinol. Metab., 93(4), 1129-1134. doi:10.1210/jc.2007-1328

Kjellberg, M. A., Backman, A. P. E., Ohvo-Rekilä, H., \& Mattjus, P. (2014). Alternation in the Glycolipid Transfer Protein Expression Causes Changes in the Cellular Lipidome. PLoS ONE, 9(5), e97263. doi:10.1371/journal.pone.0097263

Kleusch, C., Hersch, N., Hoffmann, B., Merkel, R., \& Csiszár, A. (2012). Fluorescent Lipids: Functional Parts of Fusogenic Liposomes and Tools for Cell Membrane Labeling and Visualization. Molecules, 17(1), 1055. doi:10.3390/molecules17011055

Klymchenko, Andrey S., \& Kreder, R. (2014). Fluorescent Probes for Lipid Rafts: From Model Membranes to Living Cells. Cell Chem. Biol., 21(1), 97-113. doi:10.1016/j.chembiol.2013.11.009

Krause, B. R., \& Hartman, A. D. (1984). Adipose tissue and cholesterol metabolism. J. Lipid Res., 25(2), 97-110.

Kube, S., Hersch, N., Naumovska, E., Gensch, T., Hendriks, J., Franzen, A., Landvogt, L., Siebrasse, J.-P., Kubitscheck, U., Hoffmann, B., Merkel, R., \& Csiszár, A. (2017). Fusogenic Liposomes as Nanocarriers for the Delivery of Intracellular Proteins. Langmuir, 33(4), 1051-1059. doi:10.1021/acs.langmuir.6b04304

Le Lay, S., Hajduch, E., Lindsay, M. R., Le Lièpvre, X., Thiele, C., Ferré, P., Parton, R. G., Kurzchalia, T., Simons, K., \& Dugail, I. (2006). Cholesterol-Induced Caveolin Targeting to Lipid Droplets in Adipocytes: A Role for Caveolar Endocytosis. Traffic, 7(5), 549-561. doi:10.1111/j.1600-0854.2006.00406.x

Lenz, M., Morlot, S., \& Roux, A. (2009). Mechanical requirements for membrane fission: Common facts from various examples. FEBS Lett., 583(23), 3839-3846. doi:10.1016/j.febslet.2009.11.012

Liu, L., Brown, D., McKee, M., Lebrasseur, N. K., Yang, D., Albrecht, K. H., Ravid, K., \& Pilch, P. F. (2008). Deletion of Cavin/PTRF causes global loss of caveolae, dyslipidemia, and glucose intolerance. Cell Metab., 8(4), 310-317. doi:10.1016/j.cmet.2008.07.008

Lorizate, M., Sachsenheimer, T., Glass, B., Habermann, A., Gerl, M. J., Kräusslich, H.-G., \& Brügger, B. (2013). Comparative lipidomics analysis of HIV-1 particles and their producer cell membrane in different cell lines. Cellular Microbiology, 15(2), 292304. doi:10.1111/cmi.12101

Lundmark, R., Doherty, G. J., Howes, M. T., Cortese, K., Vallis, Y., Parton, R. G., \& McMahon, H. T. (2008). The GTPase-Activating Protein GRAF1 Regulates the CLIC/GEEC Endocytic Pathway. Curr. Biol., 18(22-2), 1802-1808. doi:10.1016/j.cub.2008.10.044

Matthäus, C., Lahmann, I., Kunz, S., Jonas, W., Melo, A. A., Lehmann, M., Larsson, E., Lundmark, R., Kern, M., Blüher, M., Müller, D. N., Haucke, V., Schürmann, A., Birchmeier, C., \& Daumke, O. (2019). EHD2-mediated restriction of caveolar dynamics regulates cellular lipid uptake. bioRxiv, 511709. doi:10.1101/511709

Mohan, J., Morén, B., Larsson, E., Holst, M. R., \& Lundmark, R. (2015). Cavin3 interacts with cavin 1 and caveolin 1 to increase surface dynamics of caveolae. J. Cell Biol., 128(5), 979-991. doi:10.1242/jcs.161463

Morén, B., Hansson, B., Negoita, F., Fryklund, C., Lundmark, R., Göransson, O., \& Stenkula, K. G. (2019). EHD2 regulates adipocyte function and is enriched at cell surfaceassociated lipid droplets in primary human adipocytes. Mol. Biol. Cell, 30(10), 1147-1159. doi:10.1091/mbc.E18-10-0680

Morén, B., Shah, C., Howes, M. T., Schieber, N. L., McMahon, H. T., Parton, R. G., Daumke, O., \& Lundmark, R. (2012). EHD2 regulates caveolar dynamics via ATP-driven 
bioRxiv preprint doi: https://doi.org/10.1101/2020.01.22.915173; this version posted January 22, 2020. The copyright holder for this preprint (which was not certified by peer review) is the author/funder, who has granted bioRxiv a license to display the preprint in perpetuity. It is made available under aCC-BY 4.0 International license.

targeting and oligomerization. Mol. Biol. Cell, 23(7), 1316-1329. doi:10.1091/mbc.E11-09-0787

Nassoy, P., \& Lamaze, C. (2012). Stressing caveolae new role in cell mechanics. Trends Cell Biol., 22(7), 381-389. doi:10.1016/j.tcb.2012.04.007

Örtegren, U., Karlsson, M., Blazic, N., Blomqvist, M., Nystrom, F. H., Gustavsson, J., Fredman, P., \& Stralfors, P. (2004). Lipids and glycosphingolipids in caveolae and surrounding plasma membrane of primary rat adipocytes. Eur. J. Biochem., 271(10), 2028-2036. doi:10.1111/j.1432-1033.2004.04117.x

Parton, R. G., \& del Pozo, M. A. (2013). Caveolae as plasma membrane sensors, protectors and organizers. Nat. Rev. Mol. Cell Biol., 14(2), 98-112. doi:10.1038/nrm3512

Pelkmans, L., \& Zerial, M. (2005). Kinase-regulated quantal assemblies and kiss-and-run recycling of caveolae. Nature, 436, 128. doi:10.1038/nature03866

Pilch, P. F., \& Liu, L. (2011). Fat caves: caveolae, lipid trafficking and lipid metabolism in adipocytes. Trends Endocrinol. Metab., 22(8), 318-324. doi:10.1016/j.tem.2011.04.001

Puri, V., Watanabe, R., Singh, R. D., Dominguez, M., Brown, J. C., Wheatley, C. L., Marks, D. L., \& Pagano, R. E. (2001). Clathrin-dependent and -independent internalization of plasma membrane sphingolipids initiates two Golgi targeting pathways. J. Cell Biol., 154(3), 535-548. doi:10.1083/jcb.200102084

Razani, B., Combs, T. P., Wang, X. B., Frank, P. G., Park, D. S., Russell, R. G., Li, M., Tang, B., Jelicks, L. A., Scherer, P. E., \& Lisanti, M. P. (2002). Caveolin-1-deficient Mice Are Lean, Resistant to Diet-induced Obesity, and Show Hypertriglyceridemia with Adipocyte Abnormalities. J. Biol. Chem., 277(10), 8635-8647. doi:10.1074/jbc.M110970200

Rothberg, K. G., Heuser, J. E., Donzell, W. C., Ying, Y.-S., Glenney, J. R., \& Anderson, R. G. W. (1992). Caveolin, a protein component of caveolae membrane coats. Cell, 68(4), 673-682. doi:10.1016/0092-8674(92)90143-Z

Roux, A., Cuvelier, D., Nassoy, P., Prost, J., Bassereau, P., \& Goud, B. (2005). Role of curvature and phase transition in lipid sorting and fission of membrane tubules. EMBO J., 24(8), 1537-1545. doi:10.1038/sj.emboj.7600631

Schindelin, J., Arganda-Carreras, I., Frise, E., Kaynig, V., Longair, M., Pietzsch, T., Preibisch, S., Rueden, C., Saalfeld, S., Schmid, B., Tinevez, J.-Y., White, D. J., Hartenstein, V., Eliceiri, K., Tomancak, P., \& Cardona, A. (2012). Fiji: an opensource platform for biological-image analysis. Nat. Meth., 9(7), 676-682. doi:10.1038/nmeth.2019

Schuck, S., \& Simons, K. (2004). Polarized sorting in epithelial cells: raft clustering and the biogenesis of the apical membrane. J. Cell Biol., 117(25), 5955-5964. doi:10.1242/jcs.01596

Sharma, D. K., Brown, J. C., Choudhury, A., Peterson, T. E., Holicky, E., Marks, D. L., Simari, R., Parton, R. G., \& Pagano, R. E. (2004). Selective Stimulation of Caveolar Endocytosis by Glycosphingolipids and Cholesterol. Mol. Biol. Cell, 15(7), 31143122. doi:10.1091/mbc.E04-03-0189

Sheetz, M. P., Sable, J. E., \& Dobereiner, H. G. (2006). Continuous membranecytoskeleton adhesion requires continuous accommodation to lipid and cytoskeleton dynamics. Annu. Rev. Biophys. Biomol. Struct., 35, 417-434. doi:10.1146/annurev.biophys.35.040405.102017 
bioRxiv preprint doi: https://doi.org/10.1101/2020.01.22.915173; this version posted January 22, 2020. The copyright holder for this preprint (which was not certified by peer review) is the author/funder, who has granted bioRxiv a license to display the preprint in perpetuity. It is made available under aCC-BY 4.0 International license.

Shvets, E., Bitsikas, V., Howard, G., Hansen, C. G., \& Nichols, B. J. (2015). Dynamic caveolae exclude bulk membrane proteins and are required for sorting of excess glycosphingolipids. Nat. Commun., 6. doi:10.1038/ncomms7867

Singh, R. D., Liu, Y., Wheatley, C. L., Holicky, E. L., Makino, A., Marks, D. L., Kobayashi, T., Subramaniam, G., Bittman, R., \& Pagano, R. E. (2006). Caveolar Endocytosis and Microdomain Association of a Glycosphingolipid Analog Is Dependent on Its Sphingosine Stereochemistry. J. Biol. Chem., 281(41), 30660-30668. doi:10.1074/jbc.M606194200

Singh, R. D., Marks, D. L., Holicky, E. L., Wheatley, C. L., Kaptzan, T., Sato, S. B., Kobayashi, T., Ling, K., \& Pagano, R. E. (2010). Gangliosides and beta1-integrin are required for caveolae and membrane domains. Traffic 11(3), 348-360. doi:10.1111/j.1600-0854.2009.01022.x

Singh, R. D., Puri, V., Valiyaveettil, J. T., Marks, D. L., Bittman, R., \& Pagano, R. E. (2003). Selective Caveolin-1-dependent Endocytosis of Glycosphingolipids. Mol. Biol. Cell, 14(8), 3254-3265. doi:10.1091/mbc.E02-12-0809

Sinha, B., Köster, D., Ruez, R., Gonnord, P., Bastiani, M., Abankwa, D., Stan, R. V., ButlerBrowne, G., Vedie, B., Johannes, L., Morone, N., Parton, R. G., Raposo, G., Sens, P., Lamaze, C., \& Nassoy, P. (2011). Cells Respond to Mechanical Stress by Rapid Disassembly of Caveolae. Cell, 144(3), 402-413. doi:10.1016/j.cell.2010.12.031

Stoeber, M., Stoeck, I. K., Hänni, C., Bleck, C. K. E., Balistreri, G., \& Helenius, A. (2012). Oligomers of the ATPase EHD2 confine caveolae to the plasma membrane through association with actin. EMBO J., 31(10), 2350-2364. doi:10.1038/emboj.2012.98

Thorn, H., Stenkula, K. G., Karlsson, M., Ortegren, U., Nystrom, F. H., Gustavsson, J., \& Stralfors, P. (2003). Cell surface orifices of caveolae and localization of caveolin to the necks of caveolae in adipocytes. Mol. Biol. Cell, 14(10), 3967-3976. doi:10.1091/mbc.e03-01-0050

Walser, Piers J., Ariotti, N., Howes, M., Ferguson, C., Webb, R., Schwudke, D., Leneva, N., Cho, K.-J., Cooper, L., Rae, J., Floetenmeyer, M., Oorschot, Viola M. J., Skoglund, U., Simons, K., Hancock, John F., \& Parton, Robert G. (2012). Constitutive Formation of Caveolae in a Bacterium. Cell, 150(4), 752-763. doi:10.1016/j.cell.2012.06.042

Zebisch, K., Voigt, V., Wabitsch, M., \& Brandsch, M. (2012). Protocol for effective differentiation of 3T3-L1 cells to adipocytes. Anal. Biochem., 425(1), 88-90. doi:10.1016/j.ab.2012.03.005 
1057 Fig. 1. Rapid insertion of Bodipy-labeled lipids into the PM of living cells using 1058 fusogenic liposomes.

1059 (A) Fusogenic liposomes are used to insert Bodipy-labeled lipids into the PM. Their rapid 1060 distribution is followed in real time using TIRFM. (B) Image sequence of Bodipy-LacCer 1061 distribution throughout basal membrane of HeLa cells. Total Bodipy fluorescence intensity 1062 (FI) was measured within ROIs (yellow insert) using Zeiss Zen interface. $n=10$, three independent experiments, mean \pm SEM. (C) Quantification of endogenous SM(d18:1/16:0) using LC-ESI-MS/MS in untreated control cells or cells treated with SMase or myriocin for 2 h or 24 h, respectively. Data are shown as mean + SD. (D) Quantification of Bodipy- or d7labeled lipids (black bars) and endogenous lipids (grey bars) in cells following incubation of cells with fusogenic liposomes. Analysis was performed using mass spectrometry. Data are shown as mean + SD. (E) Incorporation rate of Bodipy-lipids into PM of live cells. HeLa cells were treated with fusogenic liposomes (final total lipid concentration $7 \mathrm{nmol} / \mathrm{mL}$ ). Total

1070 Bodipy fluorescence intensity (FI) was measured within circular ROIs (see insert) in a confocal section using spinning disk microscopy. Ten ROIs were analyzed using the Zeiss Zen system software. $n \geq 2$, two independent experiments, mean \pm SEM. Scale bars, $10 \mu \mathrm{m}$. normalized to background and reference. $n \geq 10$, mean \pm SEM. 
Fig. 2. GSLs and Chol decrease the surface stability of caveolae.

1077

1078

1079

1080

1081

1082

1083

1084

1085

1086

1087

1088

1089

1090

(A) Scheme showing different dynamic behaviors of caveolae. (B, B') Distribution of track mean speed amongst subpopulations of track duration of Cav1-mCh structures (B) and after EHD2 depletion (B'). Five datasets for each condition were analyzed from TIRF live cell movies. (C) Representative images from TIRF movies of Cav1-mCh HeLa cells and after 15 min incubation with liposomes containing Bodipy-lipids. Color-coded trajectories illustrate time that structures can be tracked at PM over 5 min (dotted square). Scale bars, $10 \mu \mathrm{m}$. See Video 1-4. (D-E) Quantification of track duration of Cav1-mCh structures from TIRF movies after incubation with liposomes containing labeled (D) or unlabeled lipids (E). Fold changes are relative to control (Cav1-mCh). (D) $n \geq 8$, at least two independent experiments; (E) $n \geq$ 8, two independent experiments, $* * *, P \leq 0.001$ vs. control. (F) Quantification of track mean speed of Cav1-mCh structures from TIRF movies (same cells as in D). (G) Quantification of track duration of Cav1-mCh structures from TIRF movies following incubation with SMase for $2 \mathrm{~h}$. Fold changes are relative to control (Cav1-mCh). $n \geq 5$. All analyses were performed using Imaris software and data are shown as mean + SEM. 
1091

1092

1093

1094

1095

1096

1097

1098

1099

1100

1101

1102

1103

1104

1105

1106

1107

1108

1109

1110

1111

1112

1113

Fig. 3. Chol and GSLs induce surface release of caveolae via an EHD2-dependent mechanism.

(A) Representative images of maximum projected confocal z-stacks of Cav1-mCh HeLa cells. Untreated cells or cells treated with LacCer-Bodipy liposomes for $1 \mathrm{~h}$, fixed and immunostained for endogenous EHD2. High-magnification images (dotted square) show localization of EHD2 to Cav1-mCh (see scatterplot for quantification). $n \geq 60$, two independent experiments, mean \pm SEM. ***, $P \leq 0.001$ vs. control. (B) Experimental protocols analogous to (A), with exception of endogenous cavin1 immunostaining. $n \geq 60$, mean \pm SEM. (C) Confocal FRAP of Cav1-mCh HeLa cells treated with either EHD2 siRNA or Bodipy-LacCer liposomes. A ROI was photobleached and recovery of mCherry FI monitored over 5 min. mCherry FI was normalized to background and reference. $n \geq 10$, mean \pm SEM. (D) Representative time-lapse series showing control Cav1-mCh HeLa cells and cells treated with either EHD2 siRNA or Bodipy-LacCer liposomes. The photobleached area is outlined with white circles. mCherry FI is intensity-coded using LUT. (E) Effects of lipids on track duration of Cav1-mCh structures were analyzed following siRNA-mediated depletion of EHD2. $n \geq 8$, two independent experiments, mean + SEM. (F) Quantification of track duration of Cav1-mCh HeLa cells transiently expressing EHD2-BFP with or without incubation with liposomes. Changes in track duration are relative to control (indicated by dotted line). $n \geq 8$, two independent experiments, mean + SEM. $* * *, P \leq 0.001$ vs. control cells. (G) Representative live cell confocal image of EHD2-647 microinjected into Cav1mCh HeLa cells. (H) Quantification of track duration of Cav1-mCh cells treated with Bodipy-LacCer and following microinjection of EHD2-647. $n=8$, mean + SEM. All scale bars, $10 \mu \mathrm{m}$. 
1114 Fig. 4. LacCer and Chol accumulate in caveolae and Chol is sequestered within these 1115 domains.

1116 (A, B) Cav1-mCh HeLa cells (A) and Cav1-mCh HeLa cells transiently expressing EHD2-

1117 BFP (B) were incubated with Bodipy-LacCer liposomes. White lines indicate location of

1118 kymograph and the corresponding intensity profiles illustrate localization of Bodipy-LacCer

1119 to Cav1-mCh either alone or in presence of EHD2-BFP. Intensity profiles are relative to

1120 maximum values for each sample. Scale bars, $10 \mu \mathrm{m}$; kymograph scale bars, $5 \mu \mathrm{m}$. See Video

1121 S3 and S4. (B') Quantification of EHD2-positive caveolae colocalizing with lipids. $n \geq 8$, at

1122 least two independent experiments, mean + SEM. (C) Cav1-mCh HeLa cells transiently

1123 expressing EHD2-BFP were incubated with Bodipy-lipids for $10 \mathrm{~min}$. Following

1124 photobleaching, recovery of Bodipy signal within caveolae was monitored over time. White

1125 arrows highlight surface connected caveolae with accumulated Bodipy-LacCer. Scale bar, 5

$1126 \mu \mathrm{m}$. (D) Recovery curves of Bodipy intensities within bleached membrane ROI. Bodipy FI

1127 was normalized to background and reference. $n \geq 10$, mean \pm SEM. 
bioRxiv preprint doi: https://doi.org/101101/2020 01 22.915173; this version posted January 22, 2020. The copyright holder for this preprint (which was not certified by peer review) is the author/funder, who has granted bioRxiv a license to display the preprint in perpetuity. It is made available under aCC-BY 4.0 International license.

1128 Fig. 5. Chol accumulation reduces the caveolae diameter in 3 T3 adipocytes

1129 (A) Representative overlays of light microscopy images with corresponding electron 1130 micrographs showing localization of caveolae (Cav1-mCh in red) and nuclei (DAPI in cyan)

1131 for untreated Cav1-mCh HeLa cells or cells treated with Bodipy-labeled Chol or LacCer.

1132 Dotted boxes show regions of higher magnification in corresponding panels below. N, 1133 nucleus; PM, plasma membrane. White arrows denote surface connected caveolae and black 1134 arrows indicate surface adjacent caveolae. Scale bars, $1 \mu \mathrm{m}$; inset scale bars, $100 \mathrm{~nm}$. (B, C) 1135 Representative electron micrographs of control 3T3-L1 adipocytes (B) and 3T3-L1 1136 adipocytes treated with Bodipy-Chol (C). Cells were chemically fixed, embedded in resin 1137 and processed for electron microscopy. Scale bars, $100 \mathrm{~nm}$. (D, D') Scatter plots showing the 1138 quantification of neck diameter (D) and bulb width (D') of surface connected caveolae in 1139 3T3-L1 adipocytes. Bulb width and neck diameter are highlighted in (B), upper panel. $n \geq 30$, 1140 mean \pm SEM. (E, E') Scatter plots showing the quantification of surface area (E) and bulb 1141 width (E') of surface adjacent caveolae in 3T3-L1 adipocytes. $n \geq 120$, mean \pm SEM. ***, $P$ $1142 \leq 0.001$. 
bioRxiv preprint doi: https://doi.org/101101/2020 01.22.915173; this version posted January 22, 2020. The copyright holder for this preprint (which was not certified by peer review) is the author/funder, who has granted bioRxiv a license to display the preprint in perpetuity. It is made available under aCC-BY 4.0 International license.

1143 Fig. 6. GSLs are internalized to the endosomal system independent of Cav1, while Chol 1144 is predominantly trafficked to lipid droplets.

1145 (A) Cav1-mCh HeLa cells expressing Rab5-BFP were incubated with Bodipy-labeled LacCer 1146 or Chol for 15 min. Individual channels are shown for selected areas (dotted box). (B)

1147 Colocalization of lipids with Rab5-positive structures after indicated time-points. (C) Cav1 1148 siRNA-treated Cav1-mCh HeLa cells expressing Rab5-BFP after incubation with Bodipy1149 labeled LacCer or Chol for 15 min. High-magnification images of selected areas (dotted box) 1150 for each channel are shown. (D) Quantification of EE positive for lipids in cells treated with 1151 siRNA control or against Cav1. Cells were incubated with Bodipy-lipids for 15 min. (E)

1152 Representative immunoblots of Cav1-mCh HeLa cells treated with control siRNA or siRNA 1153 against Cav1. Clathrin HC served as loading control. (F) Cav1-mCh HeLa cells were 1154 incubated with Bodipy-lipids for $15 \mathrm{~min}$, fixed and LDs were stained using LipidTOX-DR. 1155 (G) Colocalization of lipids to LDs. (H) Colocalization of lipids with LDs in cells depleted of 1156 Cav1 after 15 min. (B, D, E, F) $n=10$, mean + SEM. All scale bars, $5 \mu \mathrm{m}$. 
bioRxiv preprint doi: https://doi.org/10.1101/2020 01.22.915173; this version posted January 22, 2020. The copyright holder for this preprint (which was not certified by peer review) is the author/funder, who has granted bioRxiv a license to display the preprint in perpetuity. It is made available under aCC-BY 4.0 International license.

\section{Figure 1}

A
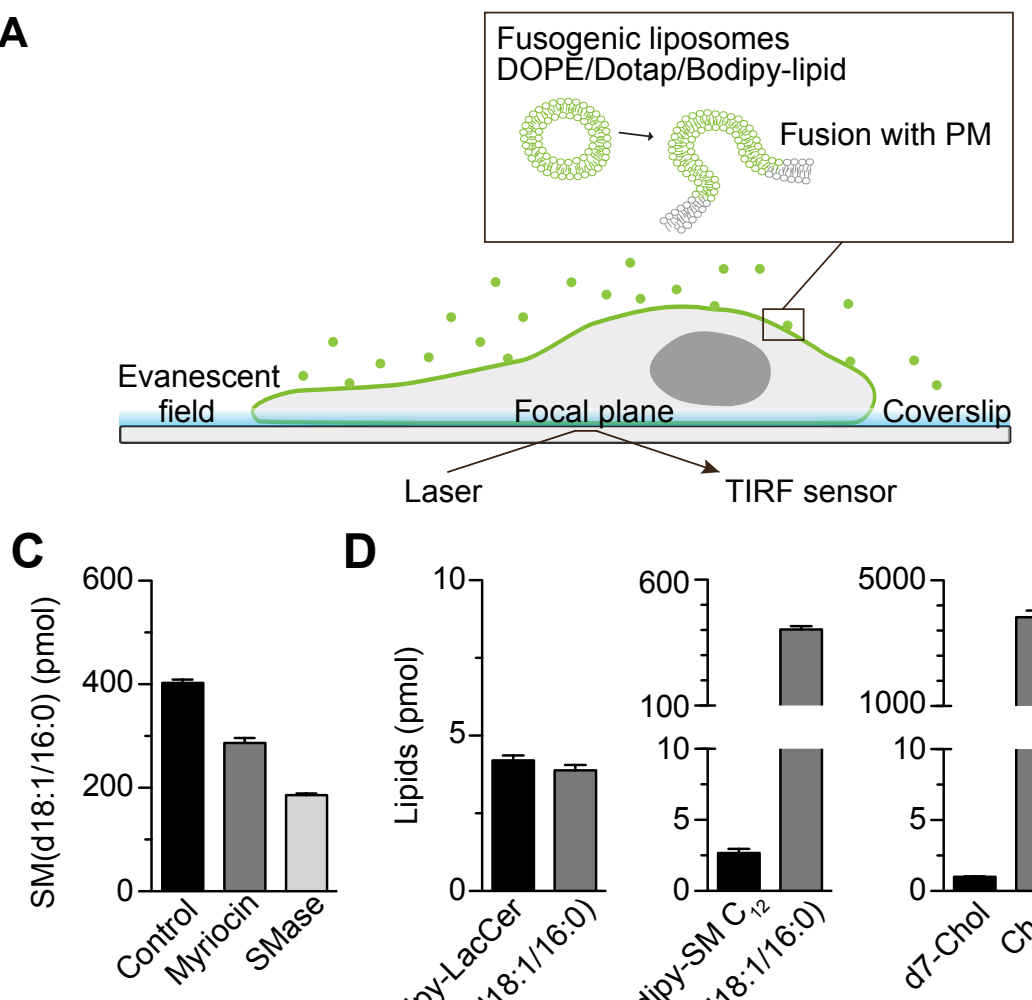

D

E
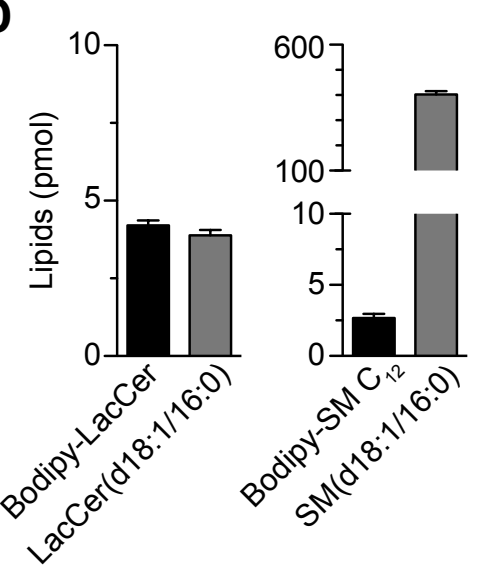

\section{$\mathbf{F}$}
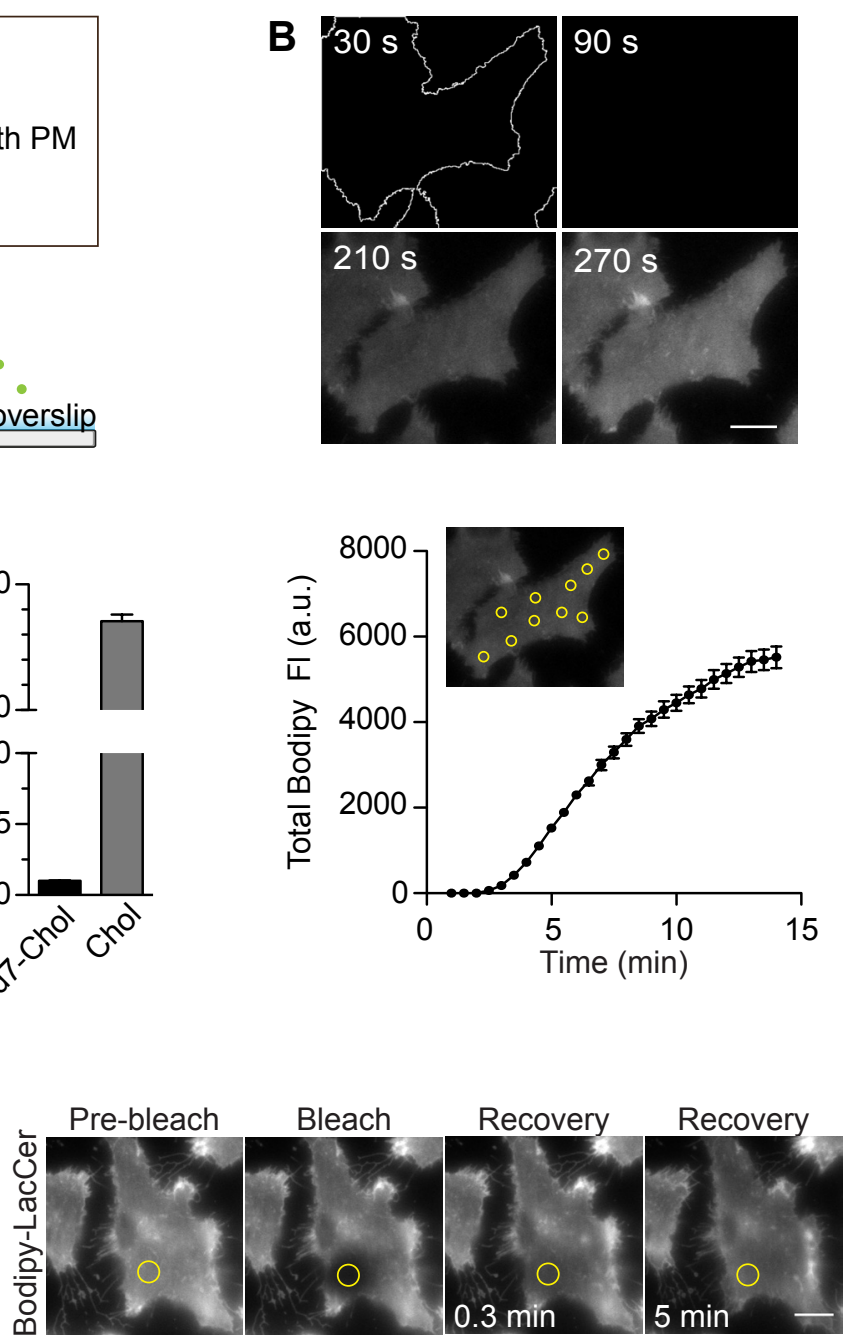

- GM1

- LacCer

- Cer

$\checkmark$ Chol

- SM C

- SM C

$\triangle \mathrm{PE}$

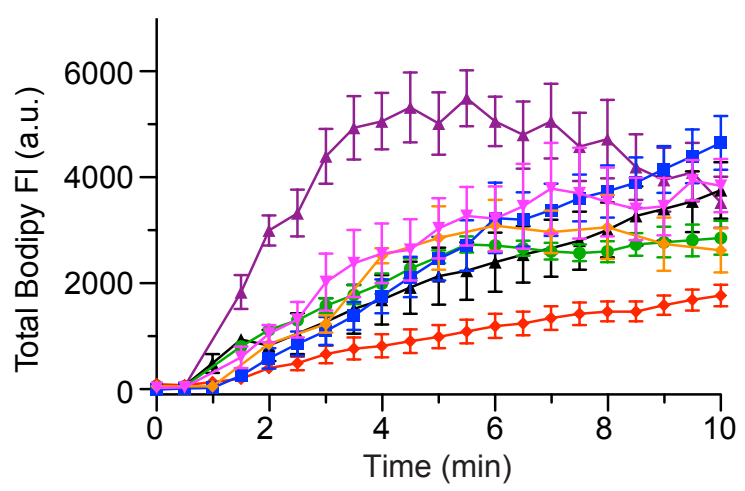

Pre-bleach Bleach

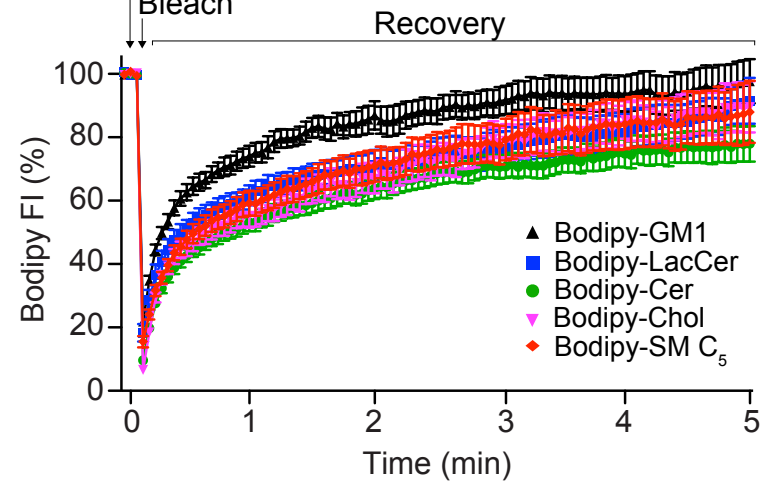


bioRxiv preprint doi: https://doi.org/10.1101/2020.01.22.915173; this version posted January 22, 2020. The copyright holder for this preprint (which was not certified by peer review) is the author/funder, who has granted bioRxiv a license to display the preprint in perpetuity. It is made available under aCC-BY 4.0 International license.

\section{Figure 2}

A

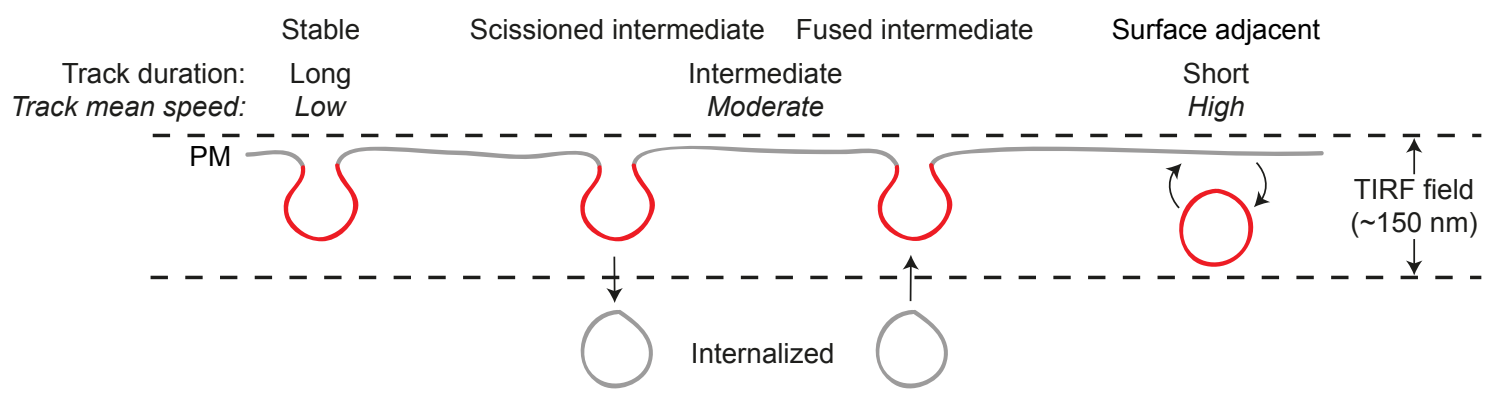

B
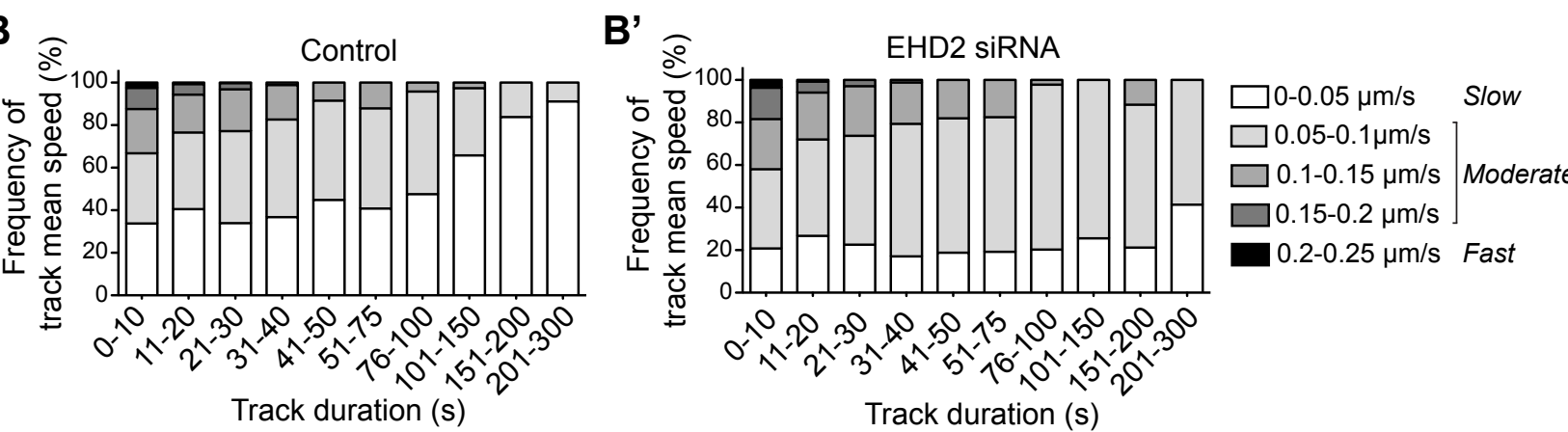

C
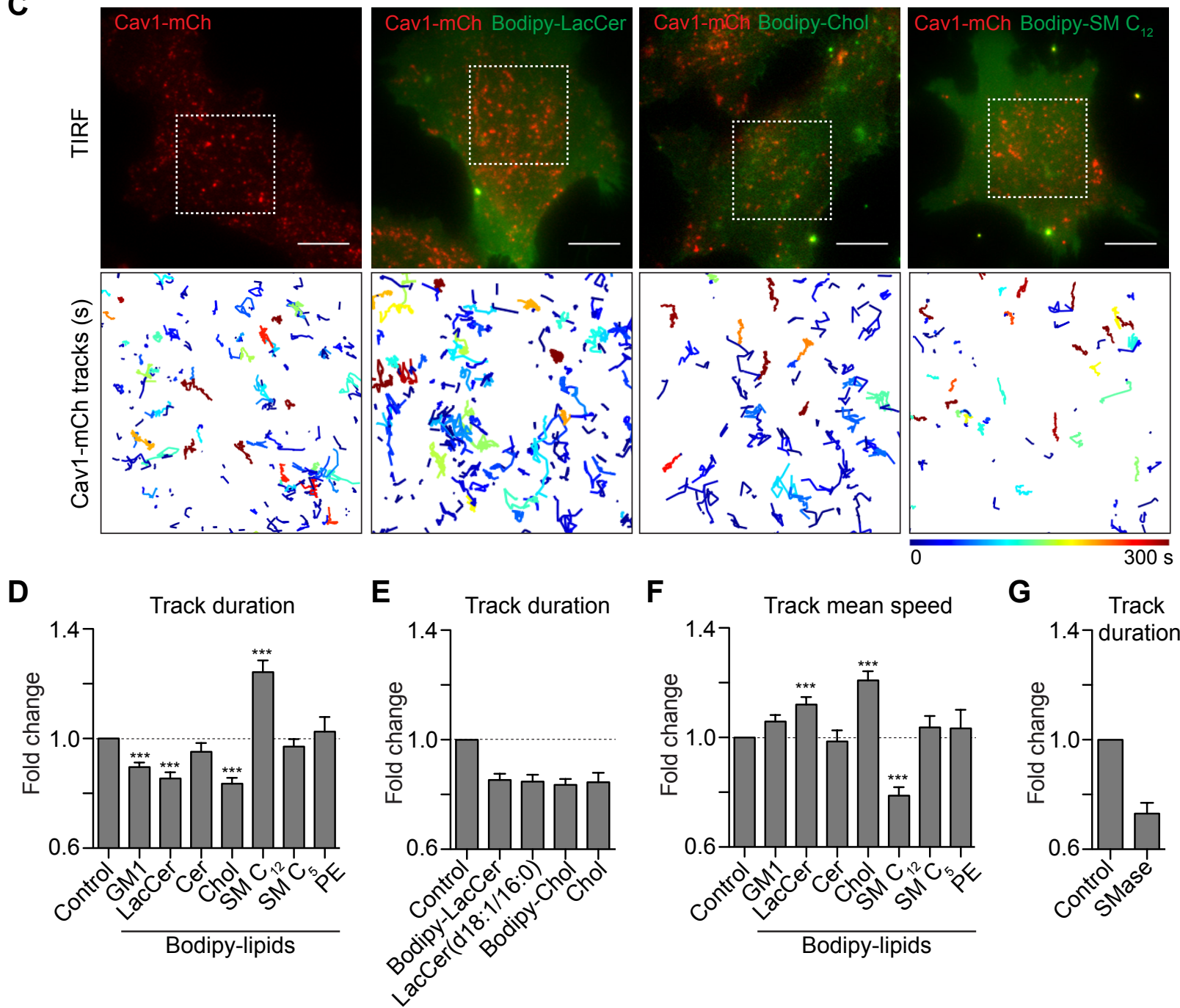
bioRxiv preprint doi: https://doi.org/10.1101/2020.01.22.915173; this version posted January 22, 2020. The copyright holder for this

preprint (which was not certified by peer review) is the author/funder, who has granted bioRxiv a license to display the preprint in

Figure 3 perpetuity. It is made available under aCC-BY 4.0 International license.

A

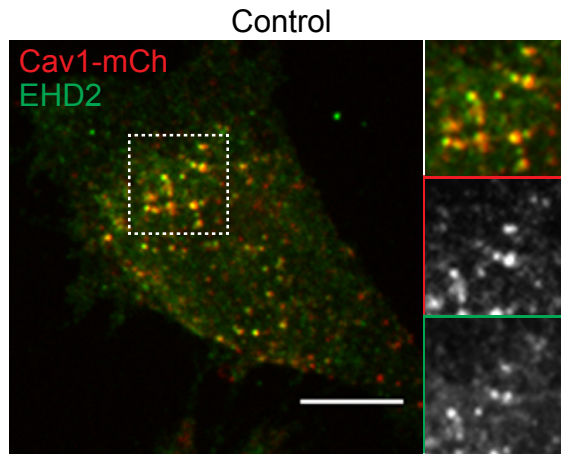

B

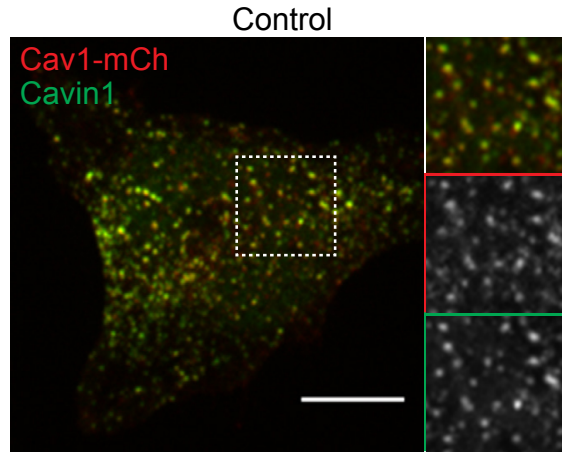

C
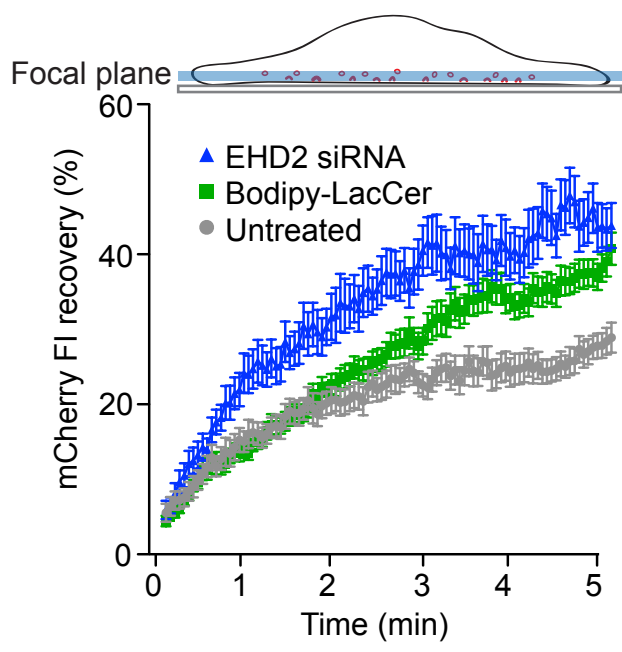

$\mathbf{E}$

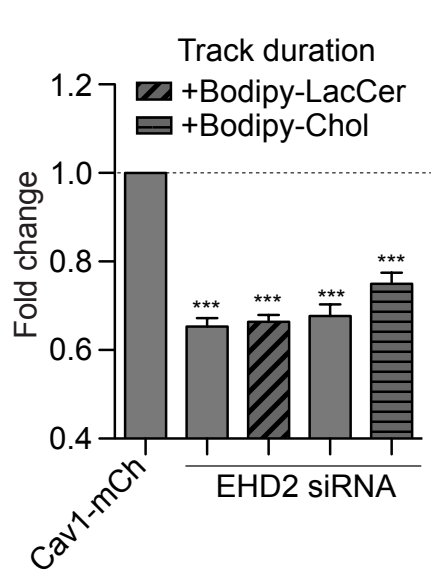

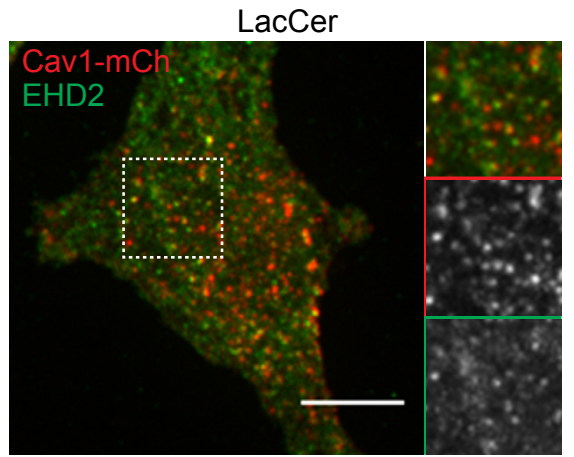
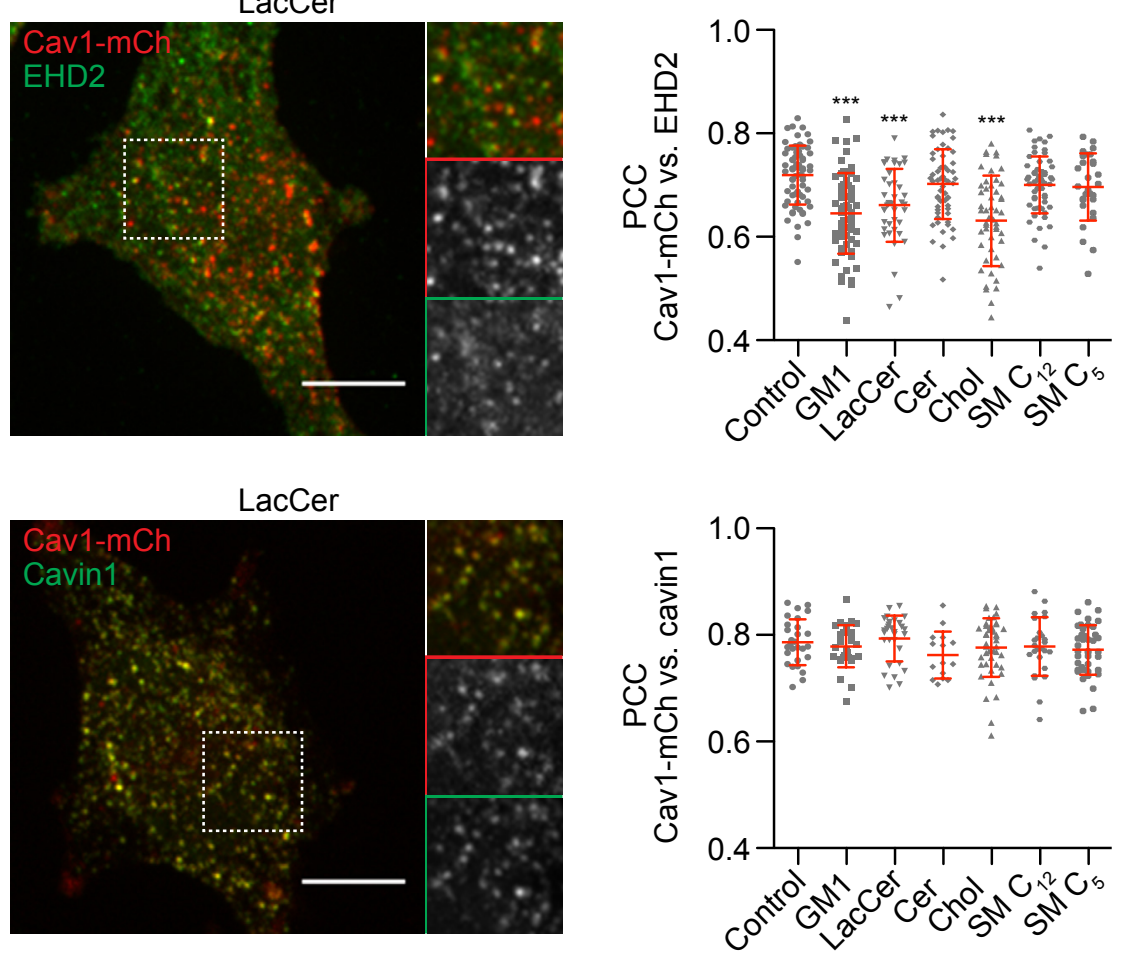

D

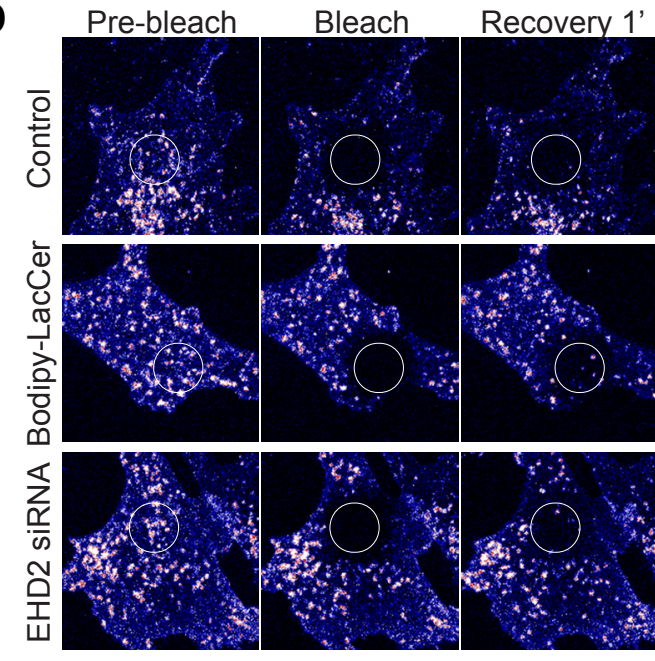

G

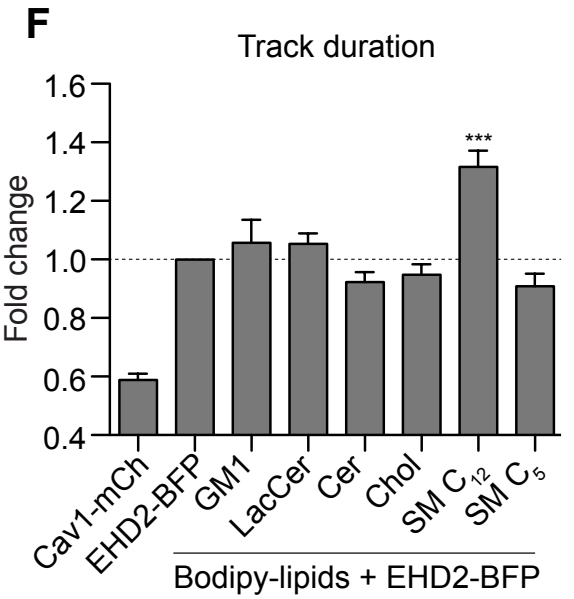

Cav1-mCh Injected EHD2-647

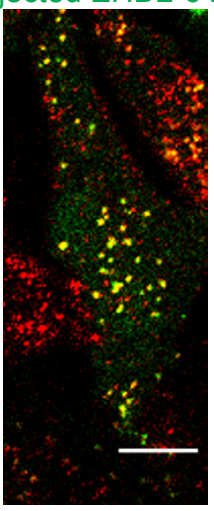

H

Recovery 2' Recovery 5'
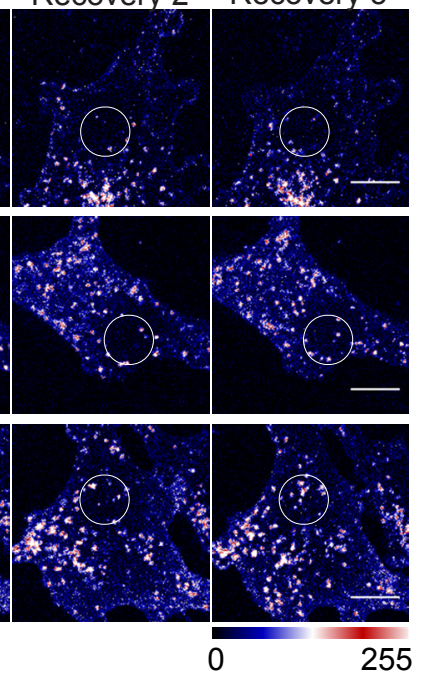

Track duration

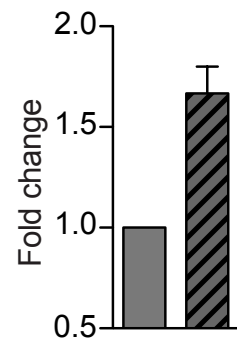

Bodipy-LacCer

ZZ Bodipy-LacCer

+ EHD2-647 
bioRxiv preprint doi: https://doi.org/10.1101/2020.01.22.915173; this version posted January 22, 2020. The copyright holder for this

preprint (which was not certified by peer review) is the author/funder, who has granted bioRxiv a license to display the preprint in Figure 4 perpetuity. It is made available under aCC-BY 4.0 International license.

A

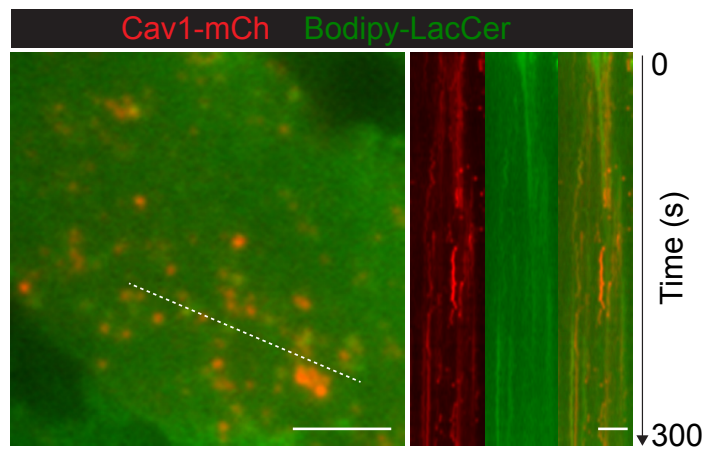

B
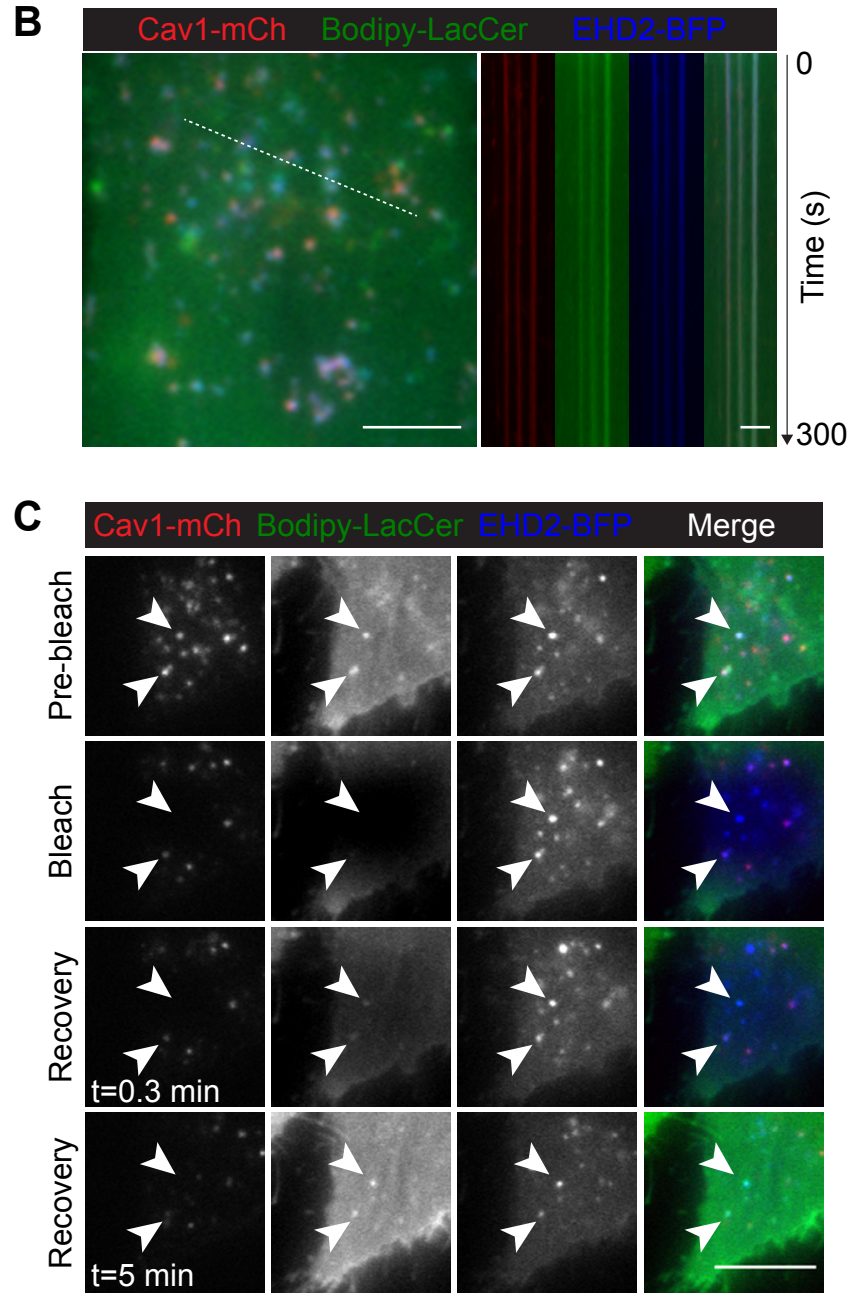

Cav1-mCh

Bodipy-LacCer
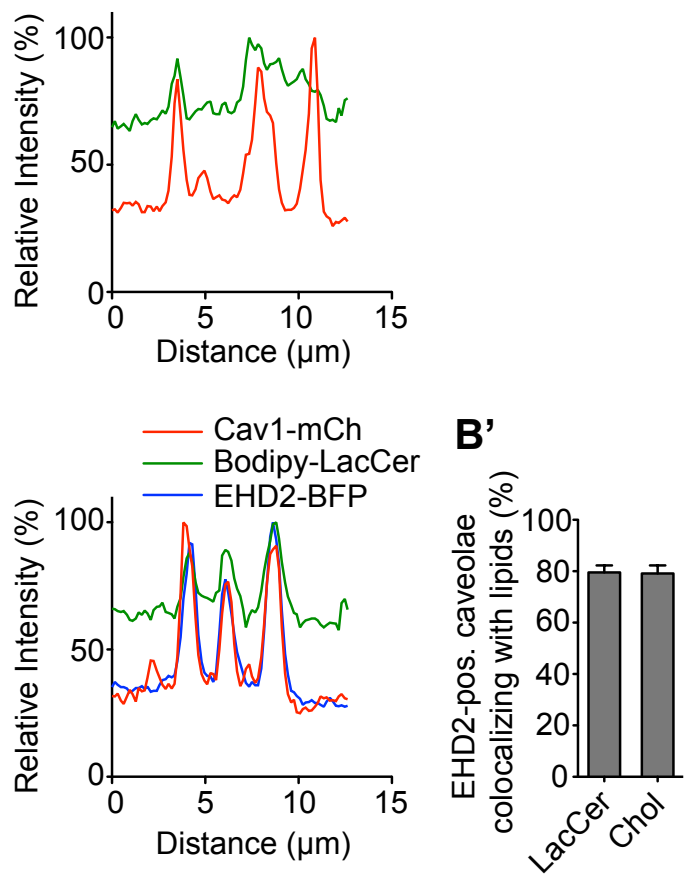

D

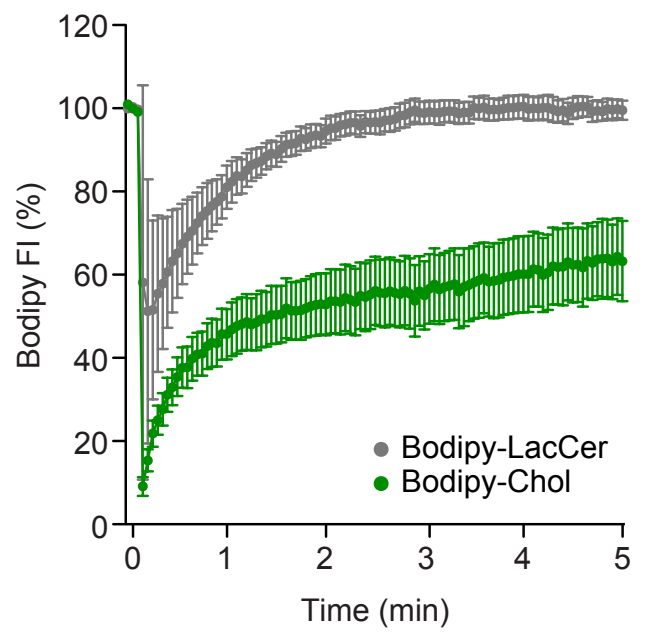


bioRxiv preprint doi: https://doi.org/10.1101/2020 01.22.915173; this version posted January 22,2020 . The copyright holder for this preprint (which was not certified by peer review) is the author/funder, who has granted bioRxiv a license to display the preprint in perpetuity. It is made available under aCC-BY 4.0 International license.

\section{Figure 5}

A Control
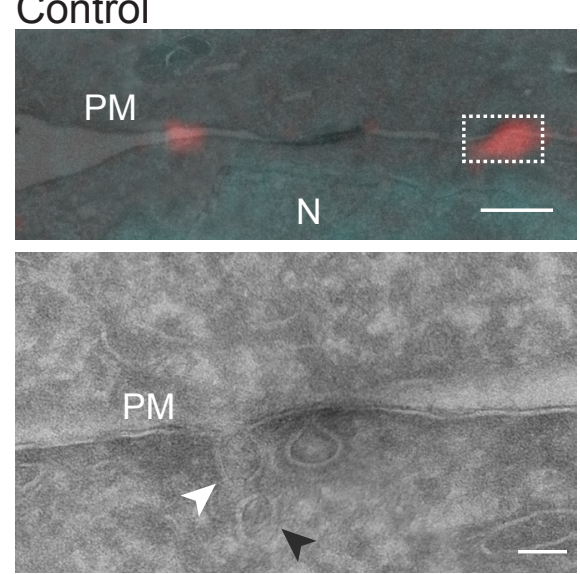

\section{B Control}
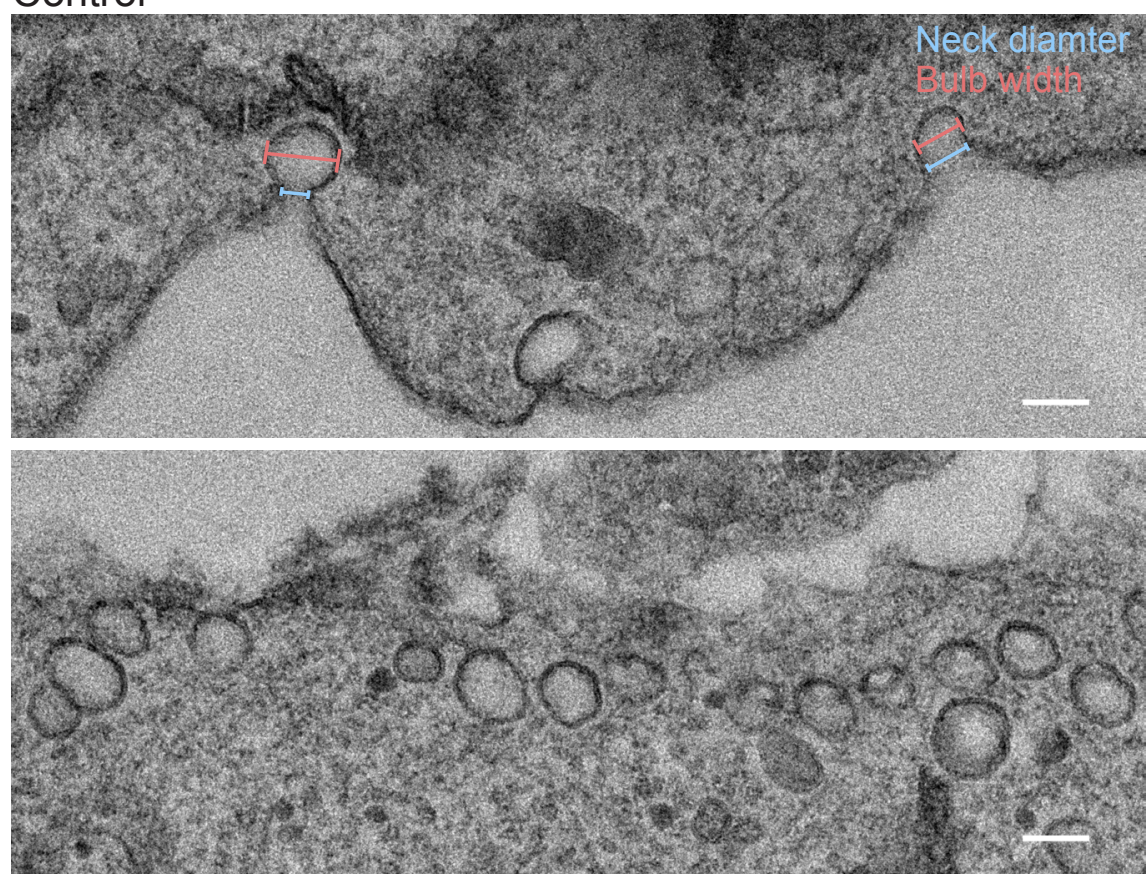

\section{Chol}
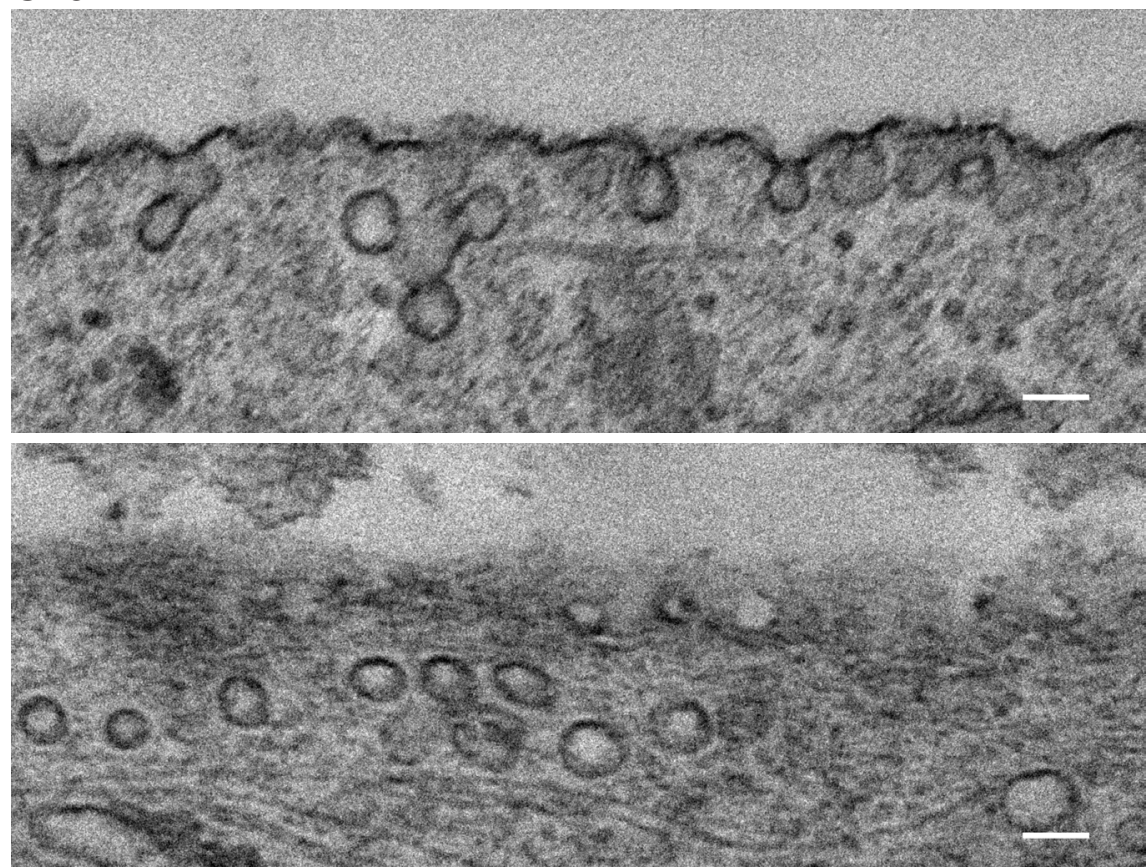

Chol
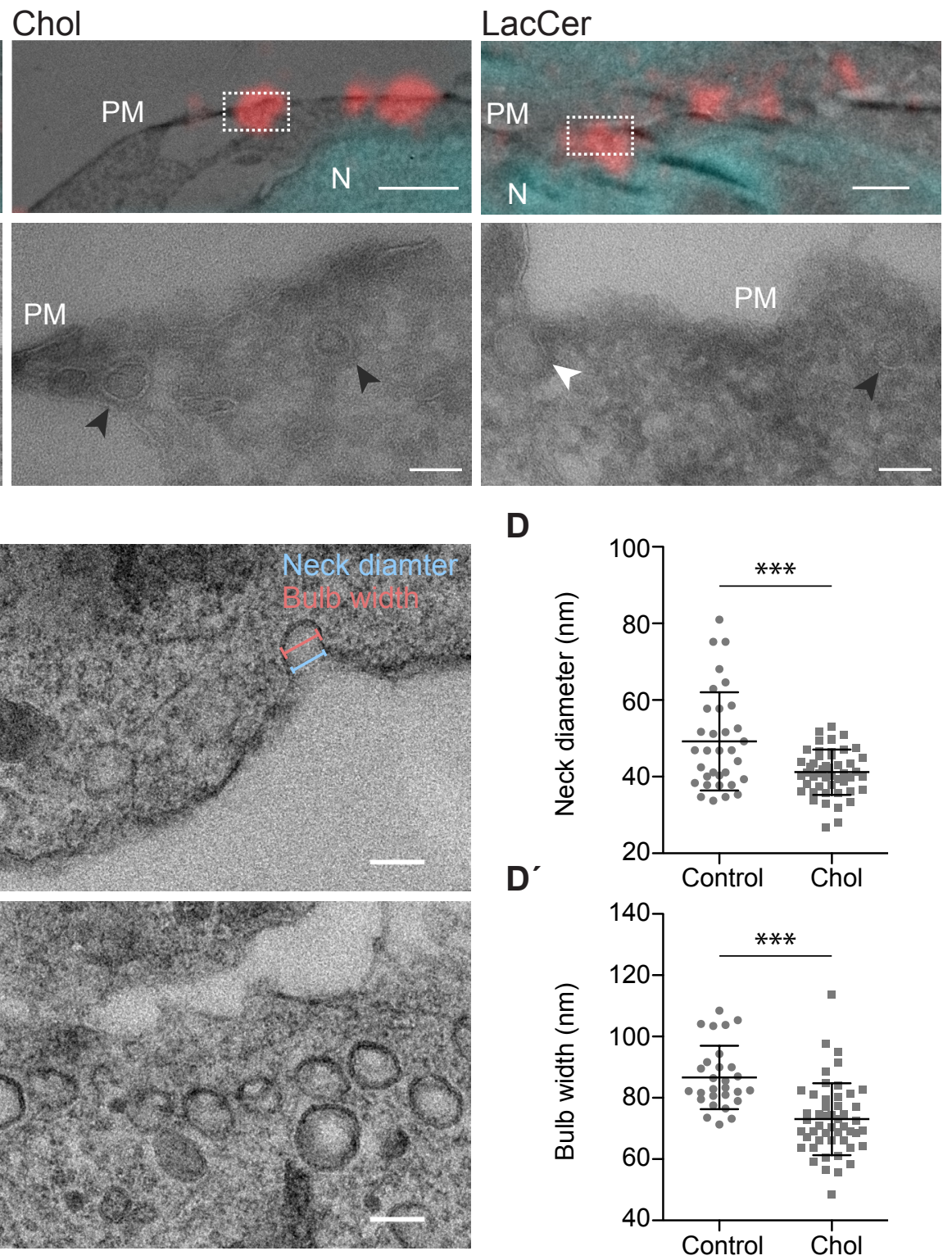

E

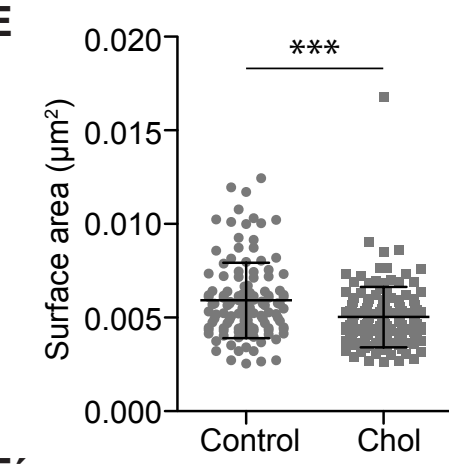

$E^{\prime}$

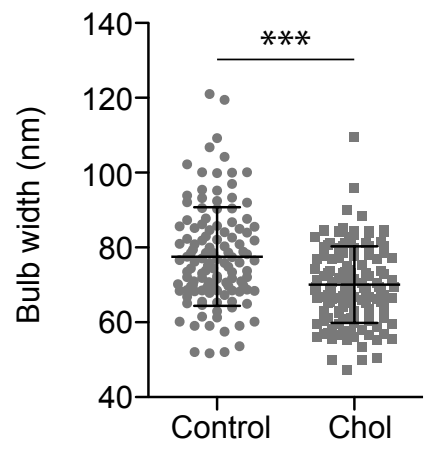


Figure 6

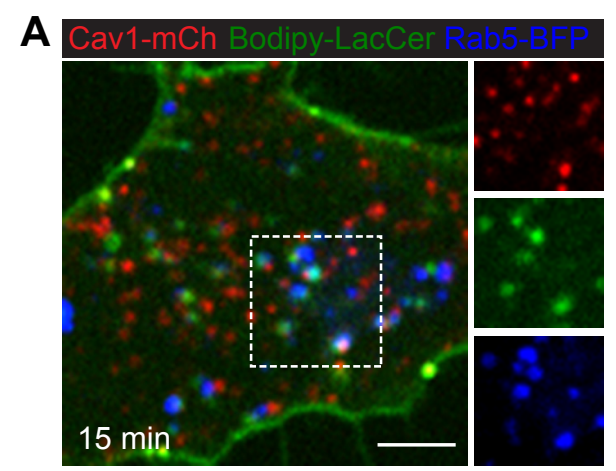

\section{C}

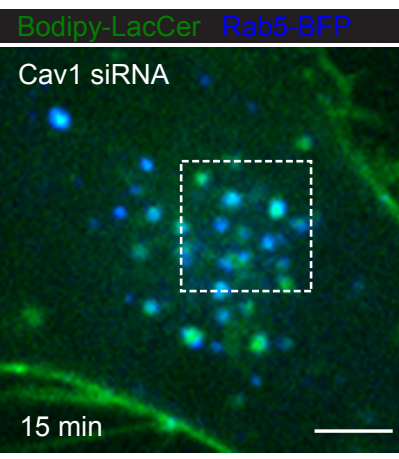

F
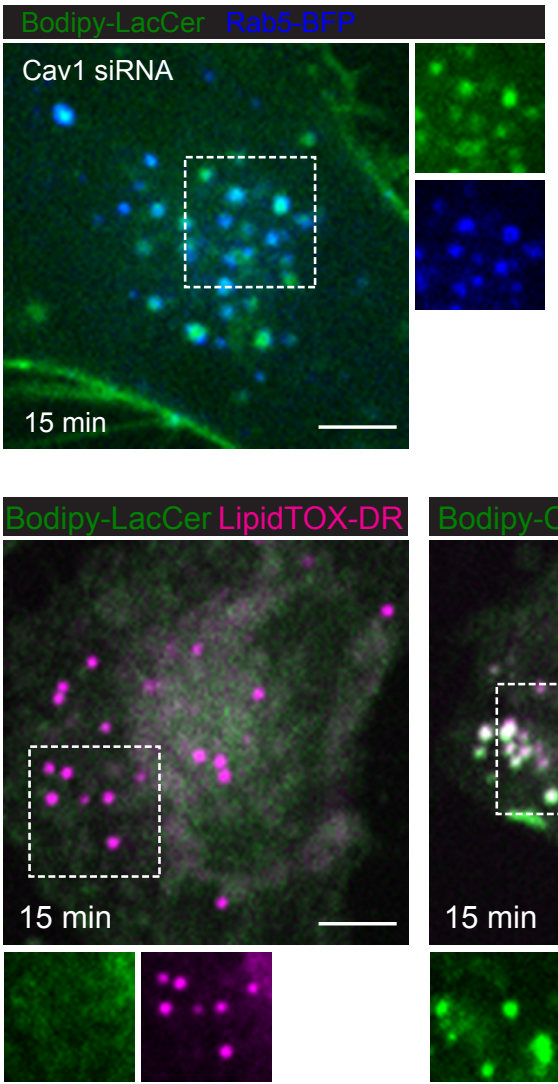
perpetuity. It is made available under aCC-BY 4.0 International license.
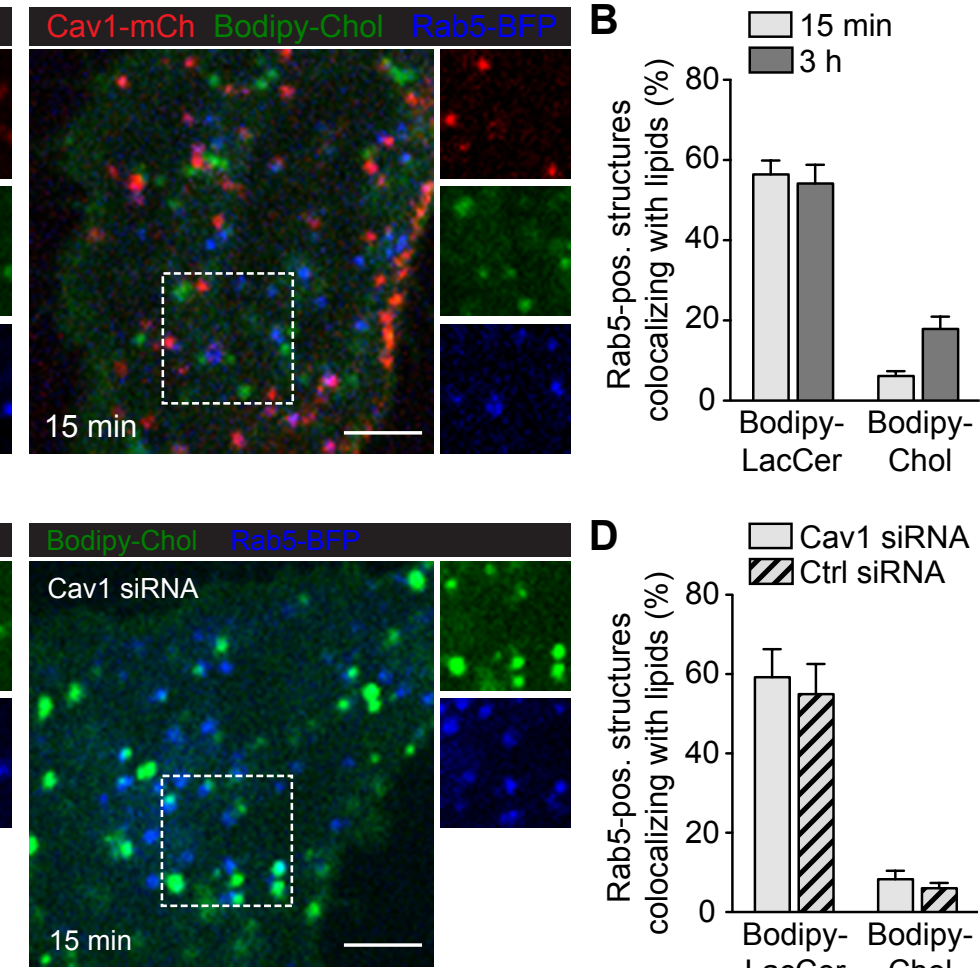

D
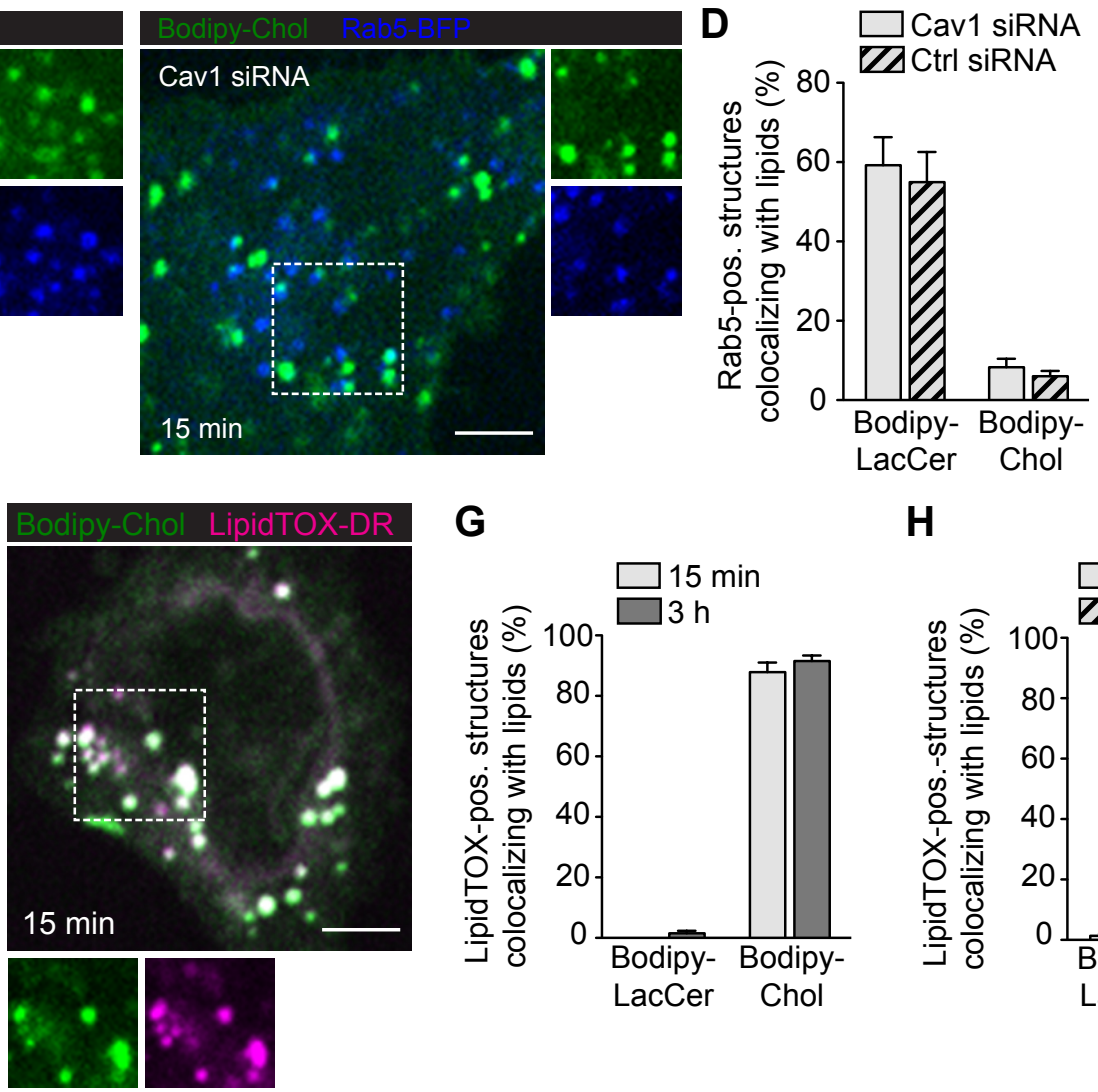

G

H

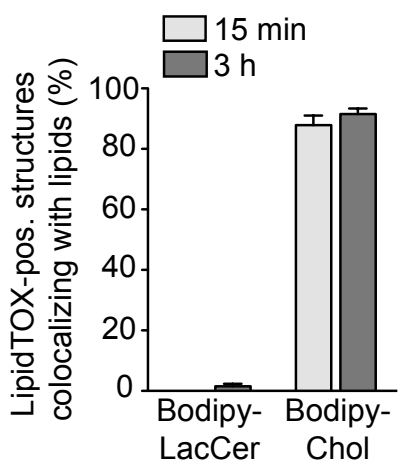

E siRNA: Ctrl Cav1 Clathrin $\mathrm{HC}$ Cav1

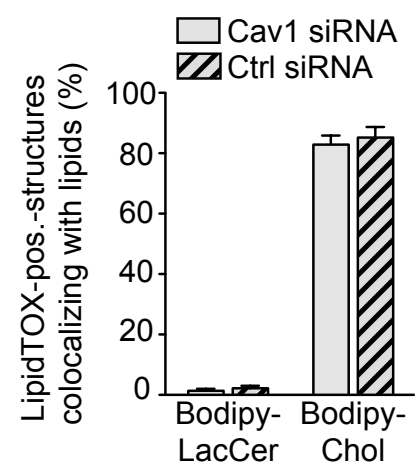




\section{Supplemental Material}

\section{Lipid accumulation promotes scission of caveolae}

Madlen Hubert ${ }^{1}$, Elin Larsson ${ }^{1}$, Naga Venkata Gayathri Vegesna ${ }^{1}$, Maria Ahnlund ${ }^{2}$, Annika I.

Johansson ${ }^{3}$, Lindon W. K. Moodie ${ }^{4, \#}$ and Richard Lundmark ${ }^{1, *}$

${ }^{1}$ Department of Integrative Medical Biology, Umeå University, SE-901 87 Umeå, Sweden

${ }^{2}$ Swedish Metabolomics Centre, Department of Forest Genetics and Plant Physiology, Swedish University of Agricultural Sciences, SE-901 83 Umeå, Sweden

${ }^{3}$ Swedish Metabolomics Centre, Department of Molecular Biology, Umeå University, SE-901 83 Umeå, Sweden

${ }^{4}$ Department of Chemistry, Umeå University, SE-901 87 Umeå, Sweden

\#Present address: Department of Medicinal Chemistry, Uppsala University, Box 574, SE-751 23

Uppsala, Sweden

*Corresponding Author:

Richard Lundmark, Department of Integrative Medical Biology, Umeå University, 90187 Umeå, Sweden, phone: +46 706202464, email: richard.lundmark@umu.se 
Figure S1 (Figure 1- Supplement 1)

A

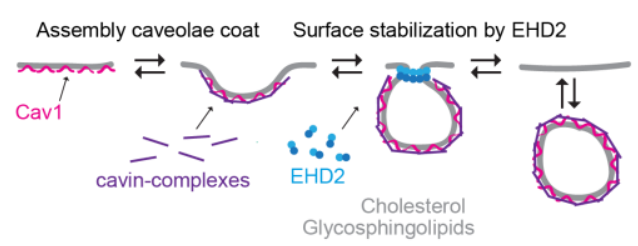

B
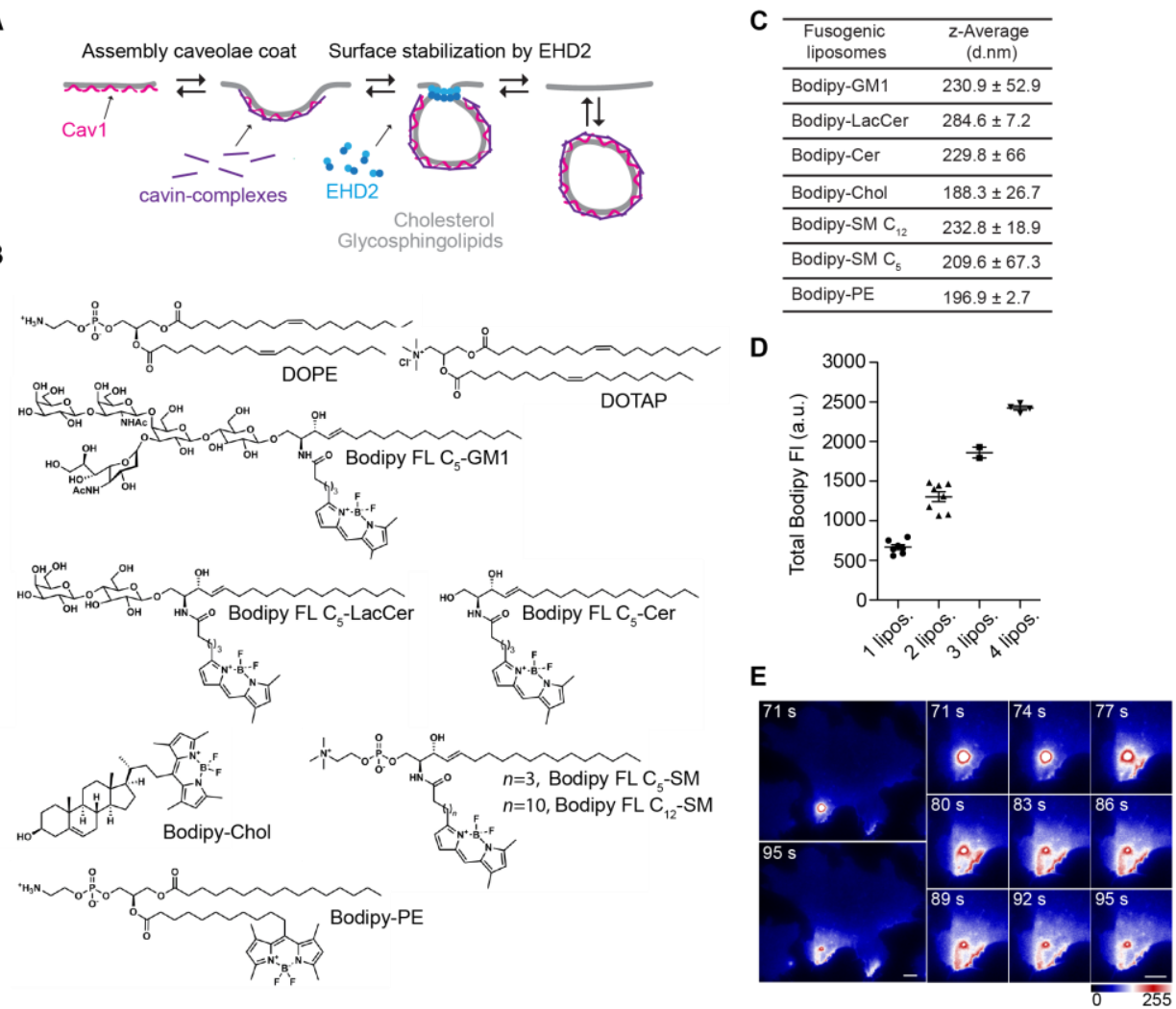

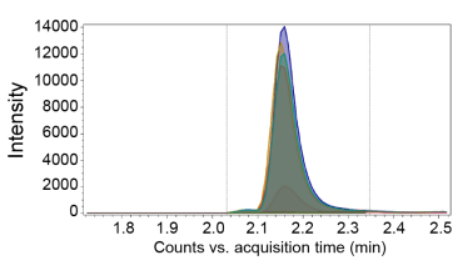

G

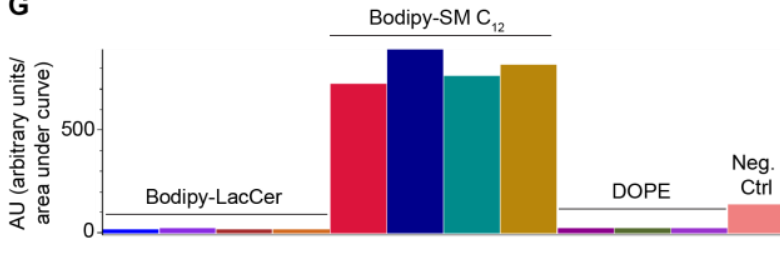

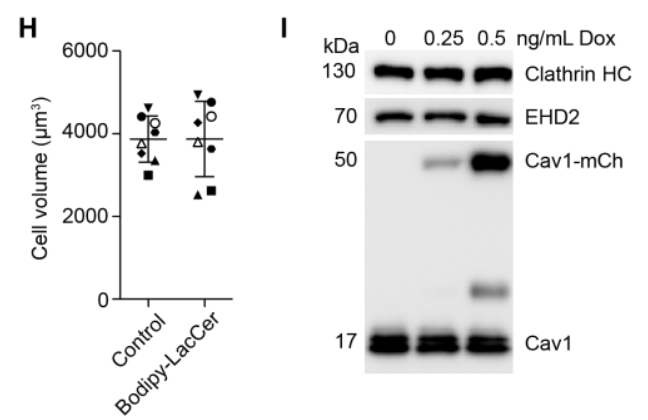

Fig. S1. Liposome characterization and incorporation efficiencies of Bodipy-lipids measured by mass spectrometry. (A) Scheme illustrating caveolae dynamics at PM. Caveolae formation and coat assembly are primarily driven by the integral membrane protein Cav1 and cavin proteins. EHD2 controls surface association of caveolae. (B) Chemical structures of lipids used in this study. (C) Hydrodynamic diameter as $z$-average of DOPE:DOTAP:Bodipy-lipid liposomes. $n=3$, three independent experiments, mean \pm SD. (D) Total Bodipy FI of liposomes containing Bodipy-LacCer was determined in a single confocal section $(0.5 \mu \mathrm{m})$ using spinning disk microscopy. Bodipy FI corresponds to the number of liposomes measured in each ROI. $n=22$, mean \pm SEM. (E) Time-lapse imaging of a vesicle fusing with the PM. A single fusion event highlights the rapid distribution of the fluorophore from the liposome-membrane contact site and subsequent fusion Distribution of Bodipy fluorescence is intensity-coded using LUT. Scale bars, $10 \mu \mathrm{m}$. (F, G) Visualization of chromatography of Bodipy-SM $\mathrm{C}_{12}$. Samples visualized: Bodipy-LacCer treated samples, Bodipy-SM $\mathrm{C}_{12}$ treated samples, DOPE control samples and a negative control of Bodipy-SM C 12 (liposomes added to wells without cells). (F) Chromatography of the samples. (G) Integrated area of each individual sample. (H) Analysis of the cell volume before and after addition of BodipyLacCer liposomes. Cell surface was segmented with Imaris using $\mathrm{mCh}$ fluorescence. Identical symbols in control and Bodipy-LacCer represent the same cell. $n=8$, mean \pm SD. (I) Representative immunoblots showing protein 
expression of EHD2, Cav1-mCh and Cav1 after induction of Cav1-mCh HeLa cells with different concentrations of Dox. Clathrin HC served as loading control. Related to Fig. 1. 
Figure S2 (Figure 2- Supplement 1)
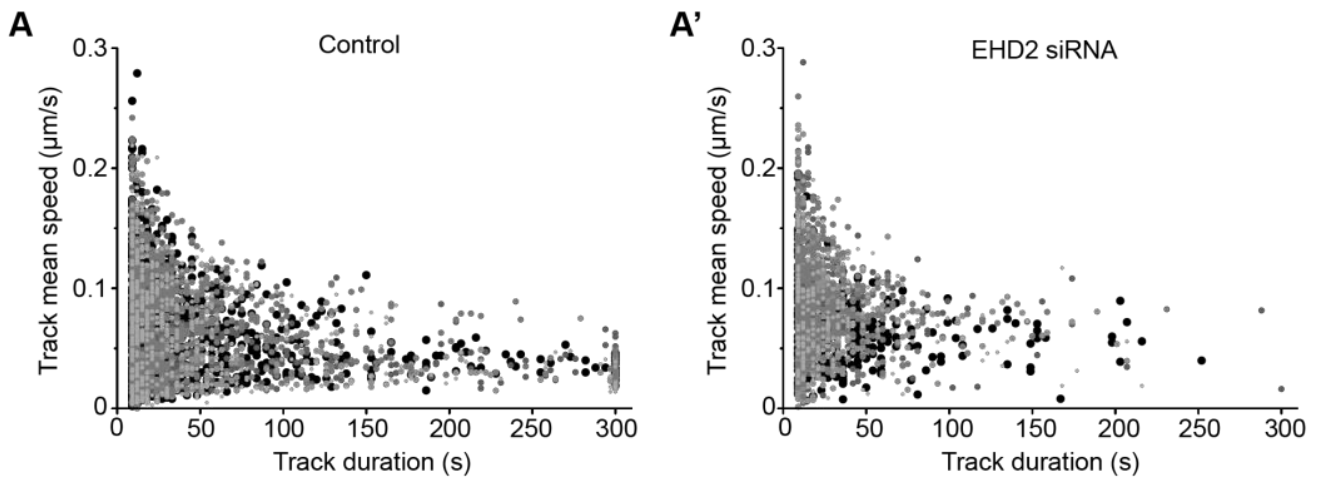

B
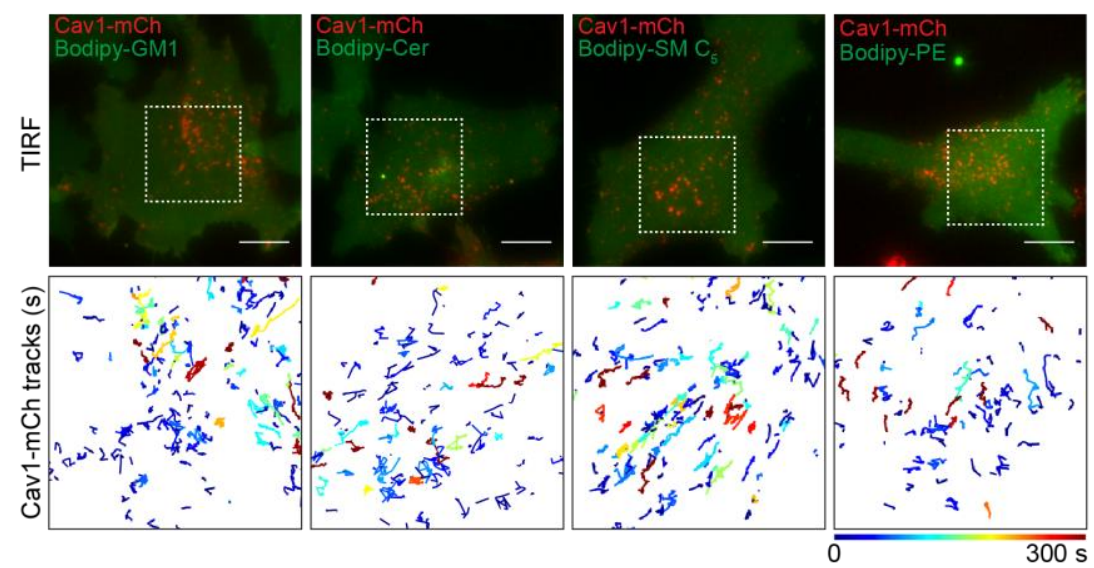

C

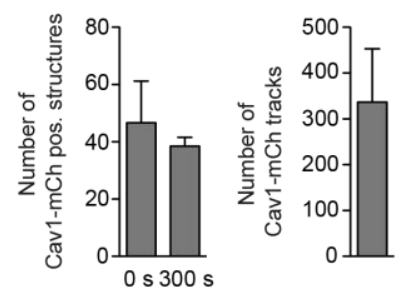

D

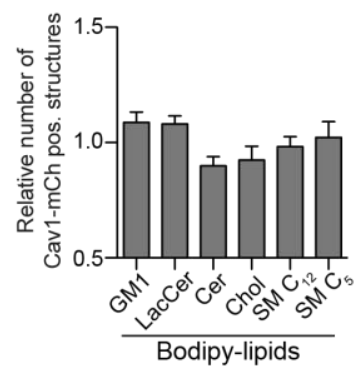

E

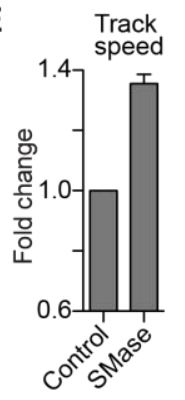

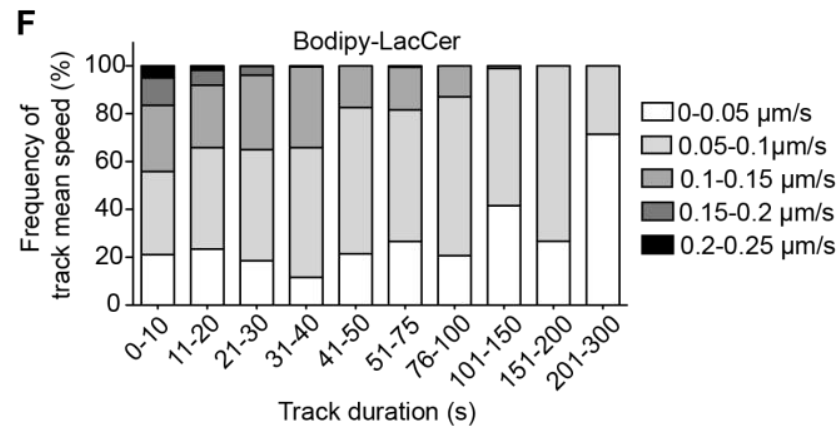

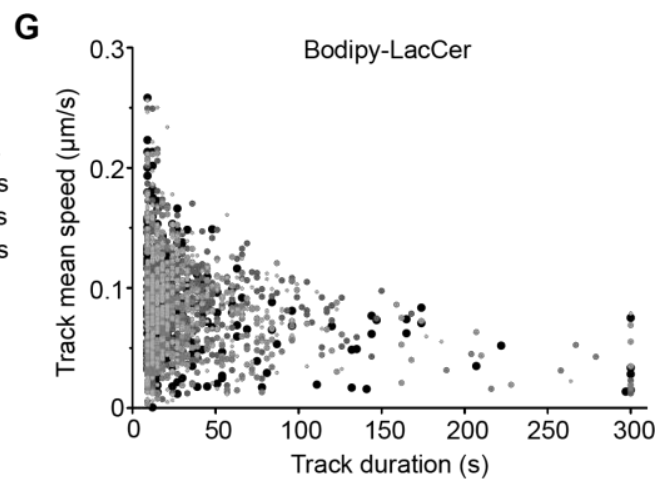

Fig. S2. GSLs and Chol affect lifetime of caveolae while caveolae numbers at the PM are unchanged. (A, A') Correlation between track duration and track mean speed. TIRF live cell movies of Cav1-mCh structures (A) and cells lacking EHD2 (A') were analyzed (five datasets for each condition). Identical symbols represent tracks from the same cell. (B) Representative images from TIRF live cell movies of Dox-induced Cav1-mCh HeLa cells after incubation with different fusogenic liposomes containing Bodipy-lipids (final total lipid concentration of 7 $\mathrm{nmol} / \mathrm{mL}$ ) for $15 \mathrm{~min}$. Cav1-mCh structures were tracked using Imaris software. Color-coded trajectories illustrate time that structures can be tracked at PM over 5 min (dotted square). Scale bars, $10 \mu \mathrm{m}$. (C) Number of Cav1-mCh positive structures at the beginning and at the end of $5 \mathrm{~min}$ TIRF movies and the corresponding number of tracks 
detected. $n \geq 8$, three independent experiments, mean + SEM. (D) Relative number of caveolae at the PM of Cav1$\mathrm{mCh} \mathrm{HeLa}$ cells before and after addition of fusogenic liposomes. TIRF live cell movies from Fig. 2C and S2B were analyzed. Number of caveolae after lipid treatment was normalized to the number of caveolae in control cells. $n \geq 8$, three independent experiments, mean + SEM. (E) Quantification of track mean speed of Cav1-mCh structures from TIRF movies following incubation with SMase for $2 \mathrm{~h}$. Fold changes are relative to control (Cav1-mCh). $n \geq 5$, mean + SEM. (F) Distribution of track mean speed in subpopulations of track duration of Cav1-mCh structures treated with Bodipy-LacCer liposomes. (G) Correlation between track duration and track mean speed of Cav1-mCh structures treated with Bodipy-LacCer liposomes. In (F) and (G) five datasets were analyzed. All analysis was performed using Imaris software. Related to Fig. 2. 
Figure S3 (Figure 3- Supplement 1)

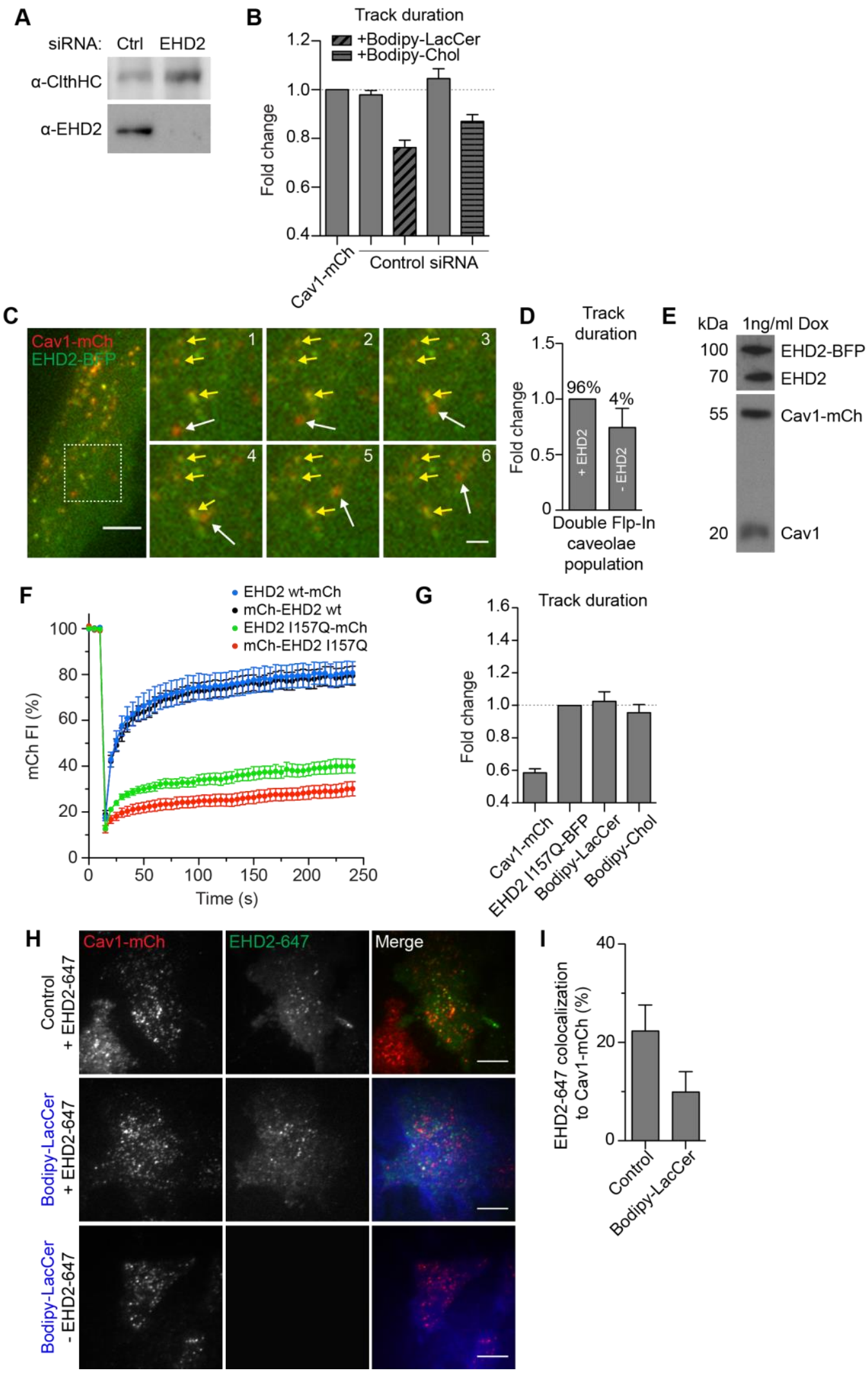

Fig. S3. Stabilization of caveolae to the PM by EHD2 and EHD2-I157Q cannot be reversed by addition of Bodipy-labeled LacCer or Chol. (A) Representative immunoblots of Cav1-mCh HeLa cells treated with Ctrl siRNA or siRNA against EHD2. Clathrin HC served as loading control. (B) Effect of lipids on track duration of Cav1-mCh structures analyzed following control siRNA-treatment. $n \geq 8$, two independent experiments, mean + SEM. (C) Representative time-lapse images of Cav1-mCh positive for EHD2-BFP (yellow arrows) or lacking EHD2-BFP (white arrows) in double Flp-In EHD2-BFP Cav1-mCh HeLa cells. Dotted box shows higher 
magnification region. Numbering corresponds to number of frames. Scale bar, $10 \mu \mathrm{m}$; inset scale bars, $2 \mu \mathrm{m}$. (D) Differences in track duration of Cav1-mCh structures positive for EHD2-BFP or lacking EHD2-BFP in double FlpIn EHD2-BFP Cav1-mCh HeLa cells. Percentage of Cav1-mCh structures positive or lacking EHD2-BFP are indicated. $n=8$, mean + SEM. (E) Representative immunoblots of double Flp-In EHD2-BFP Cav1-mCh HeLa cells induced with $1 \mathrm{ng} / \mathrm{ml}$ Dox. (F) FRAP curves of mCh-tagged EHD2 wt or EHD2 I157Q expressing HeLa cells. A ROI was photobleached and recovery of mCherry fluorescence intensity (mCherry FI) was monitored. Intensities were normalized to background and reference. $n=8$, mean \pm SEM. (G) Cav1-mCh HeLa cells transiently expressing EHD2-I157Q-BFP were incubated with Bodipy-LacCer or Bodipy-Chol liposomes and track duration was analyzed. $n \geq 8$, two independent experiments, mean + SEM. (H) Representative live cell TIRF images of Cav1-mCh HeLa cells untreated or treated with Bodipy-LacCer and with or without microinjection of EHD2-647. (I) Quantification of the colocalization of microinjected EHD2-647 to Cav1-mCh in control cells and cells treated with Bodipy-LacCer liposomes prior to injection. $n \geq 5$, mean + SEM. Scale bar, $10 \mu \mathrm{m}$. In (B, D, G) Imaris software was used to analyze data. Changes in track duration are relative to control (indicated by dotted line). Related to Fig. 3. 
Figure S4 (Figure 4- Supplement 1)
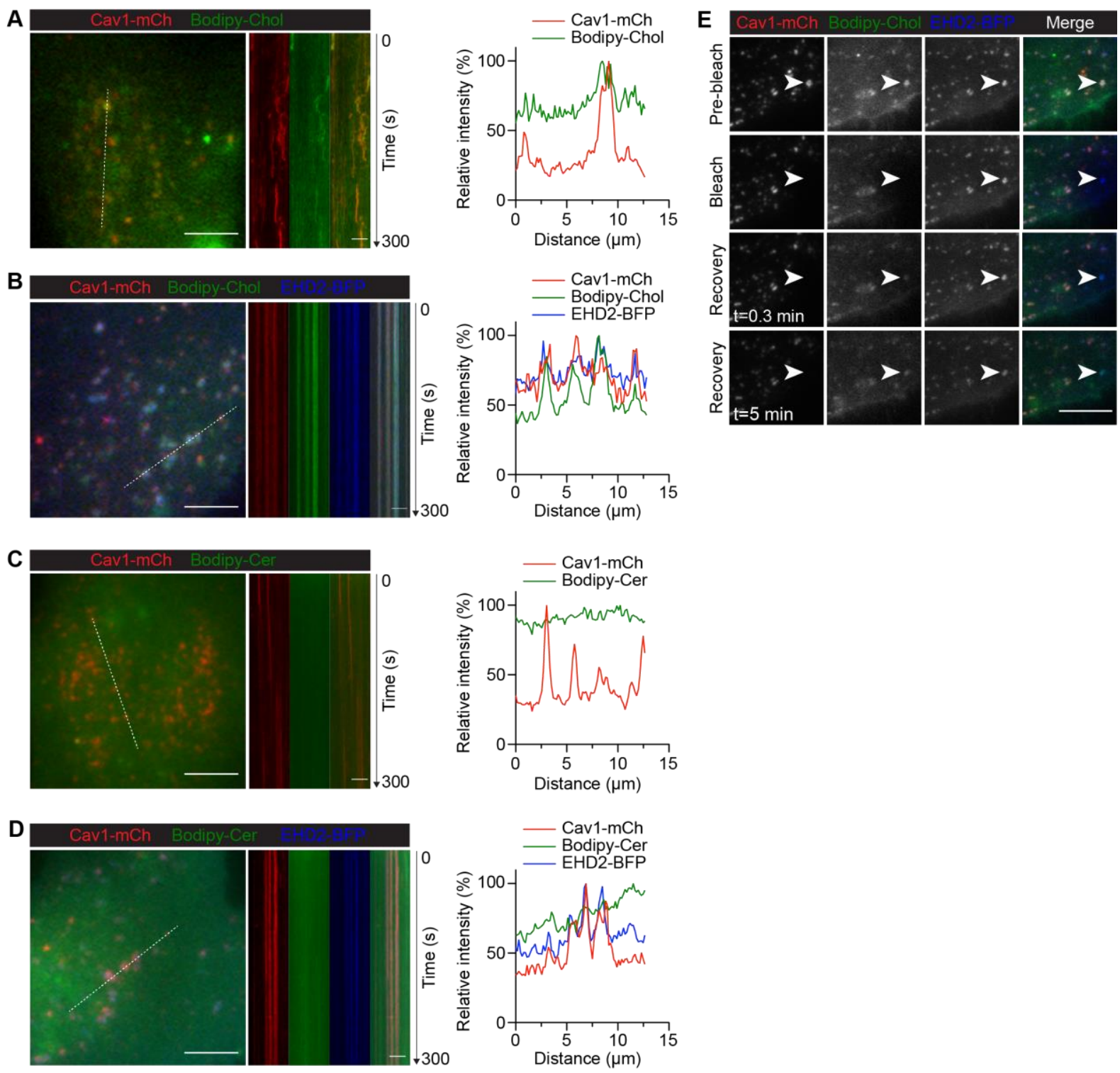

Fig. S4. LacCer and Chol but not Cer accumulate in caveolae at the PM and recover within caveolae following photobleaching. (A, B) Cav1-mCh HeLa cells (A) and Cav1-mCh HeLa cells transiently expressing EHD2-BFP (B) were incubated with Bodipy-Chol liposomes. White lines indicate the location of the kymograph and the corresponding intensity profiles illustrate the colocalization of Bodipy-Chol with Cav1-mCh either alone or in the presence of EHD2-BFP. Intensity profiles are relative to the maximum value for each sample. (C, D) As for (A, B), cells were incubated with Bodipy-Cer. Scale bars, $10 \mu \mathrm{m}$; kymograph scale bars, $5 \mu \mathrm{m}$. (E) Bodipy fluorescence recovery experiments to study the accumulation of lipids in caveolae. Cav1-mCh HeLa cells transiently expressing EHD2-BFP were incubated with Bodipy-Chol liposomes for $10 \mathrm{~min}$. Following photobleaching, the fluorescence recovery of the Bodipy signal within caveolae was monitored over time. White arrow highlights surface connected caveolae with accumulated Chol. Scale bars, $5 \mu \mathrm{m}$. Related to Fig. 4. 
Figure S5 (Figure 5- Supplement 1)

A
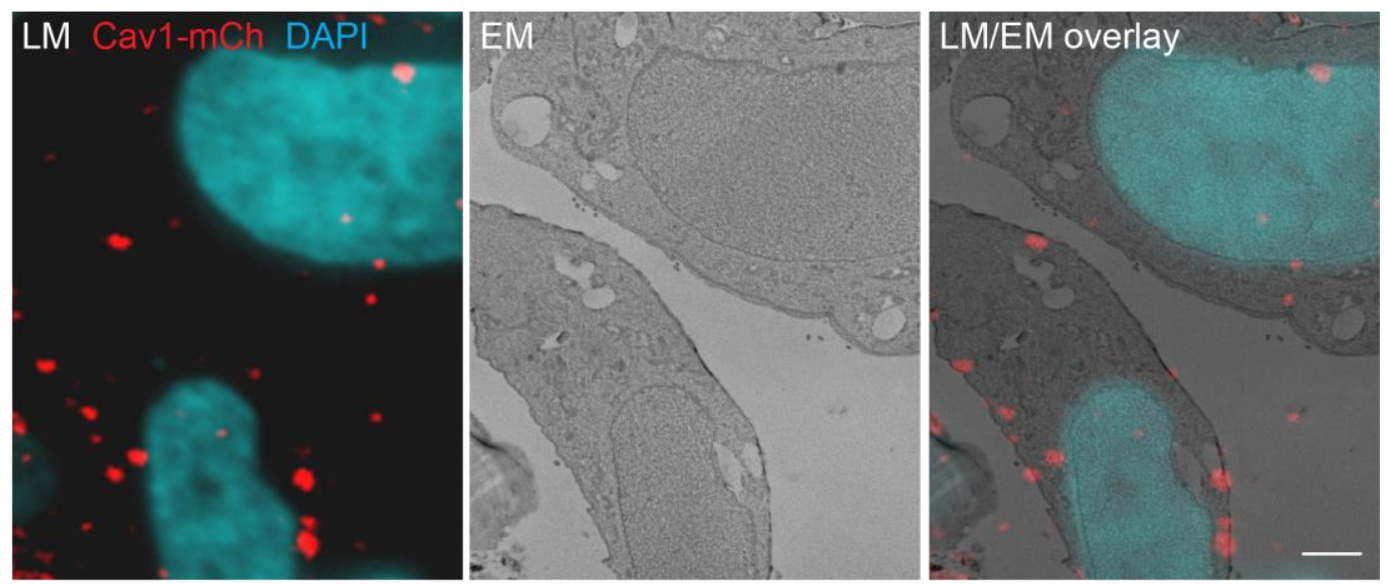

B

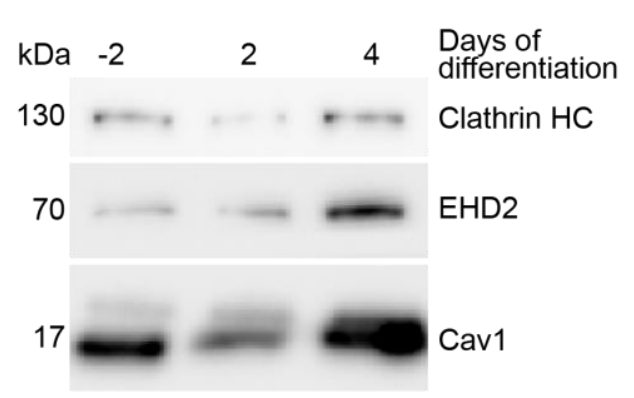

C

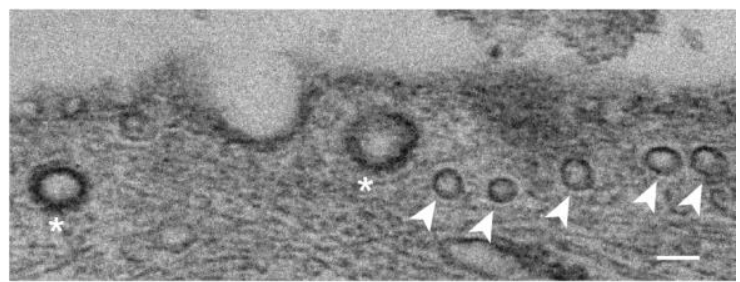

D

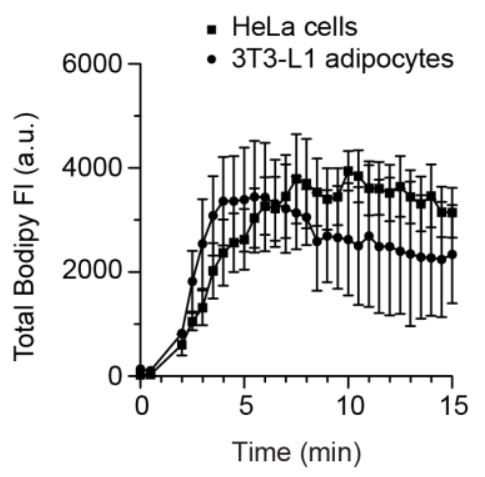

Fig. S5. Expression of EHD2 and Cav1 is upregulated in 3T3-L1 adipocytes. (A) Cav1-mCh HeLa cells were induced with Dox and transiently expressed EHD2-GFP. Light microscopy image showing localization of caveolae (Cav1-mCh) and nuclei (DAPI) within cells (LM, left panel). Middle panel depicts corresponding EM images. Overlay of LM and EM images shows correlation of fluorescently labeled structures to ultrastructure in same cells (right panel). Scale bar, $2 \mu \mathrm{m}$. (B) Representative immunoblots showing protein expression of EDH2 and Cav1 during 3T3-L1 differentiation. Clathrin HC served as loading control. (C) Representative electron micrographs of 3T3-L1 adipocytes. Caveolae (indicated by arrow) can be clearly distinguished from clathrin-coated pits (indicated by asterisk). Scale bar, $100 \mathrm{~nm}$. (D) Incorporation rate of Bodipy-Chol into the PM of live 3T3-L1 adipocytes. Cells were treated with fusogenic liposomes (final total lipid concentration $7 \mathrm{nmol} / \mathrm{mL}$ ). Total fluorescence intensity (FI) of the Bodipy signal was measured within circular ROIs in a confocal section using spinning disk microscopy. Ten ROIs were analyzed using the Zeiss Zen system software. $n=2$, mean \pm SEM. Related to Fig. 5. 
Video 1. Cell surface dynamics of Cav1-mCh. A representative TIRF live cell movie of Dox-induced Cav1-mCh HeLa cells. The image in Fig. 2C (Cav1-mCh) is taken from this movie. Movie in real time spans 5 min and was recorded at $3 \mathrm{~s}$ intervals. Scale bar, $10 \mu \mathrm{m}$. Related to Fig. 2.

Video 2. Cell surface dynamics of Cav1-mCh after treatment with Bodipy-LacCer. A representative TIRF live cell movie of Dox-induced Cav1-mCh HeLa cells after 15 min incubation with liposomes containing BodipyLacCer. The image in Fig. $2 \mathrm{C}$ is taken from this movie. Movie in real time spans $5 \mathrm{~min}$ and was recorded at $3 \mathrm{~s}$ intervals. Scale bar, $10 \mu \mathrm{m}$. Related to Fig. 2.

Video 3. Cell surface dynamics of Cav1-mCh after treatment with Bodipy-Chol. A representative TIRF live cell movie of Dox-induced Cav1-mCh HeLa cells after 15 min incubation with liposomes containing Bodipy-Chol. The image in Fig. $2 \mathrm{C}$ is taken from this movie. Movie in real time spans $5 \mathrm{~min}$ and was recorded at $3 \mathrm{~s}$ intervals. Scale bar, $10 \mu \mathrm{m}$. Related to Fig. 2.

Video 4. Cell surface dynamics of Cav1-mCh after treatment with Bodipy-SM $\mathbf{C}_{\mathbf{1 2}}$. A representative TIRF live cell movie of Dox-induced Cav1-mCh HeLa cells after 15 min incubation with liposomes containing Bodipy-SM $\mathrm{C}_{12}$. The image in Fig. $2 \mathrm{C}$ is taken from this movie. Movie in real time spans $5 \mathrm{~min}$ and was recorded at $3 \mathrm{~s}$ intervals. Scale bar, $10 \mu \mathrm{m}$. Related to Fig. 2.

Video 5. Bodipy-LacCer colocalizes with Cav1-mCh positive structures. A representative TIRF live cell movie of Dox-induced Cav1-mCh HeLa cells after incubation with liposomes containing Bodipy-LacCer. The image in Fig. 4A is taken from this movie and corresponds to the ROI highlighted by the white square. Movie in real time spans 5 min and was recorded at $3 \mathrm{~s}$ intervals. Scale bar, $10 \mu \mathrm{m}$. Related to Fig. 4.

Video 6. Bodipy-Chol colocalizes with Cav1-mCh positive structures. A representative TIRF live cell movie of Dox-induced Cav1-mCh HeLa cells after incubation with liposomes containing Bodipy-Chol. The image in Fig. $\mathrm{S} 4 \mathrm{~A}$ is taken from this movie and corresponds to the ROI highlighted by the white square. Movie in real time spans $5 \mathrm{~min}$ and was recorded at $3 \mathrm{~s}$ intervals. Scale bar, $10 \mu \mathrm{m}$. Related to Fig. 4.

Video 7. Bodipy-LacCer accumulates in caveolae. A representative TIRF live cell movie of Dox-induced Cav1$\mathrm{mCh}$ HeLa cells transiently expressing EHD2-BFP after incubation with liposomes containing Bodipy-LacCer. The image in Fig. 4B is taken from this movie and corresponds to the ROI highlighted by the white square. Movie in real time spans $5 \mathrm{~min}$ and was recorded at $3 \mathrm{~s}$ intervals. Scale bar, $10 \mu \mathrm{m}$. Related to Fig. 4.

Video 8. Bodipy-Chol accumulates in caveolae. A representative TIRF live cell movie of Dox-induced Cav1-mCh HeLa cells transiently expressing EHD2-BFP after incubation with liposomes containing Bodipy-Chol. The image in Fig. S4B is taken from this movie and corresponds to the ROI highlighted by the white square. Movie in real time spans $5 \mathrm{~min}$ and was recorded at $3 \mathrm{~s}$ intervals. Scale bar, $10 \mu \mathrm{m}$. Related to Fig. 4. 